UNIVERSIDADE DE SÃO PAULO

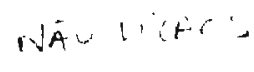

INSTITUTO DE QUÍMICA

\title{
CARACTERIZAÇÃO POR ESPECTROSCOPIA RAMAN INTENSIFICADA (SERS E RAMAN RESSONANTE) DA 2-ETINILPIRIDINA E DO SEU POLÍMERO POLI(2-HIDROCLORETO DE PIRIDINIUM-2-PIRIDILACETILENO).
}

\author{
Ricardo Prado Millen \\ Dissertação de Mestrado
}

Orientadora: Prof ${ }^{\natural}$. Dr ${ }^{\mathrm{a}}$. Márcia Laudelina A. Temperini

-São Paulo2000 


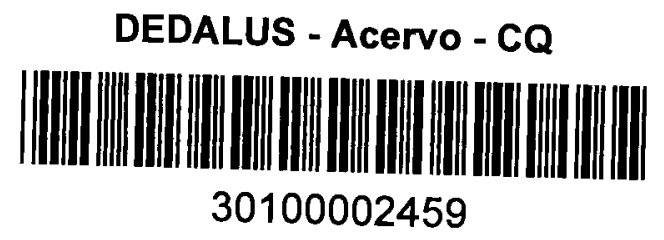

Ficha Catalográfica

Elaborada pela Divisão de Biblioteca e

Documentação do Conjunto das Quimicas da USP.

Millen, Ricardo Prado

M646c Caracterização por espectroscopia Raman intensificada (SERS e Raman ressonante) da 2-etinilpiridina e do seu polímero poli (2-hidrocloreto de piridinium-2-piridilacetileno) / Ricardo Prado Millen. -- São Paulo, 2000. $104 \mathrm{p}$.

Dissertação (mestrado) - Instituto de Química. Departamento de Química Fundamental.

Orientador: Temperini, Márcia Laudelina Arruda.

1. Espectroscopia vibracional 2. Polimeros: Química orgânica I. T. II. Temperini, Márcia Laudelina Arruda, orientador. 


\title{
"Caracterização por Espectroscopia Raman Intensificada (SERS e Raman Ressonante) da 2- Etinilpiridina e do seu Polímero Poli(2- Hidrocloreto de Piridinium-2-Piridilacetileno)"
}

\section{RICARDO PRADO MILLEN}

Dissertação de Mestrado submetida ao Instituto de Química da Universidade de São Paulo como parte dos requisitos necessários à obtenção do grau de Mestre em Ciências - Área: Físico-Química.

Aprovado por:

\author{
Profa. Dra. MARCIA LAUDELINA ARRUDA TEMPERINI \\ IQ - USP \\ (Orientadora e Presidente)
}

Prof. Dr. KOITI ARAKI
IQ - USP

Prof. Dr. OSWALDO LUIZ ALVES

IQ - UNICAMP

SÃO PAULO

O4 DE FEVEREIRO DE 2000. 
"A ciência oferece muito pouco em matéria de emoções baratas. Os padrões de evidência são rigorosos. Mas, quando obedecidos, permitem que vejamos longe, chegando, até, a iluminar uma grande escuridão." 


\section{Agradecimentos}

À Prof'. Dra . Márcia L. A. Temperini pela orientação, paciência e amizade.

Ao Prof. Dr. Oswaldo Sala pelo exemplo como pesquisador e como pessoa.

À Prof". Dr ${ }^{a}$. Dalva Lúcia A. de Faria pela amizade e pelas proveitosas discussões.

Ao Prof. Dr. David N. Batchelder, da Universidade de Leeds, que possibilitou a obtenção dos espectros Raman ressonante com a radiação excitante no ultra-violeta.

Aos meus colegas do Laboratório de Espectroscopia Molecular e de outros laboratórios pela amizade e pelo convivio.

Aos funcionários do IQ-USP.

Ao CNPq pelo auxilio financeiro para a realização deste trabalho.

E principalmente,

Aos meus pais, Glauco e Nercila, e ao meu irmão, Rodrigo, que são os grandes responsáveis por eu estar aqui... 


\section{ÍNDICE}

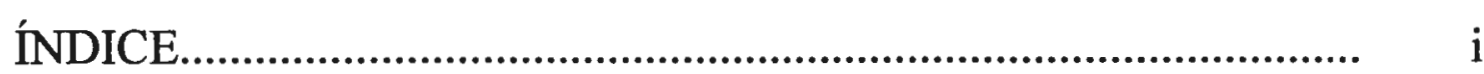

RESUMO......................................................................... iii

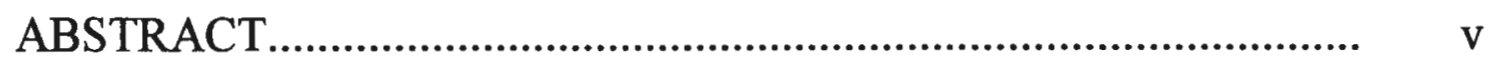

1- INTRODUÇÃO.............................................................................

1.1- Polímeros Condutores.................................................................. 2

1.2- Poliacetileno........................................................................... 5

1.2.1- Características Gerais...................................................... 5

1.2.2- Espectroscopia Vibracional................................................... 9

1.2.3- Polipiridilacetileno e Seus Derivados.................................. 17

1.3- Efeito SERS (Surface Enhanced Raman Scattering)................... 22

1.3.1- Regras de Seleção para Espectroscopia SERS.................... 24

1.4- Objetivos e Metas Alcançadas...................................................... 27

2- PARTE EXPERIMENTAL....................................................... 28

2.1- Síntese dos Poliacetilenos Substituídos com Anéis Piridínicos.... 29

2.1.1- Poli(2-Hidrocloreto de Piridinium-2-Piridilacetileno).......... 29

2.1.2- Desprotonação do P2EPH............................................... 30

2.2- Síntese da Poli-2-Vinilpiridina Protonada, P2VPH..................... 31

2.3- Síntese do 2-Piridilacetileto de Prata............................................ 31

2.4- Preparação dos Substratos de Prata............................................ 31

2.4.1- Discos Compactados de Prata Metálica............................... 31 
2.4.2- Colóide de Prata.................................................................. 32

2.4.3- Eletrodo de Prata................................................................. 32

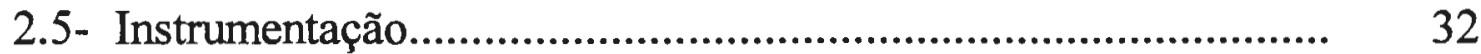

3- RESULTADOS E DISCUSSÃO................................................ 35

3.1- Poli(2-Hidrocloreto de Piridinium-2-Piridilacetileno).................. 36

3.2- Comportamento da 2-Etinilpiridina em Eletrodo de Prata............ 67

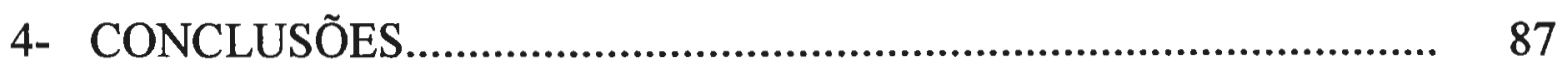

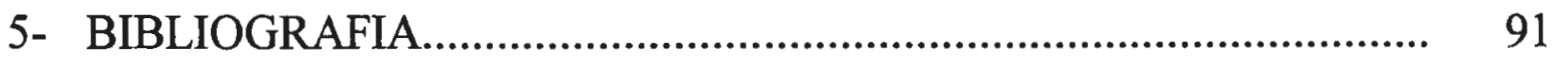

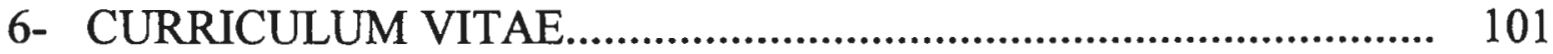




\section{Resumo}

Neste trabalho sintetizamos o poli(2-hidrocloreto de 2-piridinium-2piridilacetileno), P2EPH, e o estudamos do ponto de vista vibracional.

$\mathrm{O}$ produto obtido na síntese deste polímero possuía quantidade diferente de anéis piridínicos protonados e não protonados em relação àquela proposta na literatura, indicando a necessidade de uma revisão do mecanismo sugerido para esta polimerização.

Para a obtenção dos espectros Raman do P2EPH, a interferência da fluorescência apresentada por este polímero na região visível foi eliminada pela utilização de superfícies de prata metálica (eletrodo, pastilha e colóide) ou de radiação excitante no UV (244,0 nm). A obtenção dos espectros Raman deste polímero permitiu uma atribuição mais precisa de suas bandas através da comparação com os espectros Raman de outros polímeros similares. Esta, por sua vez, possibilitou a correção da atribuição corrente na literatura das bandas do estiramento $\mathrm{C}=\mathrm{C}$ da cadeia polimérica e do anel piridínico.

Variando a energia da radiação excitante percebemos que a freqüência de algumas bandas Raman (em aproximadamente 1160, 1230, 1300 e 1500 $\mathrm{cm}^{-1}$ ) apresentavam deslocamento. Esta característica, denominada dispersão Raman ou fotosseletividade, também é notada para o poliacetileno e é atribuída à heterogeneidade da amostra polimérica. Outra variação observada nos espectros Raman com diferentes excitações foi a da intensidade relativa das bandas. Para radiações excitantes de menor energia as bandas mais proeminentes do espectro foram aquelas atribuídas, principalmente, a vibrações da cadeia poliacetilênica, enquanto que, para excitações de maior energia as bandas relativas aos anéis de piridina e piridinium se sobressaíram. 
Esta diferença é atribuída à ressonância das radiações excitantes com os diferentes cromóforos do polímero. Mesmo quando a excitação foi feita com radiação em $244 \mathrm{~nm}$ alguns modos da cadeia poliacetilênica puderam ser observados e quando utilizamos radiação excitante em $632,8 \mathrm{~nm}$ apareceram bandas dos anéis piridínicos, mostrando que existe acoplamento mecânico entre os cromóforos.

Também estudamos o comportamento do monômero do P2EPH, a 2etinilpiridina, em eletrodo de prata variando o potencial aplicado e o $\mathrm{pH}$ da solução, através do efeito SERS (Surface Enhanced Raman Scattering). As variações observadas na intensidade das bandas foram interpretadas considerando uma mudança de orientação da molécula em relação à superfície. Foi também observada a formação do íon 2-piridilacetileto (formado pela abstração do hidrogênio acetilênico da 2-etinilpiridina) em potenciais inferiores ou igual $\mathrm{a}-0,7 \mathrm{~V}$ na solução não acidulada. 
Abstract

\section{Abstract}

In this work we synthesized and studied the vibrational spectra of poly(2-pyridinium hydrochloride-2-pyridylacetylene), P2EPH.

This polymer presents different amounts of pyridine and pyridinium rings when compared with previously reported data in literature. This difference points out the need of a review in the proposed mechanism.

The fluorescence interference presented by this polymer was precluded using silver surfaces (electrode, pellet or colloid) or excitation in $244.0 \mathrm{~nm}$. Raman spectra obtained through these techniques were useful to improve the assignment of P2EPH peaks. The assignment proposed in this work corrects the current one, showing that the peaks due to polyacetylenic backbone, pyridine and pyridinium ring $\mathrm{C}=\mathrm{C}$ stretching appear, respectively, at 1532 , 1588 and $1620 \mathrm{~cm}^{-1}$.

When the energy of the excitation was changed we observed a shift in some Raman bands (close to $1160,1230,1300$ and $1500 \mathrm{~cm}^{-1}$ ). This feature, called Raman dispersion or photoselectivity, has been observed in polyacetylene and was related to the polymeric sample inhomogeneity.

Besides the frequency variation, the relative intensities have changed with different exciting radiation. When lower energy radiation was used, the Raman spectra obtained were similar to the polyacetylene spectrum, while, for higher energy the most intense peaks observed were pyridine and pyridinium ring vibrations. These changes in relative intensities are due to the resonance of the incident light with different chromophoric groups in the polymer. In spite of this, some peaks from backbone were observed in UVRaman spectrum and a group of pyridine and pyridinium bands were still 
observed with excitation in $632.8 \mathrm{~nm}$, showing the presence of mechanical coupling between the backbone and side groups vibrations.

We also studied the SERS (Surface Enhanced Raman Scattering) behaviour of the P2EPH monomer, 2-ethynylpyridine, in silver electrode sweeping the potential and changing the solution $\mathrm{pH}$. The changes in the band intensities were assigned to different molecule orientation on the surface. The ion 2-pyridylacetylide (2-ethynylpyridine without the acetylenic proton) was formed when the potential was $-0,7 \mathrm{~V}$ or more negative than that. 


\section{INTRODUCÃO}


Introdução

\section{1- Introdução}

\section{1- Polímeros Condutores}

Os materiais poliméricos, que inicialmente foram utilizados como isolantes elétricos, tornaram-se úteis como condutores elétricos nos anos 60 quando descobriu-se que a incorporação de cargas condutoras, como fibras metálicas ou negro de fumo, à matriz polimérica provocava a diminuição da resistência elétrica destes materiais. Estes polímeros são denominados condutores extrínsecos, pois as cargas incorporadas são as responsáveis pela condutibilidade do material ${ }^{1}$.

Em 1977 Shirakawa e colaboradores ${ }^{2}$ descobriram que o poliacetileno tinha sua condutividade drasticamente aumentada quando dopado, ou seja, quando exposto a um processo redox que envolve transferência de carga com subsequente criação de espécies carregadas. Estes polímeros são denominados condutores intrínsecos pois a condutividade está relacionada com a natureza desse material.

Apesar do termo "dopagem" ter sido retirado dos semicondutores inorgânicos, a função dos dopantes nos polímeros condutores é a neutralização das cargas criadas pela remoção ou adição de elétrons ao polímero, diferentemente do que ocorre nos semicondutores inorgânicos. Além disso, enquanto a dopagem em semicondutores inorgânicos é feita em níveis de ppm, nos polímeros condutores ela pode alcançar $50 \%$ da massa do material. 

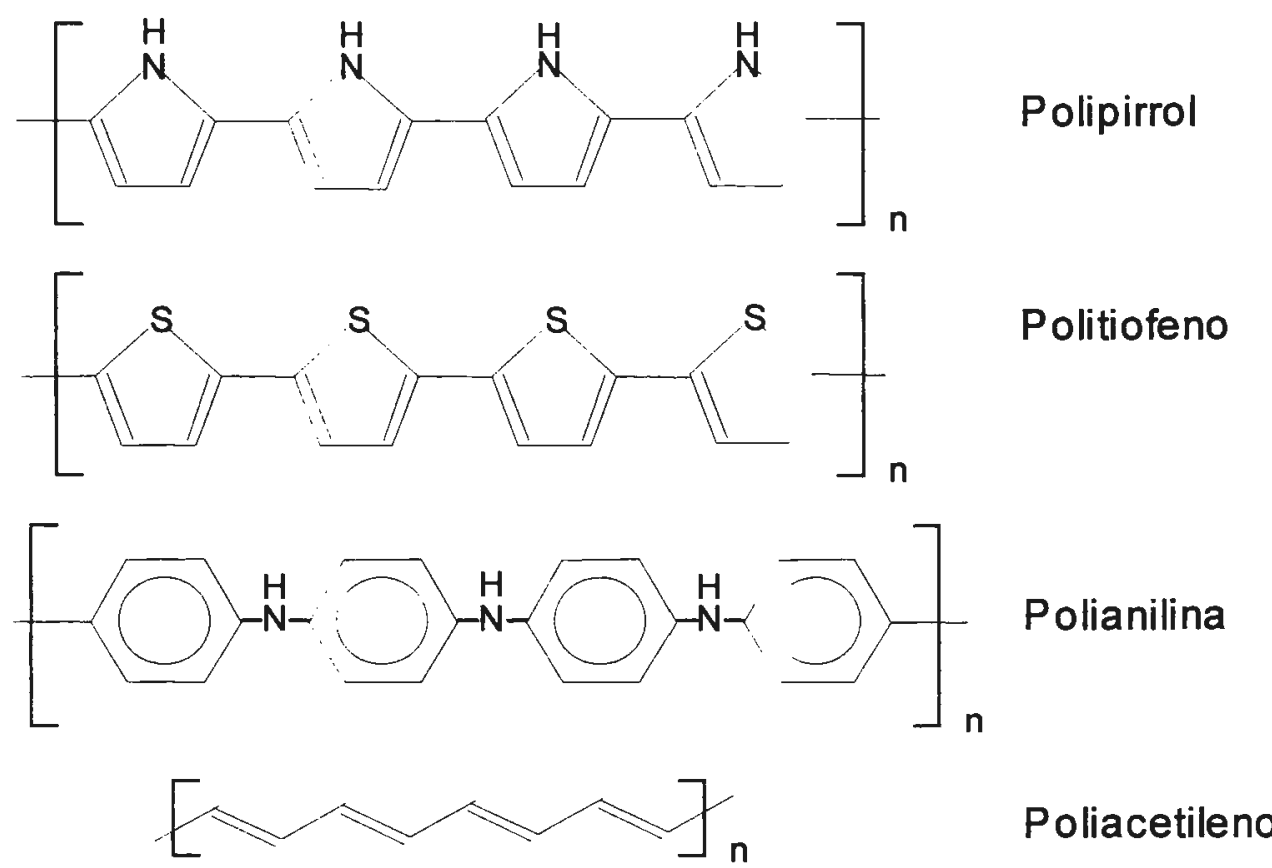

Figura 1.1: Representação esquemática de alguns polímeros condutores intrínsecos.

Desde então, outros polímeros mostraram-se também condutores intrínsecos, como o polipirrol ${ }^{3}$, o politiofeno ${ }^{4}$, o polifurano ${ }^{5}$, o poli( $p$-fenileno $)^{6}$ e a polianilina ${ }^{7}$. Na figura 1.1 é mostrada a representação esquemática de alguns destes polímeros.

Um modelo teórico usado para explicar a condutividade elétrica é o modelo de bandas. Neste modelo, os orbitais ligantes formam um contínuo denominado banda de valência (BV) e os orbitais antiligantes formam outro contínuo denominado banda de condução (BC), sendo estes separados por uma região de energia proibida, à qual chamamos "gap". O tamanho do "gap" indicaria se o composto é um condutor, um semicondutor ou um isolante.

A dopagem removeria elétrons da banda de valência ou adicionaria elétrons à banda de condução, analogamente ao mecanismo de geração de 
carregadores de cargas em semicondutores inorgânicos dopados. Todavia a associação, que é feita para alguns polímeros condutores, da condutividade com portadores de cargas de spin zero e não com elétrons desemparelhados, não é contemplada por este modelo de dopagem ${ }^{8-12}$.

Outro modelo propõe a existência de defeitos estruturais na cadeia polimérica, formando sólitons (radicais livres) neutros no poliacetileno não dopado $^{13}$. Estes defeitos levam ao aparecimento de um nível eletrônico semipreenchido no meio do "gap", como mostra a figura 1.2a. Removendo ou adicionando um elétron, ou seja, dopando, (figura $1.2 \mathrm{~b}-\mathrm{c}$ ) o resultado seria sólitons carregados com spin zero.

Em alguns polímeros, como o polipirrol, o politiofeno, a polianilina e o poli( $p$-fenileno), há o surgimento de outros tipos de transportadores de cargas, como os pólarons (íons radicais) e os bipólarons (dicátions ou diânions), que são associados com a presença de estados eletrônicos dentro do "gap".

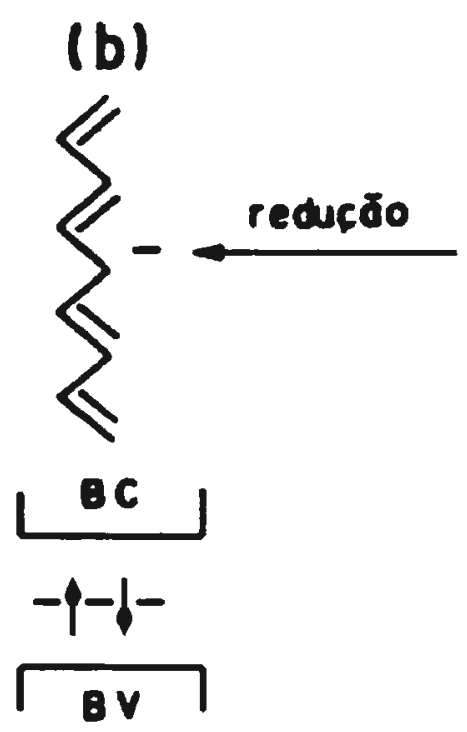

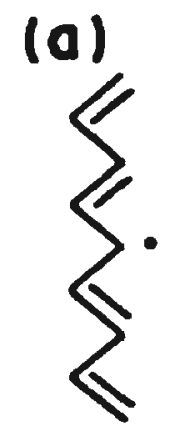

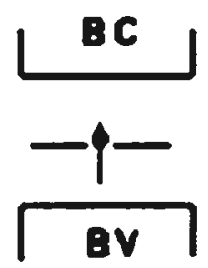

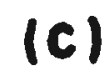
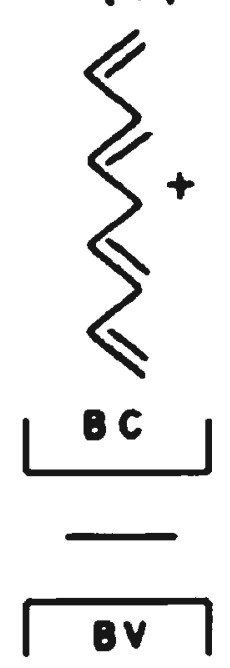

Figura 1.2: Esquema de sólitons na estrutura do poliacetileno: a) sóliton neutro; b) sóliton negativo; c) sóliton positivo. 


\section{2- Poliacetileno}

\subsection{1- Características Gerais}

O poliacetileno (PA) foi obtido pela primeira vez em 1958 por Natta e colaboradores $^{14}$ como um pó insolúvel e infusível. Quando preparado, a estrutura do poliacetileno é cis, porém esta transforma-se, por isomerização térmica, na forma trans, que é a estrutura mais estável dos isômeros do poliacetileno $^{15}$ e à qual comumente chamaremos de trans-poliacetileno ou simplesmente poliacetileno. A figura 1.3 mostra estas estruturas.
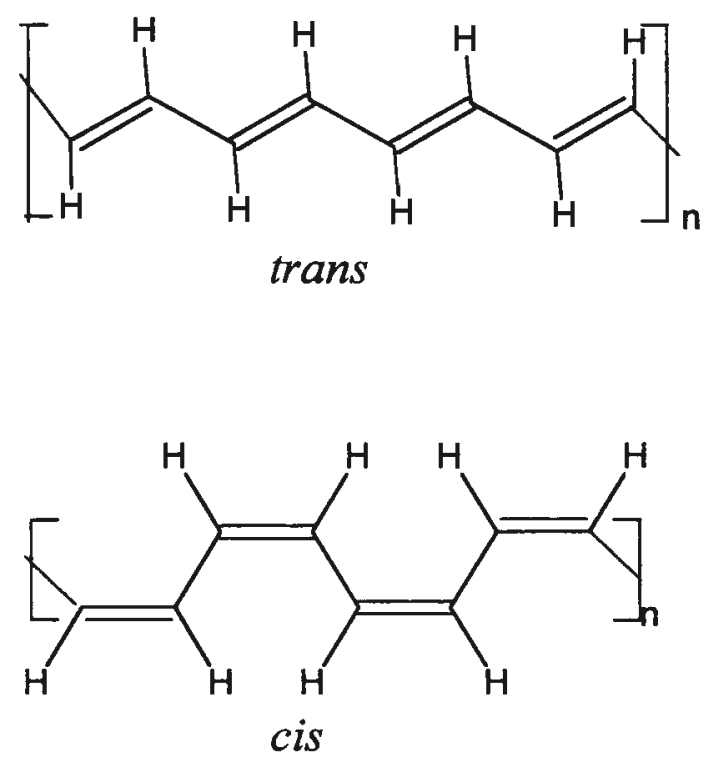

Figura 1.3: Representação esquemática do trans e do cis poliacetileno 
Introdução

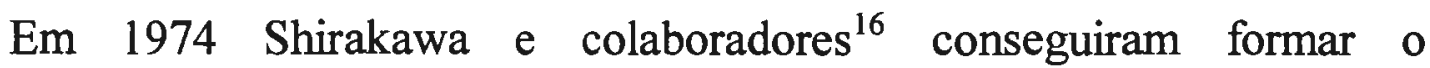
poliacetileno como um filme usando catalisador de Ziegler-Natta, mais especificamente $\mathrm{Ti}\left(\mathrm{OC}_{4} \mathrm{H}_{9}\right)_{4}-\mathrm{Al}\left(\mathrm{C}_{2} \mathrm{H}_{5}\right)_{3}$. A espessura do filme podia ser controlada variando-se a pressão do acetileno, a duração da polimerização e a concentração do catalisador. Em 1977, como já dito anteriormente, foi descoberto que o poliacetileno torna-se condutor elétrico quando dopado ${ }^{2}$.

Somente na década de 80 foram descobertas rotas sintéticas para a produção de poliacetilenos mais processáveis. Edwards e Feast ${ }^{17}$ encontraram um método de sobrepujar a falta de processabilidade do poliacetileno obtendo um precursor processável que pode ser facilmente transformado em poliacetileno. O polímero, conhecido como PA de Durham, é formado em três passos: cicloadição de Diels-Alder entre um ciclooctatetraeno e um alcino adequado; abertura do anel do monômero e polimerização deste formando o precursor solúvel; decomposição térmica do precursor dando poliacetileno. Este polímero tem cristalinidade diferente do produzido por Shirakawa, sendo a cristalinidade do PA de Durham dependente das condições utilizadas para converter o precursor em poliacetileno, podendo produzir desde polímeros amorfos a altamente orientados.

Outra maneira encontrada para melhorar a processabilidade do poliacetileno foi a inserção deste polímero em matriz de polibutadieno, poliestireno ou poliisopreno ${ }^{18,19}$. O composto assim sintetizado é mais solúvel que os outros poliacetilenos.

Também na década de 80 , sintetizou-se o poliacetileno altamente orientado $^{20}$ permitindo a medida da anisotropia do seu índice de refração ${ }^{21}$. A partir da rota de Durham também chegou-se a polímeros orientados ${ }^{22}$.

Finalmente, um outro tipo de síntese produz filmes muito regulares, 
Introdução

compactos e cristalinos com planos paralelos bem definidos ${ }^{23-26}$. São os chamados PA de Naarmann, os quais, quando estirados e dopados, apresentam valores de condutividade muito altos (ao redor de $10^{5} \mathrm{~S} / \mathrm{cm}$ ). Além disso o PA de Naarmann tem maior estabilidade que a maioria dos poliacetilenos obtidos por outras rotas sintéticas.

Independentemente do tipo de síntese realizada, o poliacetileno obtido será somente um semicondutor. Para que ele adquira caráter de um composto condutor é necessário que seja dopado. Esta dopagem pode ser feita por diferentes métodos sendo os principais a dopagem química em solução ${ }^{27}$ e por vapor $^{2}$ e a eletroquímica ${ }^{28}$. O baixo valor do potencial de ionização do poliacetileno indica que este polímero pode ser facilmente oxidado por um dopante receptor de elétrons como os halogênios ou ácidos de Lewis (dopagem tipo p) e a alta afinidade eletrônica deste polímero indica que ele pode ser reduzido por um dopante doador de elétrons como os metais alcalinos e alcalinos terrosos (dopagem tipo $\mathrm{n}$ ). A tabela 1.1 nos mostra alguns dos vários dopantes utilizados para o poliacetileno ${ }^{29}$.

De todos os dopantes do PA o mais estudado é o $\mathrm{I}_{2}{ }^{2,30-39}$. Geralmente esta dopagem é realizada submetendo o polímero ao vapor de $I_{2}$ ou utilizando uma solução do dopante em clorofórmio ou tetracloreto de carbono. Estudos do poliacetileno dopado com $\mathrm{I}_{2}$ mostraram, através do espalhamento Raman, espectroscopia Mössbauer e difração de raio X, que as espécies $\mathrm{I}^{-}, \mathrm{I}_{3}^{-}$e $\mathrm{I}_{5}{ }^{-}$são formadas na dopagem ${ }^{33-39}$. A quantidade de cada espécie é dependente da concentração inicial de $\mathrm{I}_{2}$. 


\section{Tabela 1.1}

Alguns dopantes utilizados para o poliacetileno

Dopantes Receptores de Elétrons

\begin{tabular}{|c|c|}
\hline Halogênios & $\mathrm{Cl}_{2}, \mathrm{Br}_{2}, \mathrm{I}_{2}, \mathrm{ICl}, \mathrm{ICl}_{3}, \mathrm{IBr}, \mathrm{IF}_{5}$ \\
\hline $\begin{array}{l}\text { Haletos de metais e } \\
\text { semi-metais }\end{array}$ & $\begin{array}{l}\mathrm{PF}_{5}, \mathrm{AsF}_{5}, \mathrm{BBr}_{3}, \mathrm{SO}_{3}, \mathrm{AlCl}_{3}, \mathrm{TiCl}_{4}, \mathrm{ZrCl}_{4}, \mathrm{TaCl}_{5}, \\
\mathrm{MoCl}_{5}, \mathrm{WCl}_{6}, \mathrm{FeCl}_{3}, \mathrm{LnCl}_{3}(\mathrm{Ln}=\mathrm{La}, \mathrm{Ce}, \mathrm{Pr}, \mathrm{Nd})\end{array}$ \\
\hline Receptores orgânicos & $\mathrm{TCNE}^{\mathrm{a}}, \mathrm{TCNQ}^{\mathrm{b}}$, Cloranil, $\mathrm{DDQ}^{\mathrm{c}}$ \\
\hline Outros & $\begin{array}{l}\mathrm{XeOF}_{4}, \quad \mathrm{XeF}_{\mathrm{n}}, \quad\left(\mathrm{NO}_{2}\right)^{+}\left(\mathrm{PF}_{6}\right)^{-}, \quad\left(\mathrm{NO}_{2}\right)^{+}\left(\mathrm{SbF}_{6}\right)^{-}, \\
\left(\mathrm{NO}_{2}\right)^{+}\left(\mathrm{BF}_{4}\right)^{-}, \quad(\mathrm{NO})^{+}\left(\mathrm{SbCl}_{6}\right)^{-}, \quad\left(\mathrm{Me}_{3} \mathrm{O}\right)^{+}\left(\mathrm{SbCl}_{6}\right)^{-}, \\
\mathrm{FSO}_{2} \mathrm{OOSO}_{2} \mathrm{~F}\end{array}$ \\
\hline
\end{tabular}

Dopantes Doadores de Elétrons

\begin{tabular}{l|l}
\hline Metais alcalinos & $\mathrm{Li}, \mathrm{Na}, \mathrm{K}, \mathrm{Rb}, \mathrm{Cs}$ \\
Metais alcalinos terrosos & $\mathrm{Ca}, \mathrm{Sr}, \mathrm{Ba}$ \\
Lantanídeos & $\mathrm{Eu}$ \\
\hline
\end{tabular}

Tetracianoetileno

b 7,7,8,8-Tetracianoquinodimetano

c 2,3-Dicloro-5,6-diciano-p-benzoquinona

Quando o poliacetileno é dopado eletroquimicamente pode-se obter algumas vantagens em relação à dopagem química como, por exemplo, a dopagem tipo $\mathrm{n}$ e tipo $\mathrm{p}$ simultaneamente e o controle exato do nível de dopagem pela voltagem aplicada. Além disto, também é possível desdopar o poliacetileno mudando a voltagem aplicada. ${ }^{29}$

Outra propriedade presente no poliacetileno, porém de menor relevância tecnológica que a condutividade elétrica, é a resposta óptica não-linear. Esta propriedade está relacionada, em termos microscópicos, aos termos não lineares da série de expansão do vetor de momento de dipolo induzido, $\mu$, 
como função do vetor campo elétrico aplicado, $\mathbf{E}$ :

$$
\boldsymbol{\mu}=\mu_{0}+\alpha . \mathbf{E}+\beta / 2 . \mathbf{E} \cdot \mathbf{E}+\gamma / 6 . \mathbf{E} \cdot \mathbf{E} . \mathbf{E}+\ldots
$$

onde $\mu_{0}$ é o momento de dipolo permanente da molécula e $\alpha, \beta$ e $\gamma$ são os tensores de polarizabilidade e de hiperpolarizabilidades de primeira e segunda ordens, respectivamente.

$\mathrm{O}$ vetor momento de dipolo induzido traduz-se macroscopicamente pelo vetor polarização (P). Este pode ser relacionado com o campo elétrico aplicado de maneira análoga ao momento de dipolo induzido:

$$
\mathbf{P}=\mathbf{P}_{\mathbf{0}}+\chi^{(1)} \cdot \mathbf{E}+\chi^{(2)} \cdot \mathbf{E} \cdot \mathbf{E}+\chi^{(3)} \cdot \mathbf{E} \cdot \mathbf{E} \cdot \mathbf{E}+\ldots
$$

onde $\mathbf{P}_{0}$ é o vetor de polarização da amostra na ausência de campo elétrico e $\chi^{(\mathrm{n})}$ é a suscetibilidade de enésima ordem do meio. Esta suscetibilidade é um tensor de grau $(n+1)$ que contém $3^{(n+1)}$ elementos ${ }^{40}$.

Sinclair e colaboradores ${ }^{41}$ mediram a susceptibilidade óptica não-linear de terceira ordem do poliacetileno e o valor obtido, $5 \times 10^{-10} \mathrm{esu}$, foi comparável à alta susceptibilidade apresentada pelo polidiacetileno.

\subsection{2- Espectroscopia Vibracional}

A espectroscopia Raman e no infravermelho são duas técnicas que nos permite obter informações sobre os níveis vibracionais e sobre a estrutura das moléculas.

A espectroscopia de absorção (ou de emissão) no infravermelho está 
Introdução

associada à variação do momento de dipolo com a vibração, sendo um processo de absorção (ou emissão) ressonante onde a freqüência absorvida (ou emitida) é idêntica à de oscilação do dipolo ${ }^{42}$.

Por outro lado, a espectroscopia Raman está associada à variação da polarizabilidade com a vibração e é devida ao espalhamento inelástico, pela amostra, de uma radiação monocromática de energia maior que as energias vibracionais. A energia da radiação espalhada pode ser maior (espalhamento anti-Stokes) ou menor (espalhamento Stokes) que a energia incidente e a diferença entre a radiação incidente e a espalhada será igual à energia de transição vibracional da molécula. Caso as energias incidente e espalhada tenham os mesmos valores, o espalhamento será elástico (também chamado de espalhamento Rayleigh) e nenhuma informação vibracional estará nele contida. Comumente o espalhamento Stokes é o mais utilizado devido à maior intensidade de seu sinal em relação ao espalhamento anti-Stokes ${ }^{42}$. Os mecanismos de espalhamento estão representados na figura 1.4.

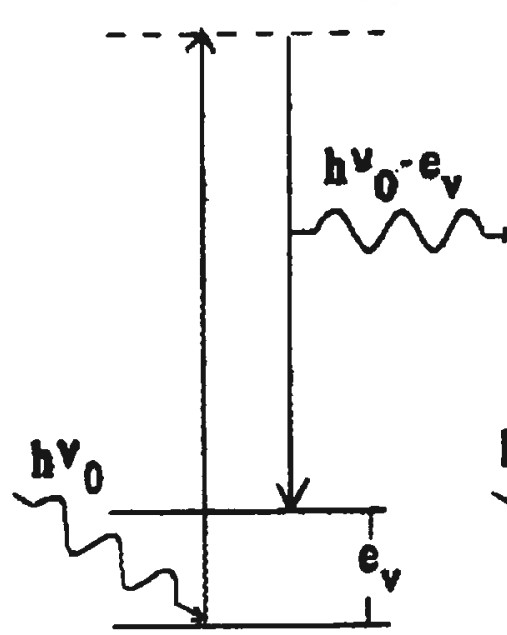

Stokes

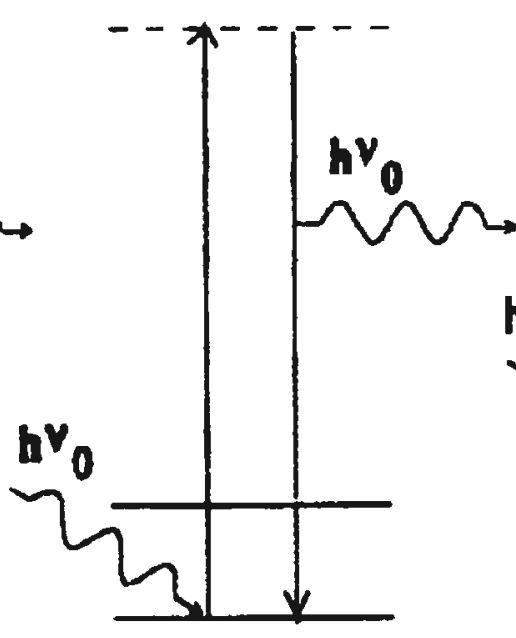

Rayleigh

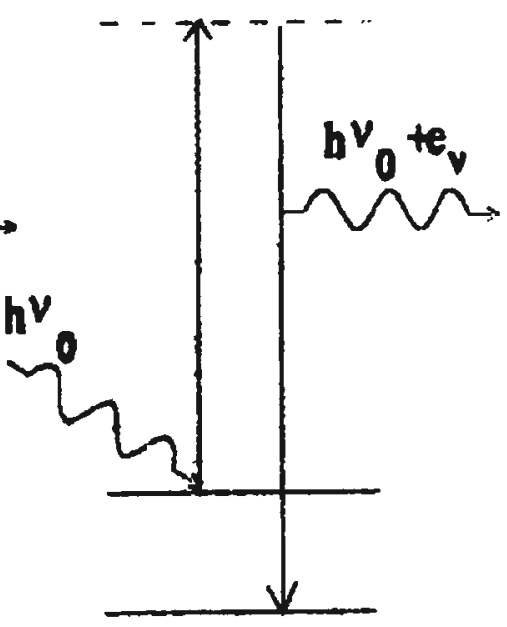

Anti -Stokes

Figura 1.4- Esquema dos mecanismos de espalhamento elástico (Rayleigh) e inelástico (Stokes e anti-Stokes). 
Quando, em um espectro Raman, a energia incidente coincide ou se aproxima da energia de uma transição eletrônica permitida da molécula há intensificação de alguns modos desse espectro que pode chegar a um fator de $10^{5}$. Em moléculas poliatômicas, geralmente somente as intensidades das bandas cujos modos normais de vibração contenham coordenadas internas que sofreram variação entre os estados eletrônicos fundamental e excitado devem ser intensificadas. Este efeito é chamado de Raman ressonante e, além da informação vibracional, nos permite obter também informações do estado eletrônico excitado através da medida da intensidade Raman em função da freqüência da radiação excitante (perfil Raman ressonante) ${ }^{42,43}$.

Se considerarmos o poliacetileno como um cristal unidimensional de cadeia infinita e perfeita, podemos esperar que possua os seguintes parâmetros geométricos: $\mathrm{R}_{\mathrm{C}=\mathrm{C}}=1,36 \AA, \mathrm{R}_{\mathrm{C}-\mathrm{C}}=1,45 \AA$ e $\alpha_{\mathrm{CCC}}=122^{\circ}$, onde $\mathrm{R}$ é a distância entre dois átomos e $\alpha$ é o ângulo formado por três átomos. Além disso deve apresentar a estrutura de representação irredutível dada pelo grupo de ponto $\mathrm{C}_{2 \mathrm{~h}}, \Gamma=4 \mathrm{~A}_{\mathrm{g}}+1 \mathrm{~B}_{\mathrm{g}}+1 \mathrm{~A}_{\mathrm{u}}+2 \mathrm{~B}_{\mathrm{u}}$, sendo os dois primeiros componentes desta representação $\left(4 \mathrm{~A}_{\mathrm{g}}+1 \mathrm{~B}_{\mathrm{g}}\right)$ ativos no Raman enquanto os dois últimos $\left(1 \mathrm{~A}_{\mathrm{u}}+\right.$ $2 \mathrm{~B}_{\mathrm{u}}$ ) são ativos no infravermelho ${ }^{15}$. Devemos, portanto, esperar três bandas ativas no infravermelho e cinco Raman ativas. As bandas preditas no infravermelho são observadas em 1015, 1292 e $3013 \mathrm{~cm}^{-1}$ (figura 1.5) e foram atribuídas à deformação angular $\mathrm{CCH}$ fora do plano, à deformação angular $\mathrm{CCH}$ no plano e ao estiramento $\mathrm{CH}$, respectivamente ${ }^{44}$. Das cincos bandas esperadas no espectro Raman, contudo, apenas três foram observadas (figura 1.6). As bandas observadas no espectro Raman ressonante do poliacetileno são referentes a modos com maior contribuição do estiramento $\mathrm{C}=\mathrm{C}$ (aproximadamente $1500 \mathrm{~cm}^{-1}, v_{1}$ ), da deformação angular CCC (cerca de 1300 
Introdução

$\mathrm{cm}^{-1}, v_{2}$ ) e do estiramento C-C (aproximadamente $1100 \mathrm{~cm}^{-1}, v_{3}$ ).

Os espectros Raman ressonante do poliacetileno mostraram que tanto o contorno quanto a posição das bandas são dependentes, principalmente, de dois fatores: da natureza da amostra ${ }^{45}$ e do comprimento de onda da radiação excitante $e^{32,34,46,47}$. A tabela 1.2 mostra a variação da freqüência Raman $v_{1}$ para poliacetilenos preparados por diferentes sinteses enquanto a tabela 1.3 mostra a variação nas posições das bandas com a radiação excitante (para uma mesma síntese). Esta variação da freqüência da banda Raman com a radiação excitante é denominada dispersão Raman ou fotosseletividade.

Inicialmente a fotosseletividade foi associada ao comprimento da cadeia polimérica ${ }^{47}$. Hoje é geralmente aceito que a fotosseletividade está associada a uma heterogeneidade na amostra polimérica e que esta heterogeneidade está relacionada, de alguma maneira, com o comprimento de conjugação da cadeia polimérica, isto é, com o comprimento da deslocalização dos elétrons $\pi$ na cadeia. Apesar disto, ainda não existe um consenso sobre como a heterogeneidade polimérica provoca a fotosseletividade. Existem na literatura três modelos que procuram descrever este fenômeno: o modelo de comprimento de conjugação (Conjugation Length Model, CLM) ${ }^{56-60}$, o modelo de modo de amplitude (Amplitude Mode Model, AMM) ${ }^{61-63}$ e o modelo de coordenada de conjugação efetiva (Effective Conjugation Coordinate Model, ECCM) $)^{64-66}$.

No CLM o comprimento de conjugação é quem desempenha o papel principal. O polímero é considerado como sendo constituído por cadeias com diferentes comprimentos de conjugação em distribuição bimodal. Este tipo de distribuição acaba distinguindo as cadeias com alto e baixo comprimento de conjugação (distribuição bimodal) dando origem à heterogeneidade na amostra. 


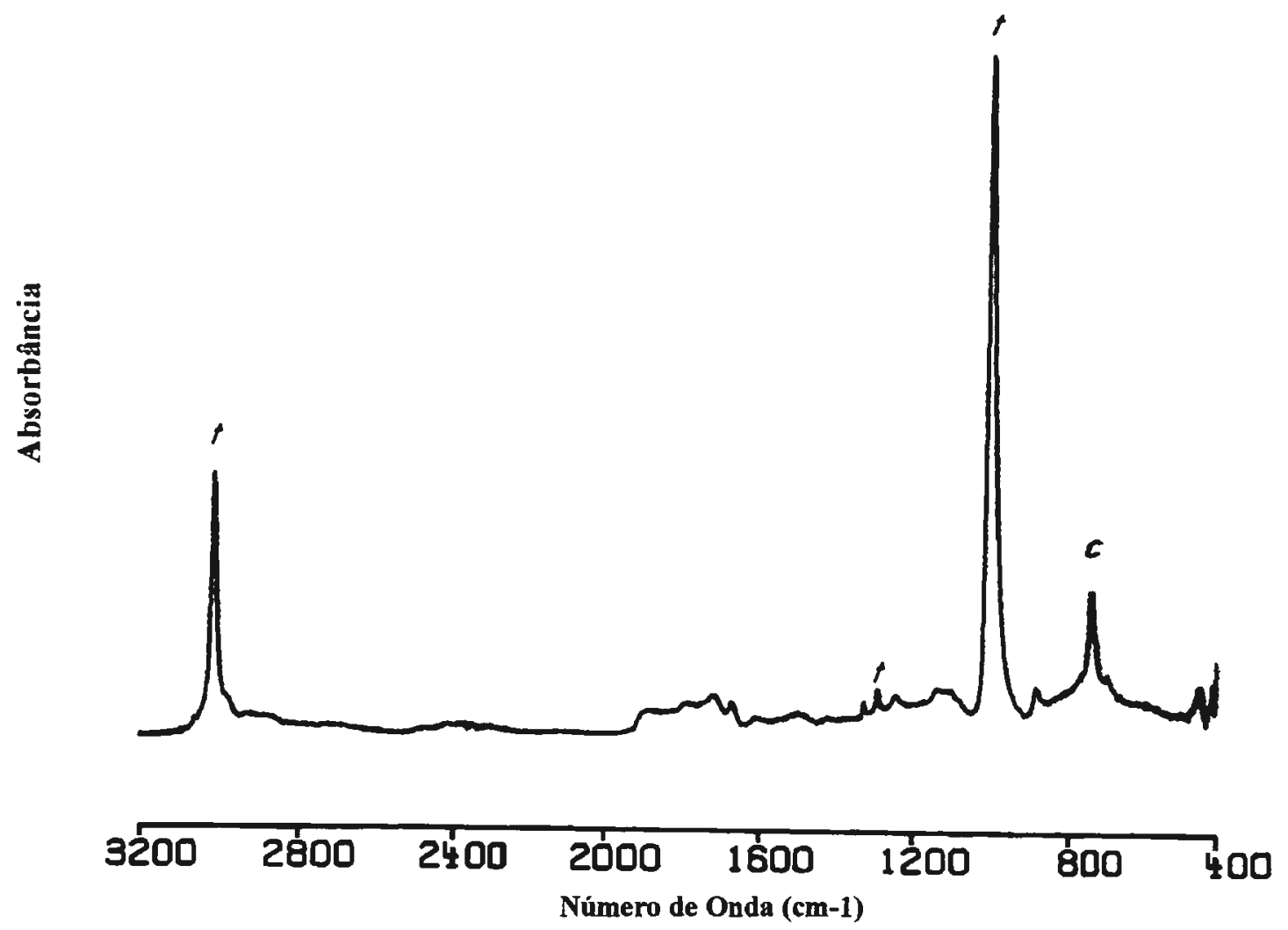

Figura 1.5- Espectro no infravermelho de uma amostra de poliacetileno rica em segmentos com configuração trans ${ }^{15}$. As bandas marcadas com a letra $t$ são aquelas referentes à configuração trans, enquanto que as assinaladas $\operatorname{com} c$ são da configuração $c i s$ 
Tabela 1.2

Valores da freqüência Raman ativa $v_{1}$ do PA preparado de várias formas

\begin{tabular}{|c|c|c|c|c|c|}
\hline Amostra $^{a}$ & \multicolumn{4}{|c|}{ Freqüência $/ \mathrm{cm}^{-1} \mathrm{~b}$} & Referência \\
\hline SHPA & $\begin{array}{c}1457 \\
{[632,8]}\end{array}$ & & & & 48 \\
\hline $\begin{array}{l}\text { SHPA } \\
\text { fino }\end{array}$ & $\begin{array}{c}1469 \\
{[647,1]}\end{array}$ & $\begin{array}{c}1494 \\
{[488,0]}\end{array}$ & & $\begin{array}{c}1589 \\
{[350,7]}\end{array}$ & 32 \\
\hline $\begin{array}{l}\text { SHPA } \\
80 \mathrm{~K}\end{array}$ & $\begin{array}{l}1458 \\
{[650]}\end{array}$ & & $\begin{array}{c}1516 \\
{[457,9]}\end{array}$ & & 49 \\
\hline $\begin{array}{l}\text { SHPA } \\
\mathrm{CH}_{1,00}\end{array}$ & $\begin{array}{c}1460 \\
{[632,8]}\end{array}$ & $\begin{array}{cc}1472 & 1488 \\
{[514,5]} & {[488,0]}\end{array}$ & $\begin{array}{c}1500 \\
{[457,9]}\end{array}$ & & 50 \\
\hline $\begin{array}{l}\text { SHPA } \\
\mathrm{CH}_{1,17}\end{array}$ & $\begin{array}{c}1464 \\
{[632,8]}\end{array}$ & $\begin{array}{cc}1476 & 1508 \\
{[514,5]} & {[488,0]}\end{array}$ & $\begin{array}{c}1517 \\
{[457,9]}\end{array}$ & & 50 \\
\hline $\begin{array}{l}\text { SHPA baixo } \\
\text { peso molec. }\end{array}$ & $\begin{array}{c}1467 \\
{[676,4]}\end{array}$ & & $\begin{array}{c}1498 \\
{[457,9]}\end{array}$ & & 51 \\
\hline $\begin{array}{l}\text { SHPA alto } \\
\text { peso molec. }\end{array}$ & $\begin{array}{c}1459 \\
{[676,4]}\end{array}$ & & & & 51 \\
\hline DRPA & & & $\begin{array}{c}1495 \\
{[457,9]}\end{array}$ & & 52 \\
\hline $\begin{array}{c}\text { DRPA } \\
\text { Estirado }\end{array}$ & & & $\begin{array}{c}1465 \\
{[457,9]}\end{array}$ & & 52 \\
\hline HOPA & & $\begin{array}{c}1477 \\
{[514,5]}\end{array}$ & & $\begin{array}{l}1533 \\
{[386]}\end{array}$ & 53 \\
\hline HOPA & $\begin{array}{c}1466 \\
{[647,1]}\end{array}$ & & $\begin{array}{c}1506 \\
{[457,9]}\end{array}$ & & 54 \\
\hline MPA & $\begin{array}{c}1460 \\
{[604,2]}\end{array}$ & & & & 55 \\
\hline
\end{tabular}

$\overline{\text { a }}$ SHPA $=$ poliacetileno preparado pelo método proposto por Shirakawa e colaboradores $^{16} ;$ DRPA $=$ PA do Durham $^{17} ;$ HOPA $=$ poliacetileno altamente orientado $^{20} ; \mathrm{MPA}=$ poliacetileno em uma matriz de poliestireno e poliisopreno ${ }^{18}$.

b Os valores entre colchetes referem-se à radiação excitante (nm). 


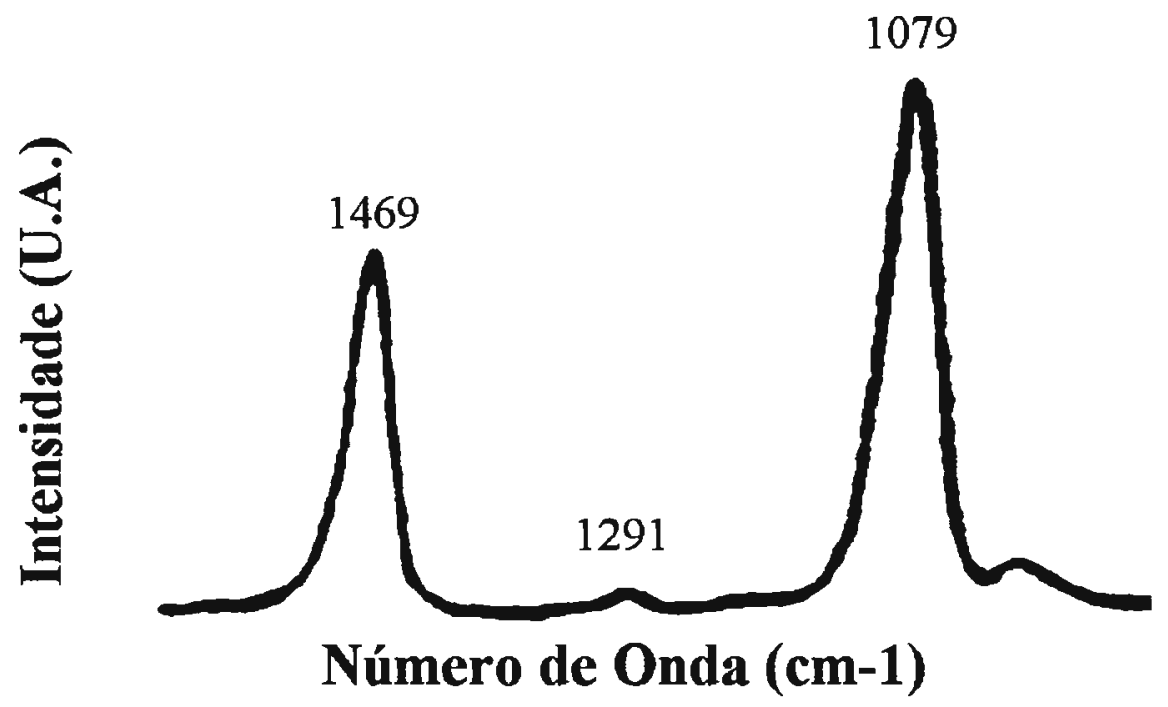

Figura 1.6- Espectro Raman do trans-poliacetileno com excitação em 647,1 $\mathrm{nm}^{32}$.

Tabela 1.3

Variação da freqüência Raman dos modos $v_{1}, v_{2}$ e $v_{3}$ do poliacetileno (SHPA) com a radiação excitante ${ }^{32}$

\begin{tabular}{c|c|c|c}
\hline $\begin{array}{c}\text { Radiação Excitante } \\
\lambda_{0} / \mathrm{nm}\end{array}$ & \multicolumn{3}{|c}{ Freqüência/cm } \\
\cline { 2 - 4 } & $v_{1}$ & $v_{2}$ & $v_{3}$ \\
\hline 647,1 & 1469 & 1291 & 1079 \\
488,0 & 1494 & 1297 & 1120 \\
350,7 & 1589 & 1299 & 1151 \\
\hline
\end{tabular}


As bandas do espectro Raman ressonante, ainda segundo o modelo CLM, serão um envelope das diferentes contribuições dos vários segmentos. Este modelo se concentra principalmente na intensidade e no contorno das bandas, que são calculadas usando a teoria de Albrecht ${ }^{67,68}$. Os modos vibracionais do poliacetileno variam linearmente com $1 / \mathrm{N}$, onde $\mathrm{N}$ é o comprimento de conjugação do polímero ${ }^{56,58-60}$.

O tratamento AMM é centralizado na constante de acoplamento elétronfónon efetiva, $\lambda$, a qual representa as perturbações do potencial intramolecular devido a mudanças no comprimento de conjugação. $O$ modelo recebeu esta denominação devido as vibrações dos modos normais induzirem oscilações na distribuição de carga na rede polimérica (onda de densidade de carga) (2,69 $^{6}$ quais podem ser assumidas como um modo de amplitude. As bandas Raman ressonante são novamente um envelope das contribuições das várias cadeias.

Esta teoria considera o polímero como sendo constituído de uma cadeia infinita e unidimensional. A heterogeneidade é introduzida ao assumirmos que as cadeias poliméricas têm diferentes valores de $\lambda$ apesar de todas serem infinitas. Embora as cadeias tenham o mesmo tamanho, valores diferentes de $\lambda$ aparecem como conseqüência de uma distribuição de diferentes comprimentos de conjugação ${ }^{70}$. Os resultados obtidos demonstram que o valor de $\lambda$ aumenta conforme o "gap" de energia $\left(E_{g}\right)$ cresce. Podemos relacionar o valor de $\lambda$ com a frequiência Raman da seguinte forma ${ }^{61}$ :

$$
2 \lambda=\prod_{n}\left[\frac{\omega_{n}^{R}}{\omega_{n}^{0}}\right]^{2}
$$

onde $n$ é cada um dos modos vibracionais, $\omega_{n}{ }^{0}$ é a freqüência vibracional sem o 
acoplamento elétron-fónon e $\omega_{n}{ }^{R}$ é a freqüência Raman obtida experimentalmente.

O modelo ECCM é uma reformulação do formalismo do AMM. Neste modelo as cadeias são quase-finitas. Uma coordenada de conjugação efetiva, $\mathrm{Q}_{J a}$, onde $J \mathrm{a}$ é a diferença entre as distâncias das ligações $\mathrm{C}=\mathrm{C}$ e $\mathrm{C}-\mathrm{C}$, é introduzida e descreve uma deformação das ligações $\mathrm{CC}$ com o forte acoplamento dos elétrons $\pi$. A oscilação da coordenada $Q_{J a}$ no modelo ECCM corresponde ao modo de amplitude no $A M M$. Cada $Q_{J a}$ terá uma constante de força efetiva, $f_{\mathrm{Ja}}$, específica que será diferente para polímeros com diferentes comprimentos de conjugação, portanto $f_{\mathrm{Ja}}$ desempenhará a função da heterogeneidade neste modelo. Os cálculos são baseados em uma versão reduzida do formalismo $\mathrm{GF}^{42}$.

Dos três modelos apresentados o CLM é aquele que melhor descreve, para o poliacetileno, a intensidade e o contorno das bandas Raman enquanto que o AMM e o ECCM descrevem melhor as freqüências Raman.

\subsection{3- Polipiridilacetileno e Seus Derivados}

Poliacetilenos substituídos são, em geral, mais estáveis e mais processáveis que o poliacetileno ${ }^{71}$. Em contrapartida pode haver redução do comprimento de conjugação da cadeia devido ao impedimento estérico produzido pelos substituintes que provocam torções na ligação $\sigma$ da cadeia linear, produzindo um decréscimo da condutividade elétrica e de outras propriedades em relação ao poliacetileno ${ }^{72,73}$. A utilização de anéis piridínicos quaternizados como substituintes formam polímeros que apresentam alta conjugação. Esta conjugação é atribuída à interação entre os contra-íons e os 
Introdução

anéis piridínicos, impedindo as torções das ligações da cadeia polimérica ${ }^{72}$.

Derivados do poliacetileno com anéis piridínicos foram primeiramente sintetizados por Okamoto e Alia $^{74}$ em 1964 aquecendo a n-etinilpiridina $(n=2$, 3 ou 4), em tubo selado, a $150{ }^{\circ} \mathrm{C}$ por $10 \mathrm{~h}$ para formar o poli-npiridilacetileno, ou poli-n-etinilpiridina $(\mathrm{PnEP})$. Desde então, pouco tem se estudado sobre estes polímeros e seus derivados.

Gal e colaboradores ${ }^{73,75}$ prepararam o P2EP, utilizando cloretos de metais de transição e compostos organometálicos como catalisadores e, após dopagem com $\mathrm{I}_{2}$, mediram a condutividade elétrica deste polímero em função da concentração de dopante. Os valores obtidos foram superiores àqueles obtidos para o polifenilacetileno.

Blumstein e colaboradores ${ }^{72,76-85}$ investigaram a síntese de vários poli-2piridilacetilenos iônicos. Um dos polímeros estudados por Blumstein foi o poli(2-hidrocloreto de piridinium-2-piridilacetileno) ${ }^{78}$, P2EPH (figura 1.7), formado pela polimerização da 2-etinilpiridina por um ácido forte. Segundo resultados de análise elementar o polímero obtido apresenta metade dos anéis piridínicos protonados e a outra metade não protonada. Isto levou os autores a propor um mecanismo de polimerização onde ocorre a formação de um complexo dimérico entre um monômero protonado e outro desprotonado via ligação de hidrogênio intermolecular (figura 1.8). Este polímero é facilmente solubilizado nos solventes mais usuais, inclusive em água, além de ter boa estabilidade ao ar, tornando-o altamente processável.

$\mathrm{Na}$ tentativa de desprotonar os anéis piridínicos protonados, adicionando $\mathrm{NaOH}$, verificou-se que a desprotonação em nenhum momento foi total, sempre restando uma pequena quantidade de anéis protonados (por volta de $5 \%$ ). Além disto, os espectros eletrônicos dos polímeros antes e após a 
tentativa de desprotonação mostraram que esta provocou uma redução no comprimento de conjugação do polímero. 


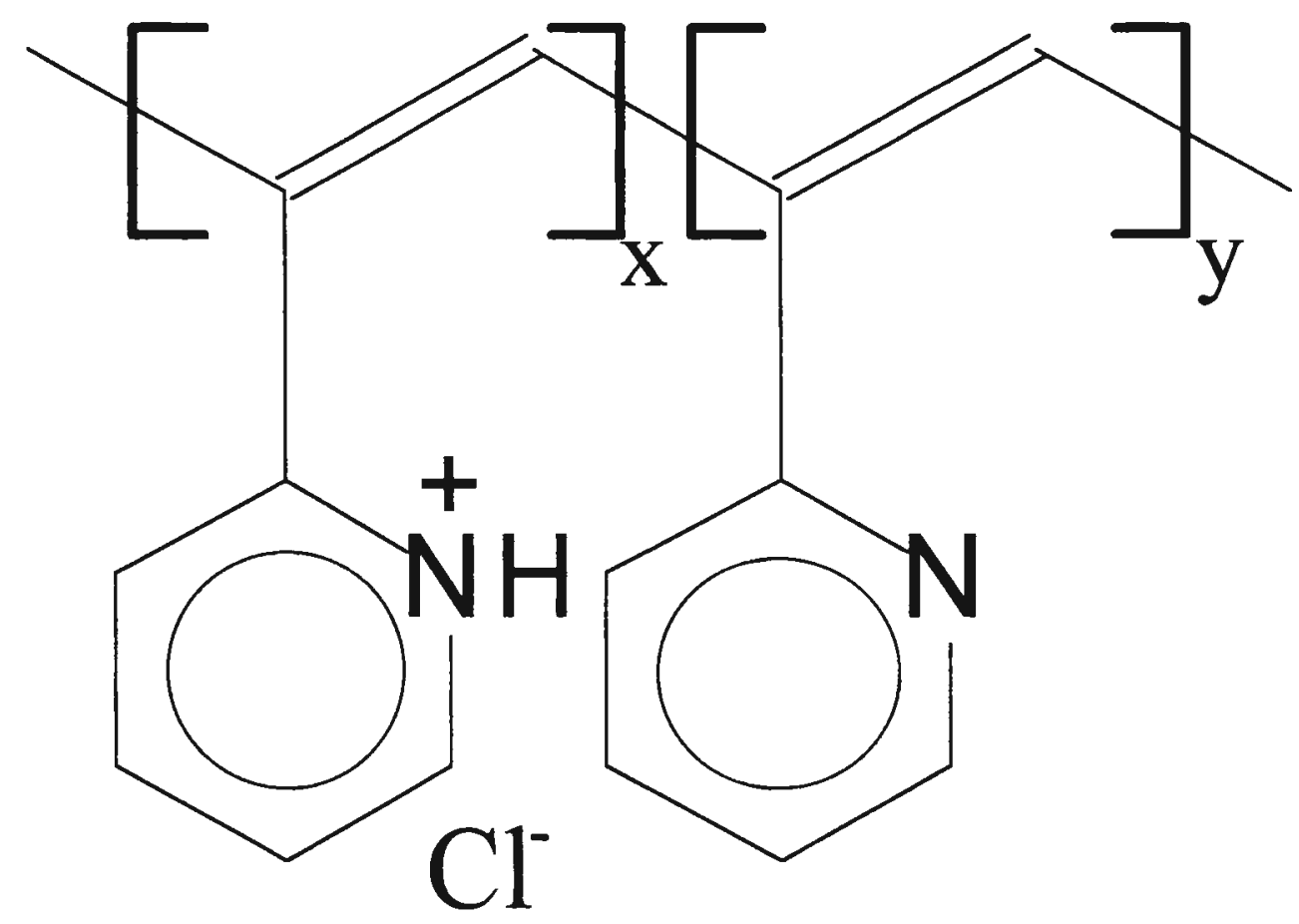

Figura 1.7- Estrutura do poli(2-hidrocloreto de piridinium-2-piridilacetileno), P2EPH 

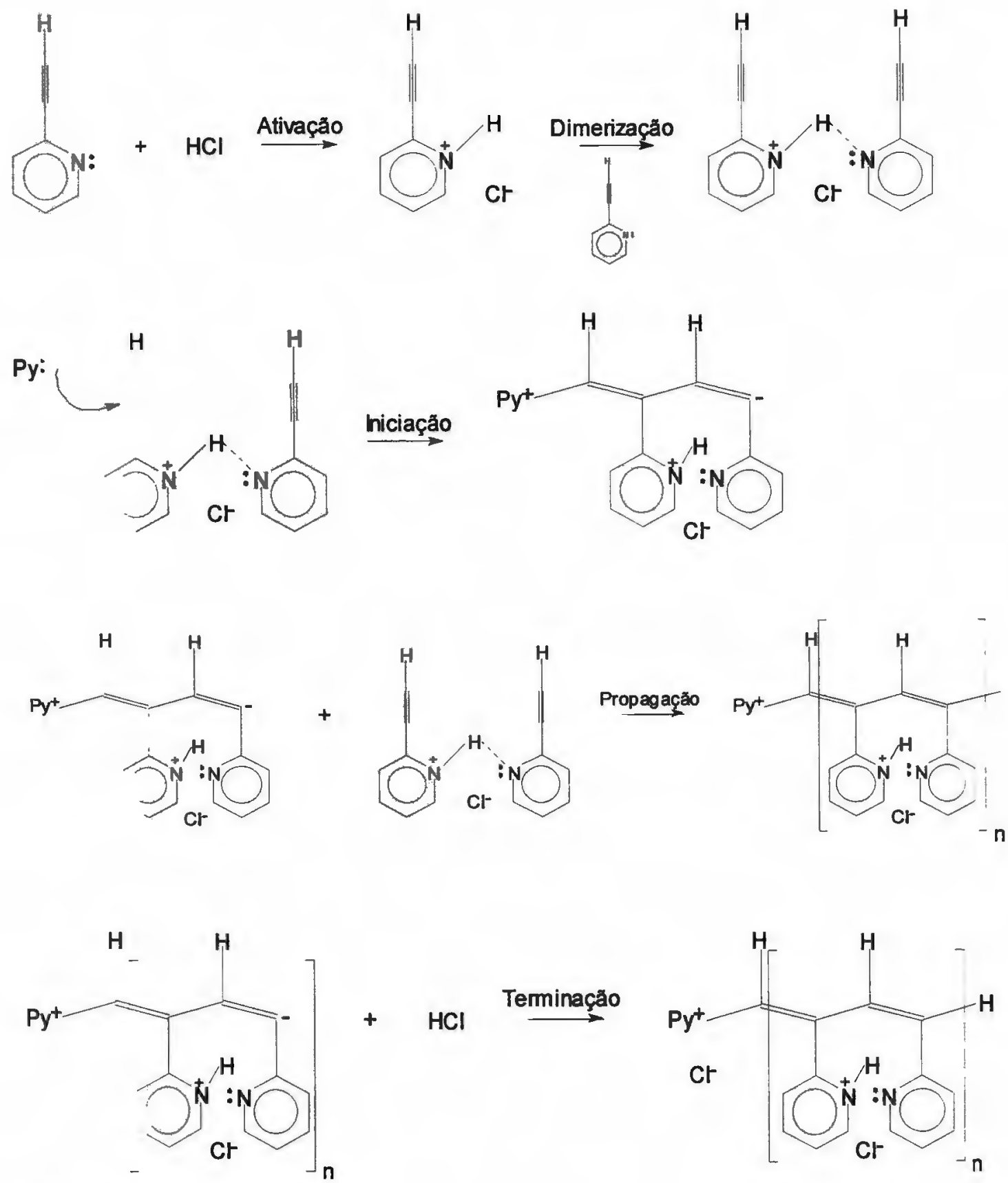

$\mathrm{HCl}$
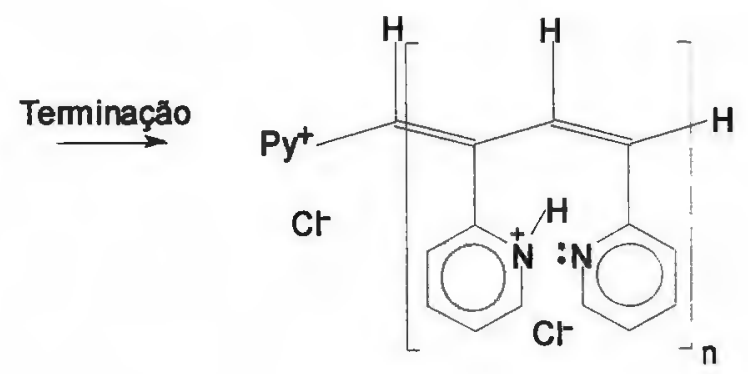

Py: = 2etinilpiridina

$\mathrm{Py}^{+}=2$-etinilpiridinium

Figura 1.8- Esquema de polimerização da 2-etinilpiridina proposto por Subramanyam e Blumstein ${ }^{78}$. 


\section{3- Efeito SERS (Surface Enhanced Raman Scattering)}

O efeito SERS é a intensificação do sinal Raman de moléculas adsorvidas em superfícies metálicas e foi reportado pela primeira vez por Fleischmann e colaboradores ${ }^{86}$ no ano de 1974. Os autores atribuíram a intensificação ao aumento da área superficial do eletrodo pois o aumento do sinal Raman somente era observado após ciclos de oxidação-redução do eletrodo de prata. Somente em 1977 Jeanmarie e Van Duyne ${ }^{87}$ e Albrecht e Creighton ${ }^{88}$, independentemente, mostraram que a alta intensidade observada não podia ser explicada apenas pelo aumento de área no eletrodo. Desde então o efeito SERS tem encontrado aplicação em inúmeras áreas como, por exemplo, corrosão ${ }^{89-91}$, cinética e mecanismo de reações ${ }^{92,93}$, caracterização de eletrodos modificados ${ }^{94-96}$ e sistemas biológicos ${ }^{97}$.

Não são todas as superfícies metálicas que provocam esta intensificação no sinal Raman. Prata, cobre e ouro são os metais mais comumente utilizados, porém, há trabalhos na literatura de SERS em superfícies de alguns outros metais $^{98-100}$. Em todos os casos o metal deve apresentar uma superfície rugosa. Vários substratos já foram testados e os mais usados são: eletrodo enrugado por ciclos de oxidação-redução, filmes finos de metal em forma de ilhas depositados em condições de ultra alto vácuo e colóides ${ }^{101}$.

Muitos mecanismos foram propostos para a intensificação provocada pelo efeito SERS. Em suma podemos reuní-los em dois modelos: o eletromagnético e o químico (ou de transferência de carga) ${ }^{102}$.

O modelo eletromagnético sugere uma intensificação do campo elétrico das radiações incidente e espalhada nas proximidades de uma superfície metálica rugosa. Como a intensidade Raman é proporcional ao quadrado do 
Introdução

momento de dipolo induzido pela radiação, que, por sua vez, é proporcional ao seu campo elétrico, a intensificação do campo elétrico resulta em um aumento da intensidade Raman. Essa intensificação do campo elétrico deve-se à ressonância com o plasma de superfície (surface plasmons) do metal utilizado. Como podemos perceber, este modelo independe da natureza química da molécula adsorvida, dependendo somente da distância desta para a superfície metálica e das características físicas do metal. Esta teoria explica intensificações a longas distâncias e o espectro obtido deve ser similar ao da molécula em solução. A intensificação, por esse modelo, pode chegar à ordem de $10^{4}$.

O modelo químico é resultante da interação eletrônica entre o metal e a molécula adsorvida provocando modificações na polarizabilidade $(\alpha)$ da molécula. A intensificação ocorre através de um mecanismo semelhante ao do efeito Raman ressonante, pois a interação do adsorbato com o metal provoca um deslocamento ou alargamento dos estados eletrônicos do adsorbato, sendo também possível a criação de novos estados eletrônicos advindos da quimioadsorção e que podem servir como estados intermediários ressonantes. Diferentemente do modelo eletromagnético, o mecanismo químico é sensível às propriedades químicas da molécula adsorvida e os espectros SERS podem ser divergentes daqueles da molécula em solução. $\mathrm{O}$ modelo químico prevê uma intensificação de até 100 vezes do espalhamento Raman.

A presença de um dos mecanismos citados acima não exclui a possibilidade de atuação do outro. Se os dois agirem simultaneamente os seus fatores de intensificação se multiplicam e podem chegar à ordem de $10^{6}$. Existe também a possibilidade da intensificação SERS combinar-se com o efeito Raman ressonante, somando a ordem de intensificação. Para tal é necessário 
que a molécula adsorvida apresente uma absorção eletrônica próxima da freqüência da radiação excitante. Esta combinação dos dois efeitos é chamada SERRS (Surface Enhanced Resonance Raman Scattering).

\subsection{1- Regras de Seleção para Espectroscopia SERS}

As regras de seleção para a espectroscopia Raman em superfícies são uma derivação daquelas obtidas para a espectroscopia no infravermelho, porém sofrem uma complicação devido ao espalhamento Raman depender da polarizabilidade molecular ao invés do momento de dipolo.

A obtenção das regras de seleção para a espectroscopia no infravermelho em superfícies é conseqüência direta da visualização de que um dipolo adsorvido a uma distância $d$ acima da superficie condutora elétrica induzirá um "dipolo imagem" no substrato a uma distância $d$ abaixo da superfície (ver figura 1.9), de mesma magnitude do dipolo real ${ }^{103}$. $\mathrm{O}$ "dipolo imagem" terá sua componente dipolar perpendicular à superfície inalterada em relação ao dipolo real enquanto que as componentes paralelas à superfície têm seus sentidos invertidos e, com isso, as componentes paralelas à superfície do dipolo total (dipolo real + "dipolo imagem") devem apresentar magnitude zero. Sendo assim, somente as vibrações que provoquem variação na componente do momento de dipolo normal à superfície, ou seja, só os modos normais perpendiculares à superfície, serão ativas no infravermelho. 

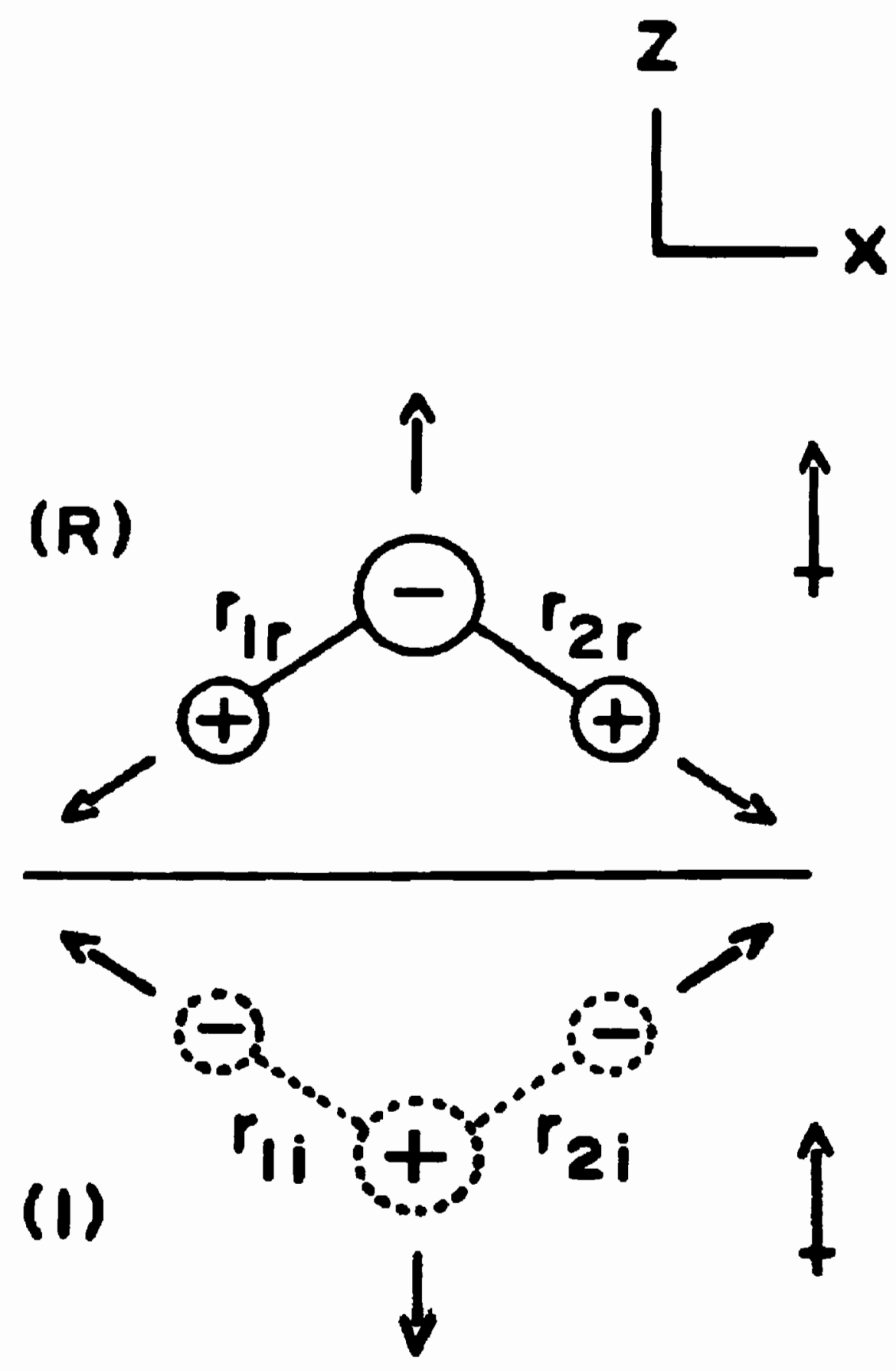

Figura 1.9- Representação do dipolo real (R) e do "dipolo imagem" (I) 
Estendendo as considerações do "dipolo imagem" para o espalhamento Raman é possível concluir que somente as bandas associadas às vibrações que provoquem variação da polarizabilidade perpendicularmente ao plano da superficie serão ativas no espectro Raman ${ }^{104,105}$, entretanto, devemos ter em mente que as regras de seleção em superfícies são menos válidas na espectroscopia Raman que na espectroscopia no infravermelho pois a indução do "dipolo imagem" depende da refletividade da luz incidente pelo metal e estas superfícies são refletores mais eficientes na região do infravermelho do que na região do visível, onde os espectros Raman são geralmente obtidos. Além disso, essas regras de seleção foram obtidas para superfícies lisas, enquanto que as superfícies SERS ativas são necessariamente rugosas.

Além desse efeito puramente eletromagnético, existe outro que envolve a simetria da molécula adsorvida. Com a adsorção a molécula poderá perder simetria e essa possível redução de simetria poderá resultar na quebra de degenerescência de alguns modos normais e/ou no aparecimento de bandas que anteriormente eram inativas e que, nessa nova simetria, passam a ter atividade $\operatorname{Raman}^{106}$. 


\section{4- Objetivos e Metas Alcançadas}

O objetivo inicial desse trabalho de mestrado era caracterizar vibracionalmente (Raman e infravermelho) poliacetilenos substituídos com anéis piridínicos, mais especificamente a poli-2-etinilpiridina, a poli-4etinilpiridina e seus derivados ácidos.

$\mathrm{O}$ trabalho foi iniciado com o P2EPH e observamos que esse polímero apresentava fluorescência, impedindo a obtenção do espectro Raman. Um dos objetivos alcançados nesse trabalho foi a eliminação da interferência provocada pela fluorescência e a obtenção do espectro Raman do P2EPH. Nessa dissertação são apresentadas duas formas experimentais de contornar o problema da fluorescência: o uso de superficies de prata metálica e a utilização de radiações excitantes na região do ultravioleta.

Outra meta atingida foi o estudo da fotosseletividade do P2EPH. Foi possível observar a variação da freqüência vibracional com a excitação e conseguimos mostrar a validade do modelo de modo de amplitude (AMM) mesmo para sistemas que não sejam unidimensionais nem tenham cadeias infinitas.

Durante o trabalho nos propusemos a sintetizar o polímero eletroquimicamente, porém constatamos, após várias tentativas fracassadas, a impossibilidade dessa síntese. Partiu dessa tentativa de polimerização o interesse no estudo SERS da 2-etinilpiridina. Esse estudo possibilitou a familiarização com a técnica SERS e os resultados obtidos permitiram observar o comportamento do monômero em superfície de prata. 


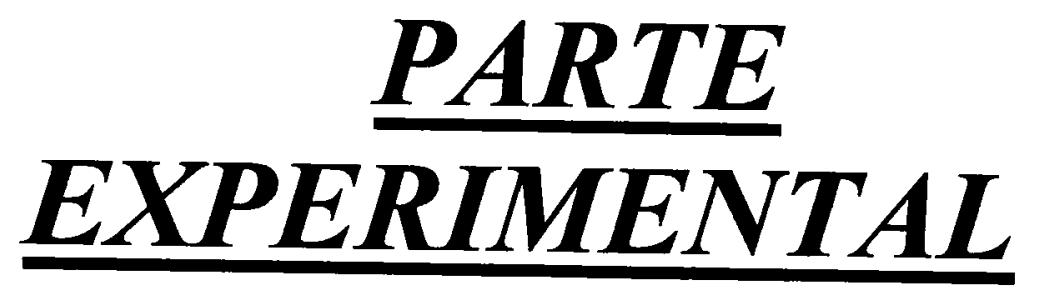




\section{2- Parte Experimental}

\section{1- Síntese dos Poliacetilenos Substituídos com Anéis Piridínicos}

\subsection{1- Poli(2-Hidrocloreto de Piridinium-2-Piridilacetileno), P2EPH}

A síntese do P2EPH seguiu o procedimento apresentado por Subramanyam e Blumstein ${ }^{78}$. Ácido clorídrico concentrado foi adicionado à 2etinilpiridina (Lancaster, $95 \%$ ) em quantidade equimolar, gota-à-gota, sob agitação e a $0{ }^{\circ} \mathrm{C}$. O monômero foi destilado a vácuo antes de sua utilização. A mistura de reação adquiriu rapidamente coloração marrom-escura, ocorreu desprendimento de calor e a viscosidade da solução aumentou. $\mathrm{O}$ polímero resultante (sólido preto) foi lavado copiosamente com éter etílico e seco sob vácuo durante 8 horas.

A análise elementar do polímero é mostrada na tabela 2.1. O resultado indicou que os anéis piridínicos não foram todos protonados, porém, a relação entre anéis protonados e não protonados não foi a mesma obtida por Subramanyam e Blumstein ${ }^{78}$. Esta discordância com o resultado descrito na literatura será discutida posteriormente. Além disto, os valores mostrados indicam que é provável que hajam moléculas de água no sólido obtido. 
Parte Experimental

\subsection{2- Desprotonação do P2EPH}

Esta desprotonação também seguiu o procedimento descrito por Subramanyam e Blumstein $^{78}$. P2EPH foi dissolvido em água destilada (aproximadamente $50 \mathrm{~mL}$ de água por grama de polímero). A um volume desta solução de P2EPH adicionamos o dobro do volume de uma solução $1,0 \mathrm{~mol} / \mathrm{L}$ de $\mathrm{NaOH}$. A mistura resultante foi deixada sob agitação por 8 horas. Após este período apareceu um precipitado de coloração marrom, o qual foi extraído com clorofórmio que posteriormente foi evaporado à pressão reduzida. Chamaremos este polímero de P2EP apesar de ele não estar totalmente desprotonado.

A análise elementar deste polímero (tabela 2.1) indica que a desprotonação não foi completa, restando ainda pouco menos de $5 \%$ de anéis piridínicos protonados. Este resultado condiz com o apresentado por Subramanyam e Blumstein ${ }^{78}$, que também não alcançaram a desprotonação completa do polímero.

Diferentemente do $\mathrm{P} 2 \mathrm{EPH}$, a análise elementar do P2EP não mostra nenhum indício de presença de água no sistema.

Tabela 2.1

Análise elementar do P2EPH e do P2EP

\begin{tabular}{ccccc}
\hline & $\% \mathrm{C}$ & $\% \mathrm{H}$ & $\% \mathrm{~N}$ & $\% \mathrm{Cl}$ \\
\hline$\left\{\left[\left(\mathrm{C}_{7} \mathrm{H}_{6} \mathrm{NCl}\right) 0.35+\left(\mathrm{C}_{7} \mathrm{H}_{5} \mathrm{~N}\right) 0.65\right] 1.2 \mathrm{H}_{2} \mathrm{O}\right\}_{\mathrm{n}}$ & 61.15 & 5.64 & 10.19 & 7.8 \\
P2EPH & 61.52 & 5.29 & 9.93 & 8.2 \\
{$\left[\left(\mathrm{C}_{7} \mathrm{H}_{6} \mathrm{NCl}\right) 0.06+\left(\mathrm{C}_{7} \mathrm{H}_{5} \mathrm{~N}\right) 0.94\right]_{\mathrm{n}}$} & 79.86 & 4.81 & 13.31 & 2.0 \\
P2EP & 80.25 & 4.74 & 13.12 & 1.8 \\
\hline
\end{tabular}




\section{2- Síntese da Poli-2-Vinilpiridina Protonada, P2VPH}

Ácido clorídrico concentrado foi adicionado, gota-à-gota, a uma solução de poli-2-vinilpiridina (Scientific Polymer Products, Inc.), P2VP, em acetona. O material, viscoso, resultante foi separado evaporando-se o solvente à pressão reduzida.

\section{3- Síntese do 2-Piridilacetileto de Prata}

Uma solução etanólica de $\mathrm{AgNO}_{3}$ (3 g) foi preparada e a esta foi adicionada algumas gotas de $\mathrm{NaOH}$. A 2-etinilpiridina $(1 \mathrm{~mL})$ foi, então, adicionada a essa solução etanólica. Ocorre rápida precipitação do 2piridilacetileto de prata, o qual é separado por filtração.

\section{4- Preparação dos Substratos de Prata}

\subsection{1- Discos Compactados de Prata Metálica}

Os discos compactados de prata com os polímeros ( $\mathrm{P} 2 \mathrm{EPH}$ ou $\mathrm{P} 2 \mathrm{EP}$ ), de aproximadamente $1,3 \mathrm{~cm}$ de diâmetro, foram preparados de forma similar à da preparação de pastilhas de $\mathrm{KBr}$ para obtenção de espectros no infravermelho, isto é, foram submetidos ao vácuo por 30 minutos e sob vácuo e pressão mecânica (aproximadamente 9 toneladas) por mais 30 minutos. A relação entre a quantidade de prata (Aldrich, 325 mesh, 99,99\%) e do polímero foi variada a fim de obtermos aquela que proporcionava o melhor espectro 
Parte Experimental

Raman.

\subsection{2- Colóide de Prata}

O colóide de prata foi preparado de acordo com o método descrito por Creighton e colaboradores ${ }^{107}$, com pequenas modificações. Uma solução de 17 mg de $\mathrm{AgNO}_{3}$ em $100 \mathrm{~mL}$ de água foi adicionada vagarosamente a uma solução de $24 \mathrm{mg}$ de $\mathrm{NaBH}_{4} \mathrm{em} 300 \mathrm{~mL}$ de água, a qual estava submetida a ultrassom e imersa em banho de gelo. A dispersão resultante, de coloração amarelada, foi aquecida para eliminação completa do excesso de $\mathrm{BH}_{4}{ }^{-}$ (transformando-o em $\mathrm{BO}_{3}{ }^{3-}$ ) e foi estocada em geladeira.

\subsection{3- Eletrodo de Prata}

O eletrodo de trabalho foi previamente limpo mergulhando-o em uma solução aquosa de $\mathrm{HNO}_{3}$ 1:1 em volume, polindo-o com lixas de 600 e 2400 mesh e posteriormente deixando-o em ultrassom por 15 a 30 minutos. Utilizamos uma solução $0,1 \mathrm{~mol} / \mathrm{L}$ de $\mathrm{KCl}$ em água bidestilada como solução eletrolítica. $\mathrm{O}$ eletrodo de trabalho foi ativado com 5 ciclos de oxidaçãoredução entre $-200 \mathrm{e}+200 \mathrm{mV}$ com velocidade de $50 \mathrm{mV} \cdot \mathrm{s}^{-1}$.

\section{5- Instrumentação}

A análise elementar foi feita usando um instrumento Perkin Elmer modelo 2400 (Central Analítica - IQUSP).

As medidas de $\mathrm{pH}$ foram realizadas em um aparelho Digimed DM20. 
Parte Experimental

Os espectros eletrônicos foram obtidos em um espectrofotômetro Beckman DU-70 que utiliza fontes de tungstênio-halogênio, para a região do visível, e de deutério, para o ultravioleta. A deteç̧ão é feita por uma fotomultiplicadora. Os espectros do P2EPH e do P2EP foram obtidos em soluções etanólicas em celas de $1 \mathrm{~mm}$ de caminho óptico e com velocidade de varredura de $60 \mathrm{~nm} / \mathrm{min}$.

Os espectros no infravermelho foram obtidos em espectrômetro Bomem DA3 utilizando fonte Globar, detector de DTGS/KBr e divisor de feixe de $\mathrm{KBr} / \mathrm{Ge}$ ou em espectrômetro Bomem MB100 que possui fonte Globar, detector de DTGS/CsI e divisor de feixe de $\mathrm{KBr}$. Os espectros foram obtidos em pastilha de $\mathrm{KBr}$, que foi feita submetendo a mistura de $\mathrm{KBr}$ e composto (aproximadamente 100:1 em massa) a 30 minutos sob vácuo e mais 15 minutos sob vácuo e pressão mecânica (aproximadamente 3 toneladas). Esses espectros são idênticos aos obtidos em dispersão em nujol. Os espectros foram obtidos com resolução de $4 \mathrm{~cm}^{-1}$ e com 128 varreduras.

Os espectros Raman, com excitação na região do visível, foram obtidos em espectrômetro com duplo monocromador Jobin Yvon U1000 utilizando como detector uma fotomultiplicadora (RCA C31034-A02) acoplada a um contador de fótons (EG \& G PARC). As radiações excitantes utilizadas foram $514,5 \mathrm{~nm}, 501,7 \mathrm{~nm}, 496,5 \mathrm{~nm}, 488,0 \mathrm{~nm}$ e 457,9 nm de um laser de $\mathrm{Ar}^{+}$ (Coherent INNOVA 90-6) e 676,4 nm, 647,1 nm e 568,2 nm de um laser de $\mathrm{Kr}^{+}$(Coherent INNOVA 90-K). A potência utilizada do laser na amostra foi, tipicamente, de $50 \mathrm{~mW}$. Também foi utilizado o espectrômetro Renishaw Raman Imaging Microscope System 3000 acoplado a um microscópio Olympus BH-2 e a um detector CCD (Wright, 600x400 pixels) resfriado por Peltier. Foi utilizada a radiação excitante em $632,8 \mathrm{~nm}$ de um laser de $\mathrm{He}-\mathrm{Ne}$ 
(Spectra Physics modelo 127).

Os espectros Raman excitados no ultravioleta foram obtidos em equipamento Renishaw System 1000 com as mesmas características descritas para o Renishaw Raman Microscope System 3000, porém com algumas adaptações para utilização no UV. A radiação excitante utilizada foi a linha em 244,0 $\mathrm{nm}$ de um laser de $\mathrm{Ar}^{+}$(FreD Coherent) obtida com cristal duplicador de freqüência $(\mathrm{PbO})$ colocado dentro da cavidade de ressonância (Department of Physics and Astronomy, University of Leeds - Reino Unido). A amostra foi dispersa em $\mathrm{KBr}$ ou dissolvida em água para a obtenção destes espectros.

Os espectros SERS em eletrodo foram obtidos usando uma cela espectroeletroquímica de teflon com três eletrodos como mostrado na figura 2.1. O eletrodo de trabalho, um cilindro de prata, foi embutido em teflon de forma a apresentar $0,1 \mathrm{~cm}^{2}$ de área exposta. Foi utilizado um fio de platina como contra-eletrodo e o eletrodo de referência era de $\mathrm{Ag} / \mathrm{AgCl}$ (solução saturada de $\mathrm{KCl})$.

A aplicação de potenciais para a obtenção de espectros SERS em eletrodo foi feita em potenciostato/galvanostato PAR 263A.

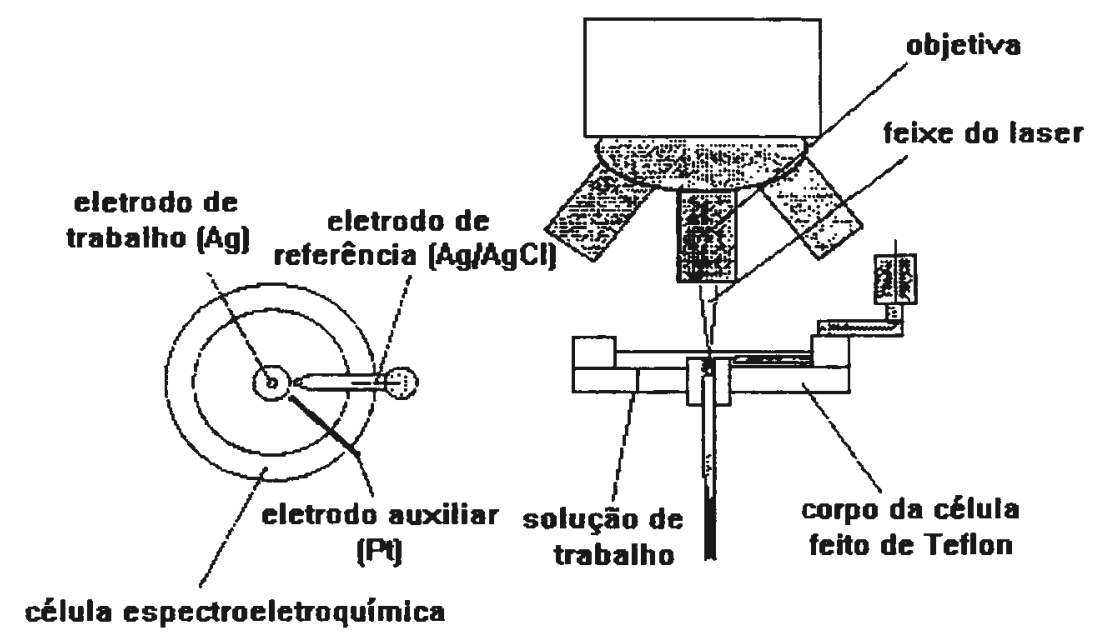

Figura 2.1: Esquema da cela espectroeletroquímica usada na obtenção dos espectros SERS em eletrodo 


\section{RESULTADOSE DISCUSSÃO}


Resultados e Discussão

\section{3- Resultados e Discussão}

\section{1- Poli(2-hidrocloreto de piridinium-2-piridilacetileno)}

Como já mencionado anteriormente, a análise elementar do P2EPH que sintetizamos não reproduziu os valores reportados na literatura, mostrando que a relação entre o número de anéis piridínicos protonados e não protonados difere daquela apresentada (50\% de cada), sendo a quantidade de anéis não protonados superior à de anéis protonados. Este resultado sugere que o mecanismo de polimerização proposto por Blumstein e colaboradores ${ }^{78}$ deve ser reformulado, pois, por esse mecanismo de polimerização, o produto final é um polímero com $50 \%$ dos anéis piridínicos protonados (ver figura 1.8).

Apesar desta diferença na análise elementar, o espectro eletrônico do P2EPH (figura 3.1) concorda com o apresentado por Blumstein na referência 78. Este espectro apresenta duas transições na região do UV, em 238 e $265 \mathrm{~nm}$ (ombro), além de uma banda larga na faixa do visível, centrada em $540 \mathrm{~nm}$. O espectro eletrônico do poliacetileno apresenta apenas uma banda na região do visível ${ }^{32}$, sendo o valor desta transição dependente do comprimento de conjugação da cadeia polimérica. Por outro lado, o espectro eletrônico da piridina mostra duas bandas em 260 e $287 \mathrm{~nm}$ (ombro) referentes às transições $\pi \rightarrow \pi^{*}$ e $\mathrm{n} \rightarrow \pi^{*}$ do anel piridínico ${ }^{108,109}$. Isto nos permite deduzir que as bandas em 238 e 265 nm do espectro eletrônico do P2EPH são associadas com as transições $\pi \rightarrow \pi^{*}$ e $n \rightarrow \pi^{*}$ do anel piridínico enquanto que a banda em $540 \mathrm{~nm}$ deve corresponder à cadeia poliacetilênica. 
Podemos através do espectro eletrônico do P2EPH fazer uma estimativa do comprimento de conjugação $(\mathrm{N})$ de um polieno ${ }^{78,110,111}$. Lewis e Calvin ${ }^{110}$ observaram que a equação $\lambda_{\max }{ }^{2}=\mathrm{kN}$ é obedecida satisfatoriamente bem. Dai e White ${ }^{111}$ mostraram que para $\mathrm{k}=17532 \mathrm{~nm}^{2}$ obtem-se boa correlação entre os valores esperados e obtidos em polienos. Subramanyam e Blumstein $^{78}$ demonstraram que a relação de Lewis-Calvin também é válida para o $\mathrm{P} 2 \mathrm{EPH}$, portanto, sabendo que $\mathrm{P} 2 \mathrm{EPH}$ apresentou $\lambda_{\max }=540 \mathrm{~nm}$, chega-se à conclusão de que o valor mais provável de $\mathrm{N}$ é 17 (existe uma distribuição de comprimentos de conjugação e não apenas um único valor para esta grandeza). Como o comprimento de conjugação não deve ser substancialmente diferente do comprimento da cadeia, podemos afirmar que o P2EPH é um oligômero. Usando o mesmo raciocínio, o comprimento de conjugação mais provável apresentado pelo P2EP é igual a 11. Esta diferença de comprimento de conjugação deve ser causada, como já dito anteriormente, pela interação dos contra-íons com os anéis piridínicos as quais evitam as torções das ligações da cadeia polimérica.

$\mathrm{O}$ espectro no infravermelho do $\mathrm{P} 2 \mathrm{EPH}$ (figura 3.2) também é concordante com o da literatura, exceto por pequenas variações de intensidade relativa na região entre 1580 e $1620 \mathrm{~cm}^{-1}$. Considerando que a intensidade dessas bandas deve ser proporcional à quantidade de anéis de piridina $\mathrm{e}$ piridinium, respectivamente, essas variações estão de acordo com o resultado obtido na análise elementar. 

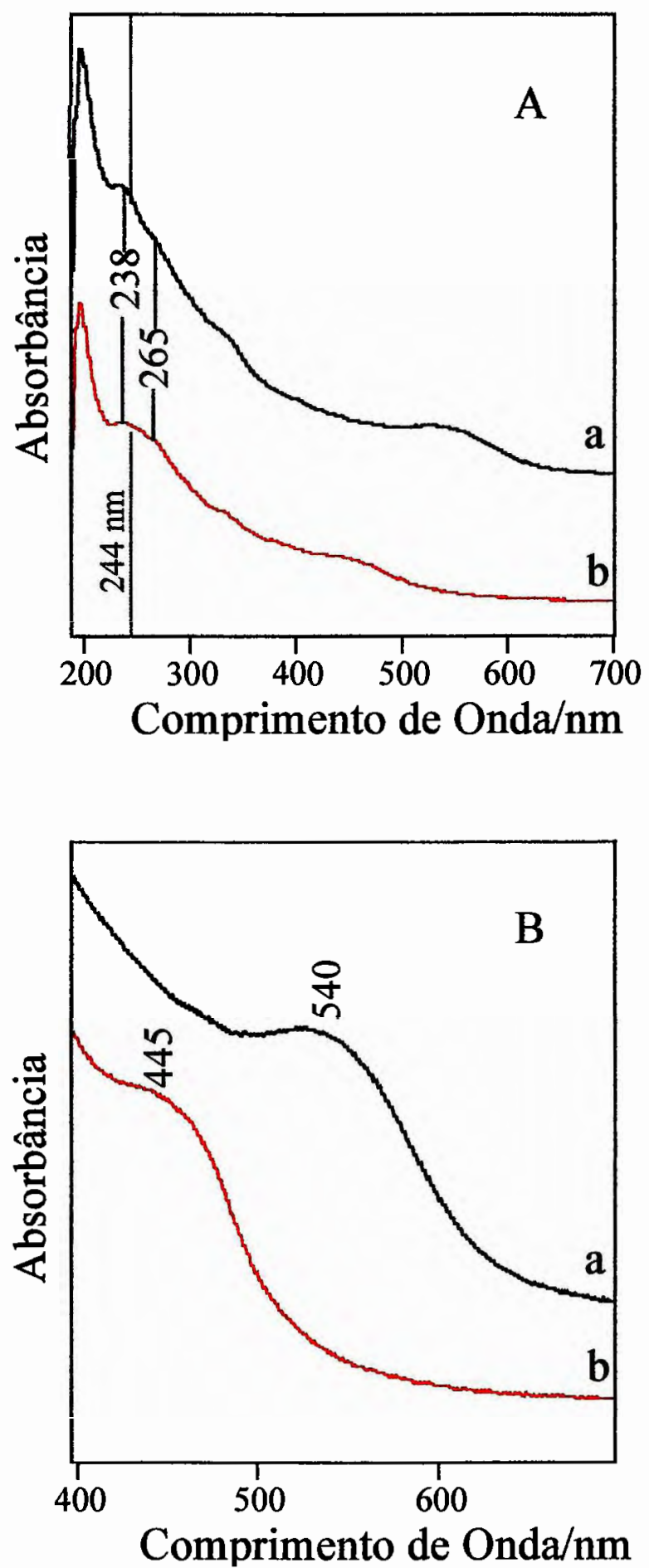

Figura 3.1- Espectro eletrônico, em etanol, do: a) P2EPH; b) P2EP. O quadro (A) mostra as regiões do visível e do UV enquanto que o quadro (B) mostra apenas a região do visível. 


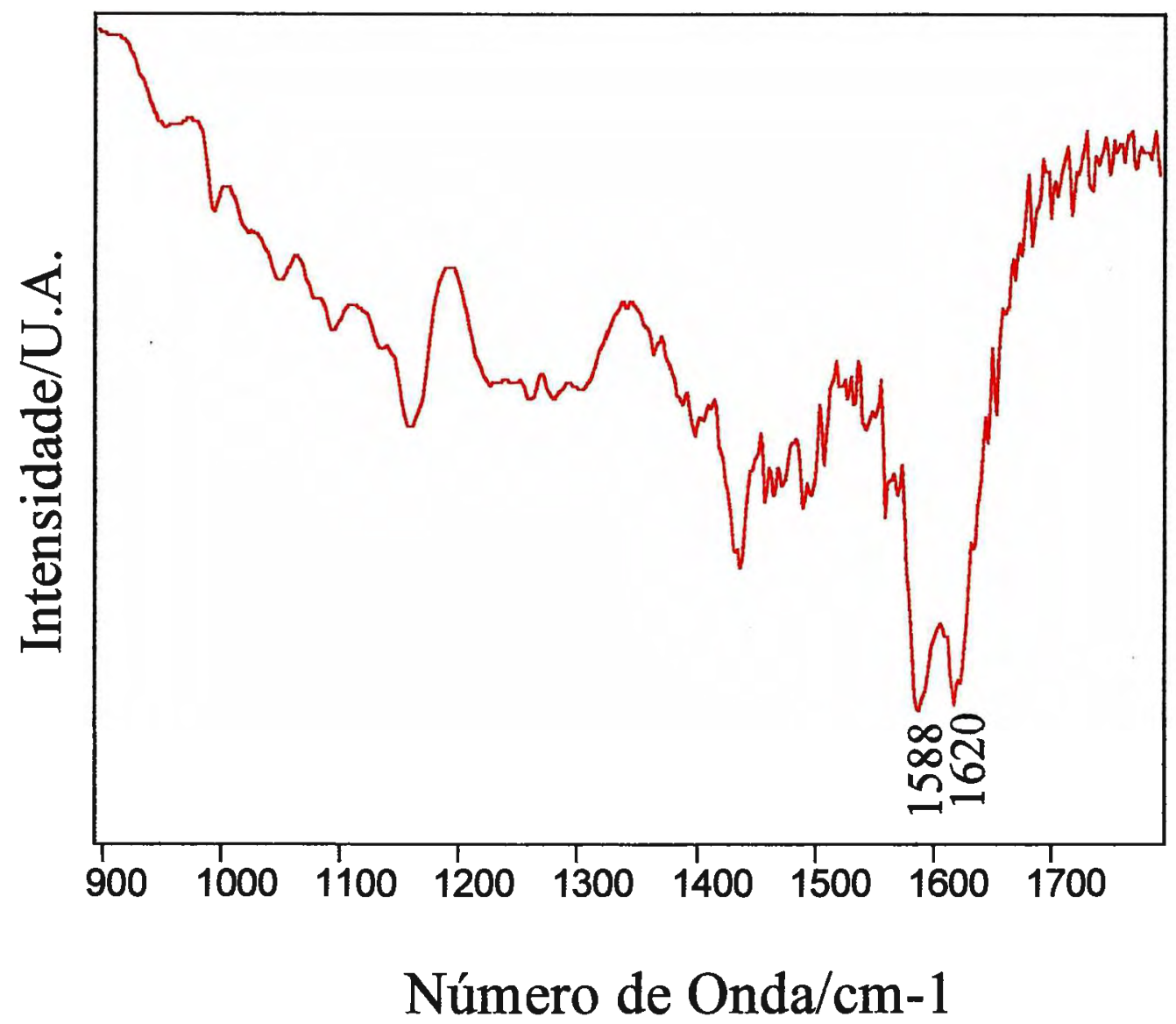

Figura 3.2- Espectro no infravermelho do P2EPH. 
A obtenção dos espectros Raman do P2EPH com excitação no visível foi dificultada pela presença de fluorescência em toda esta região espectral. A figura 3.3 mostra os espectros obtidos com algumas radiações no visível. É possível observar que para radiações excitantes de maior energia (por exemplo a excitação em 413,1 nm) algumas bandas Raman começam a aparecer apesar de ainda existir fluorescência.

A maneira mais comum de transpor a fluorescência seria utilizar a linha de laser no infravermelho próximo (1064 nm), já que esta radiação geralmente não possui energia suficiente para provocar uma transição eletrônica. Essa tentativa mostrou-se ineficiente pois, devido à necessidade de utilização de alta potência do laser, a amostra sofre degradação térmica (mesmo quando é feita uma dispersão do polímero em $\mathrm{KBr}$ ).

Outra solução descrita na literatura para este tipo de problema é a utilização de discos compactados de prata metálica ${ }^{12,113}$. Neste caso a prata metálica atuaria como um supressor de fluorescência. Ao realizarmos este procedimento foi possível notar que a fluorescência foi parcialmente suprimida, permitindo a observação das bandas Raman. A figura 3.4 mostra o espectro Raman do P2EPH em pastilha de prata excitado em $632,8 \mathrm{~nm}$. 


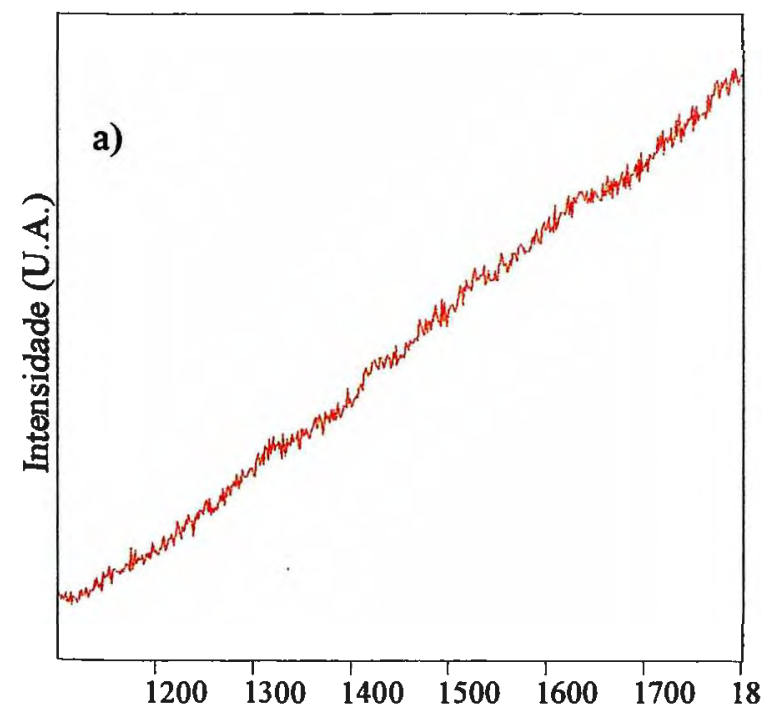

Número de Onda (cm-1)

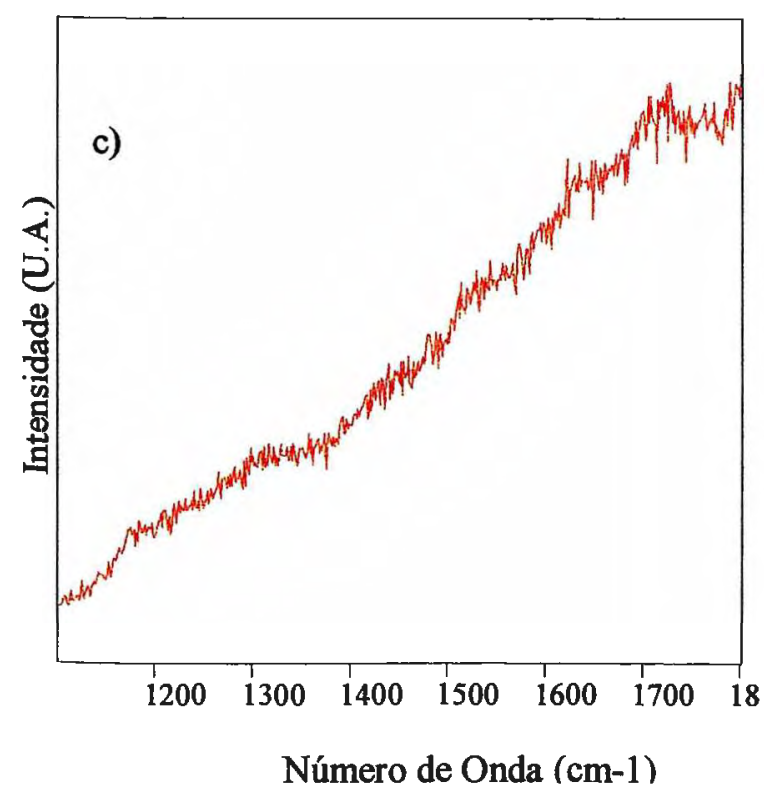

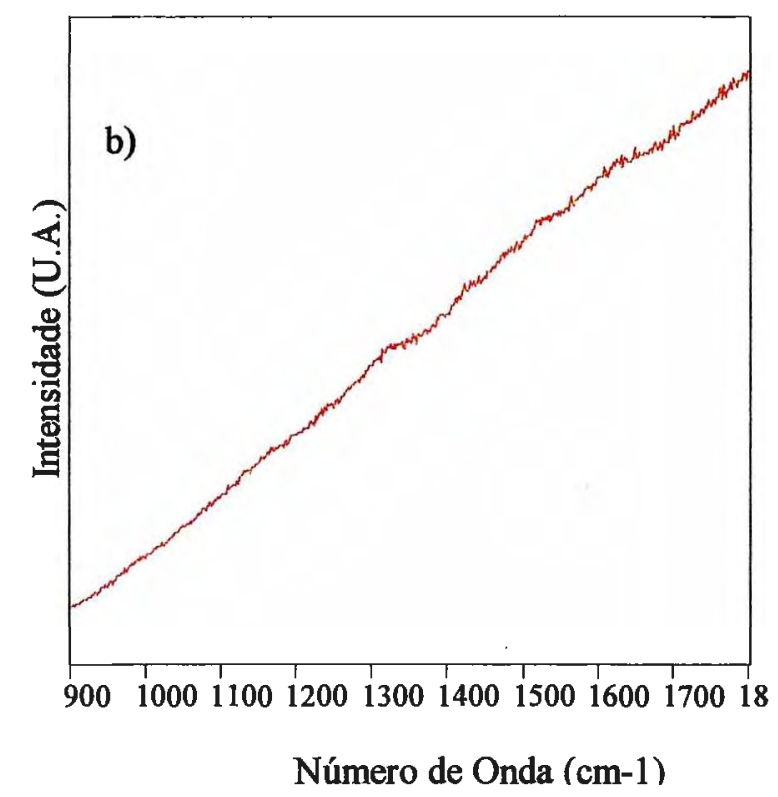

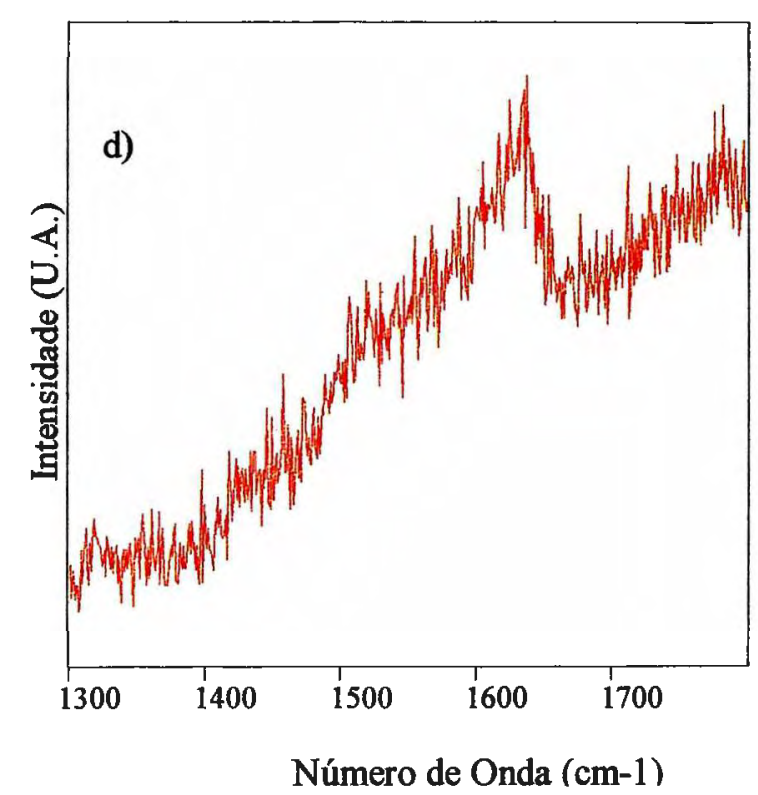

Figura 3.3- Espectro Raman do P2EPH com algumas radiações excitantes no visível: a) excitação $=514,5 \mathrm{~nm}$, potência do laser $=10 \mathrm{~mW}$;

b) excitação $=488,0 \mathrm{~nm}$, potência do laser $=10 \mathrm{~mW}$;

c) excitação $=457,9 \mathrm{~nm}$, potência do laser $=3 \mathrm{~mW}$;

d) excitação $=413,1 \mathrm{~nm}$, potência do laser $=3 \mathrm{~mW}$ 


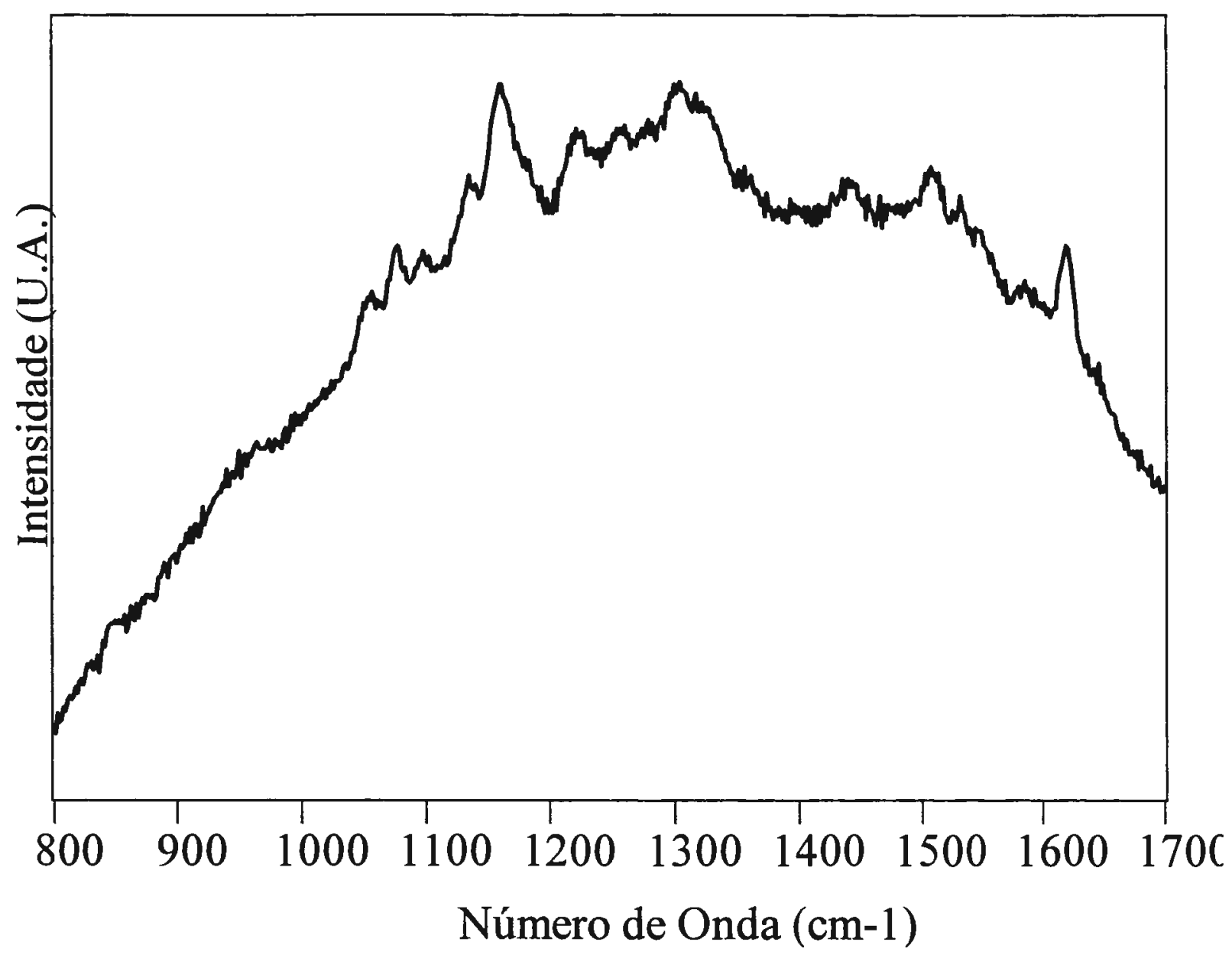

Figura 3.4- Espectro Raman do P2EPH, excitado em 632,8 nm, em pastilha de prata metálica 
Resultados e Discussão

Após a eliminação, ao menos parcial, da fluorescência, objetivamos melhorar o espectro obtido variando a relação polímero/prata metálica. A figura 3.5 nos mostra os espectros Raman do $\mathrm{P} 2 \mathrm{EPH}$ em pastilha de prata para diferentes concentrações de polímero. É possível observar que a supressão da fluorescência torna-se mais eficiente quando a relação polímero/prata é diminuída, chegando ao máximo de eficiência quando a relação polímero/prata está ao redor de 1/1300 em massa. Para concentrações muito menores (figura 3.5e) o sinal decai consideravelmente, inviabilizando a obtenção de um espectro Raman de boa qualidade.

Outras superfícies de prata metálica, como colóide de prata e eletrodo de prata ativado, foram testadas e também mostraram eliminar parcialmente a fluorescência, como observado para a pastilha de prata. A figura 3.6 mostra os espectros Raman do P2EPH em colóide e em eletrodo de prata. O espectro Raman em pastilha de prata também é mostrado nesta figura para efeito de comparação. É possível notar a semelhança existente entre estes três espectros mostrando a independência do espectro com o tipo de superfície. Ao compararmos qualquer um desses espectros Raman com o espectro no infravermelho do polímero (figura 3.7) podemos observar que as freqüências vibracionais nos dois espectros não apresentam grandes variações. Isto nos indica que a superfície de prata não está causando perturbações significativas no polímero e permite-nos utilizar as freqüências obtidas nesses espectros Raman em superfícies de prata em uma análise vibracional do P2EPH. 


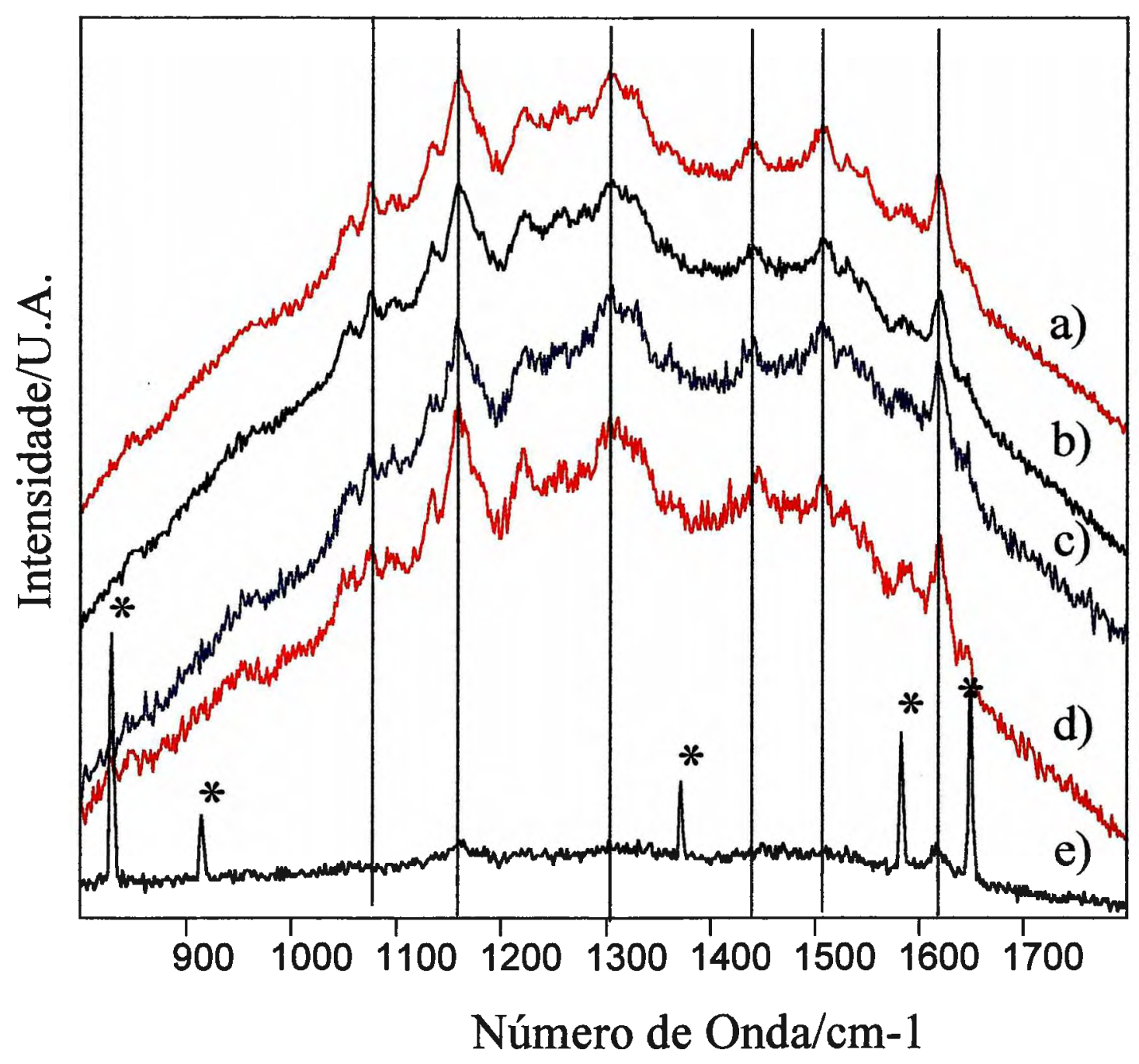

Figura 3.5- Espectro Raman do P2EPH, excitado em $632,8 \mathrm{~nm}$, em pastilha de prata com diferentes relações polímero/prata: a) 1/50; b) 1/100; c) $1 / 700$; d) $1 / 1300 ;$ e) $1 / 4000$.

* = plasma 


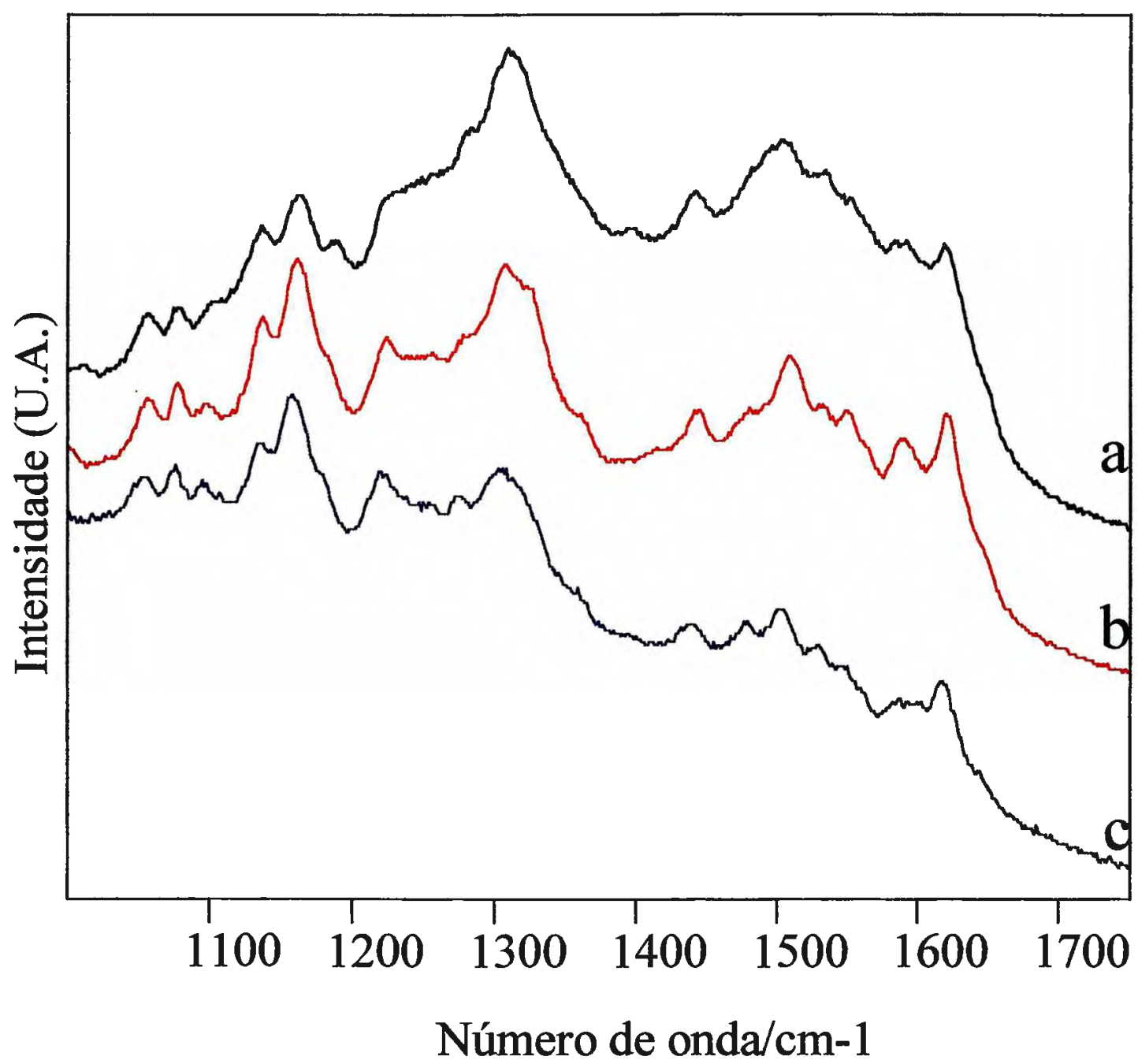

Figura 3.6- Espectro Raman do P2EPH em superfícies de prata com excitação em 632,8 nm: (a) colóide de prata; (b) eletrodo de prata (30 mV vs. $\mathrm{Ag} / \mathrm{AgCl}$ ); (c) pastilha de prata. 


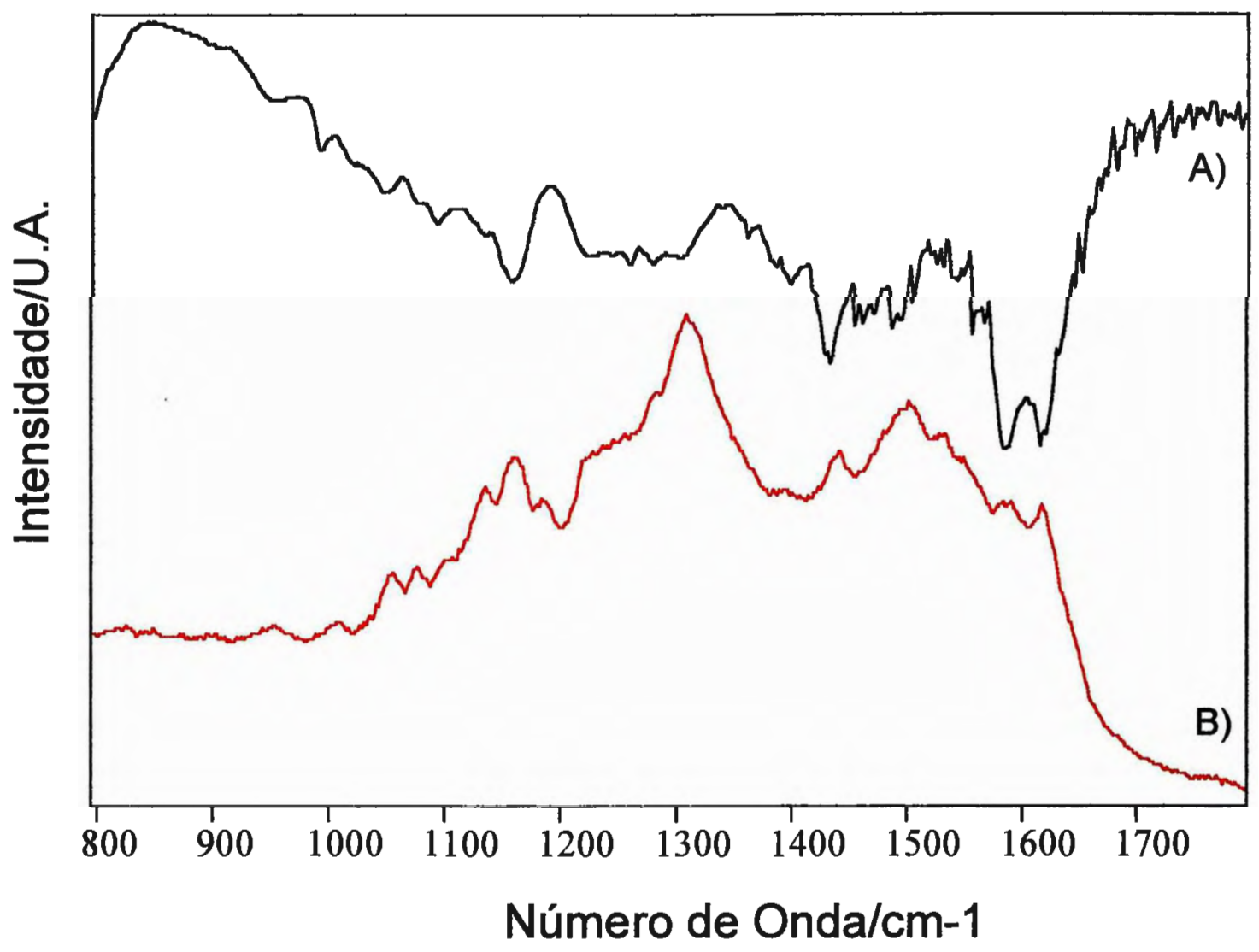

Figura 3.7- Comparação dos espectros no infravermelho (A) e Raman em colóide de prata com excitação em 632,8 nm (B) do P2EPH. 
A utilização de radiação excitante abaixo de $250 \mathrm{~nm}$ também tem se mostrado eficiente na remoção da interferência causada pela fluorescência ${ }^{114}$. Isto não é devido à supressão, total ou parcial, da fluorescência, como observado para as superfícies de prata metálica, mas porque os fótons espalhados têm energia muito maior que os da fluorescência, ficando, portanto, em regiões espectrais distintas. Sendo assim, a obtenção do espectro Raman do P2EPH com excitação nesta região do espectro é outra ferramenta importante para a análise vibracional deste polímero.

Podemos observar na figura 3.1 que o polímero apresenta transições eletrônicas na região espectral do UV, mostrando que o espectro Raman obtido com excitação em $244,0 \mathrm{~nm}$ deverá apresentar o efeito Raman ressonante. Como discutido anteriormente, as transições eletrônicas presentes nesta faixa espectral devem estar associadas com os anéis piridínicos e, portanto, é esperado que o espectro Raman ressonante excitado em $244,0 \mathrm{~nm}$ apresente intensificação, principalmente, das bandas cujos modos normais tenham grande contribuição de vibrações dos anéis piridínicos.

O espectro Raman ressonante com excitação no UV, mostrado na figura 3.8, apresenta os picos mais intensos em 1627 e $1592 \mathrm{~cm}^{-1}$, sendo estes atribuídos aos estiramentos $\mathrm{C}=\mathrm{C}$ dos anéis de piridinium e piridina, respectivamente, em concordância com os espectros Raman do piridinium e da piridina excitados no visível $(514,5 \mathrm{~nm})^{115,116}$. A banda em $1527 \mathrm{~cm}^{-1}$, de menor intensidade, corresponde ao estiramento $\mathrm{C}=\mathrm{C}$ da cadeia poliacetilênica, a qual é intensificada devido ao acoplamento mecânico e/ou eletrônico entre os modos normais. O mesmo acoplamento foi observado no espectro Raman de polidiacetilenos ${ }^{117}$. Um suporte maior à estas atribuições será mostrado posteriormente. 


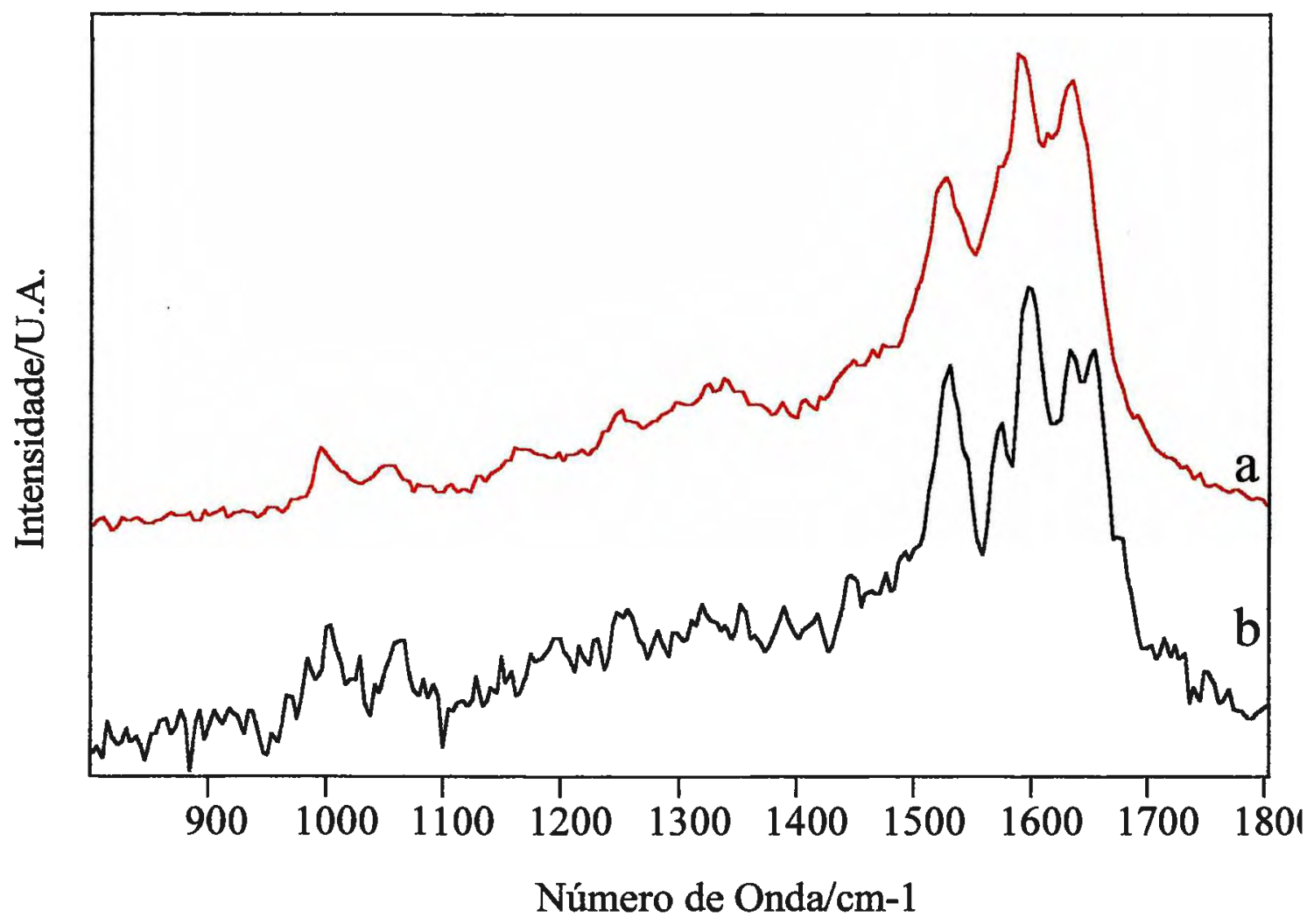

Figura 3.8- Espectros Raman do P2EPH excitados em 244,0 nm: (a) dispersão em $\mathrm{KBr}$; (b) solução aquosa (as bandas de água foram subtraídas). 
Do espectro Raman ressonante excitado no UV também podemos reiterar a afirmação feita a respeito da pequena perturbação provocada pela superfície metálica pois, se compararmos o espectro Raman excitado no UV com aqueles obtidos em superfícies de prata, notaremos que, assim como ocorreu em relação ao espectro no infravermelho, as freqüências vibracionais não sofrem alterações significativas, como mostrado na figura 3.9. As pequenas variações de frequência apresentadas por algumas bandas são devido ao efeito da fotosseletividade, que será discutido posteriormente.

A atribuição da maior parte das bandas Raman do P2EPH pode ser feita por comparação com os espectros Raman do P2EP (em pastilha de prata), da poli-2-vinilpiridina (P2VP) e do poli-2-vinilpiridinium (P2VPH), ambos sem a utilização de pastilhas de prata, sendo estes dois últimos importantes por não possuírem ligações $\mathrm{C}=\mathrm{C}$ no esqueleto polimérico. Esta comparação é mostrada na figura 3.10. As atribuições apresentadas na literatura para poliacetilenos substituídos ${ }^{118}$, para a piridina ${ }^{119}$ e para sais de piridinium ${ }^{119}$ também foram utilizadas para nos auxiliar nesta atribuição.

As bandas em 1009, 1056 e $1078 \mathrm{~cm}^{-1}$ no espectro do P2EPH foram também observadas nos espectros do P2VP e do P2VPH fazendo-nos concluir que são vibrações correspondentes aos anéis piridínicos. Por analogia com a atribuição feita para a molécula de piridina ${ }^{119}$ podemos atribuir a banda em $1009 \mathrm{~cm}^{-1}$ à "respiração" do anel enquanto que as outras duas bandas são referentes, principalmente, às deformações angulares $\mathrm{C}-\mathrm{C}-\mathrm{H}$ do anel. 


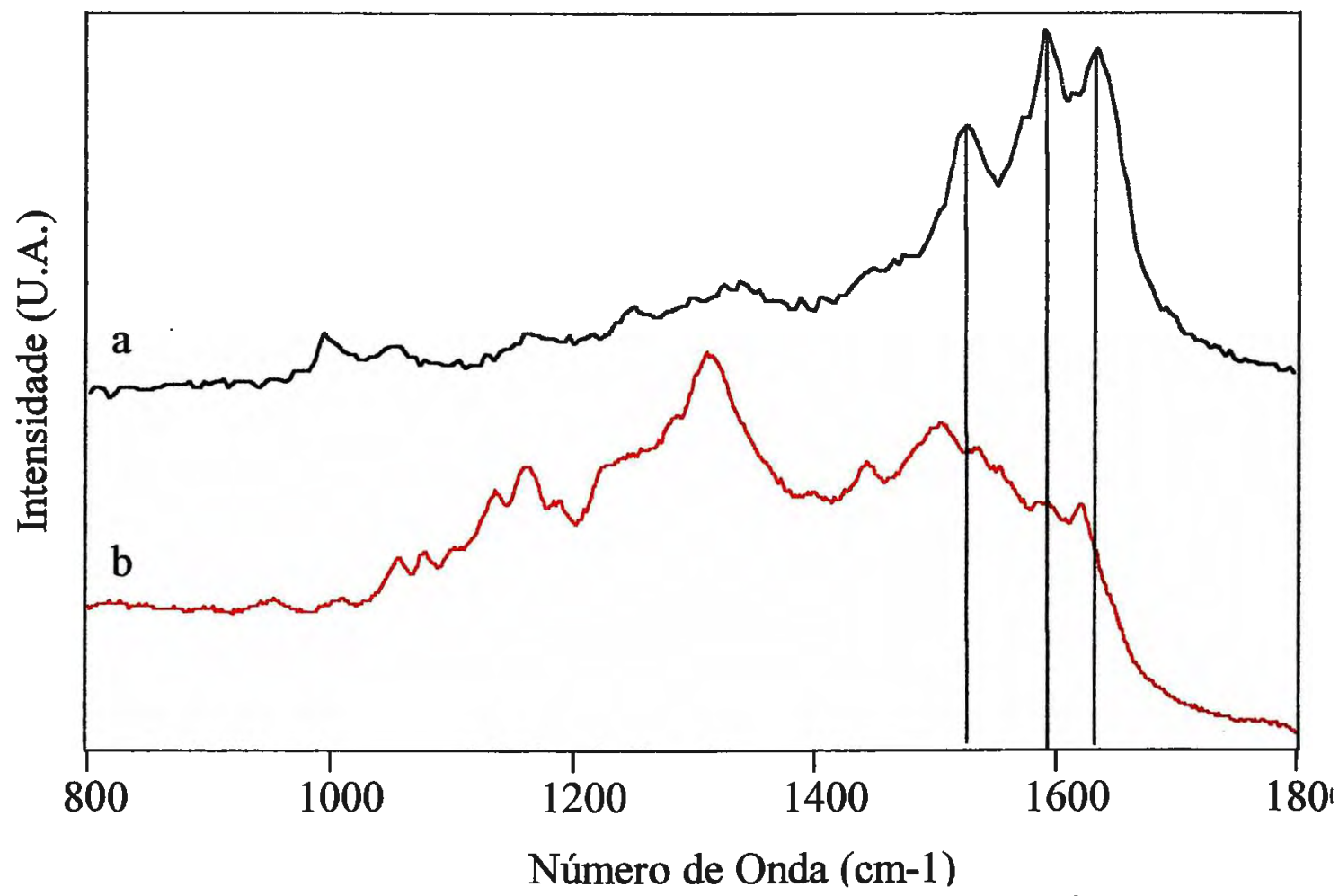

Figura 3.9- Comparação dos espectros Raman do P2EPH excitados em: (a) 244,0 nm (dispersão em $\mathrm{KBr}$ ) e; (b) 632,8 nm (em colóide de prata). 


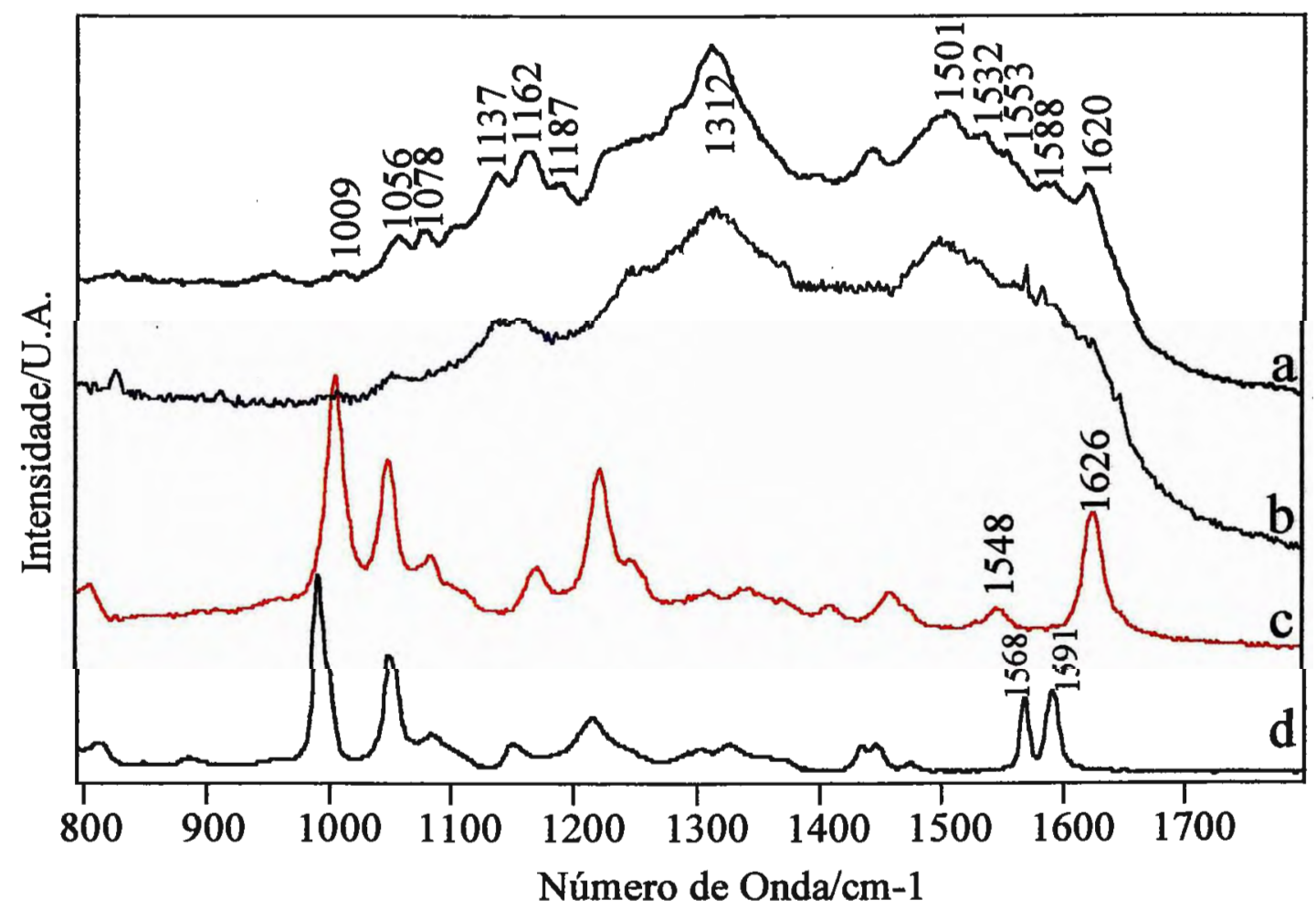

Figura 3.10- Espectros Raman excitados em 632,8 nm: (a) P2EPH (colóide de prata); (b) P2EP (colóide de prata); (c) P2VPH (solução em acetona); (d) P2VP (sólido) 
Resultados e Discussão

$\mathrm{O}$ estiramento $\mathrm{C}-\mathrm{C}$ em poliacetilenos substituídos comumente aparece entre 1100 e $1200 \mathrm{~cm}^{-1}$. ${ }^{118}$ Nesta região o espectro do P2EPH mostrou bandas em 1137, 1162 e $1187 \mathrm{~cm}^{-1}$. Nesta mesma região o P2EP apresentou apenas duas bandas em, aproximadamente, 1140 e $1160 \mathrm{~cm}^{-1}$, levando-nos a crer que a banda em $1187 \mathrm{~cm}^{-1}$ do espectro do P2EPH refere-se ao anel piridínico protonado $\left(\mathrm{pyH}^{+}\right)$. Esta atribuição também é sustentada pela presença de uma banda em $1171 \mathrm{~cm}^{-1}$ para o P2VPH a qual não foi observada no espectro do P2VP. Esta vibração refere-se à deformação angular $\mathrm{C}-\mathrm{C}-\mathrm{H}$ do anel de piridinium. As duas bandas restantes, em 1137 e $1162 \mathrm{~cm}^{-1}$, não puderam ser inequivocamente atribuídas pois o P2VP apresentou uma banda $\left(1151 \mathrm{~cm}^{-1}\right)$ em posição intermediária entre as duas bandas do $\mathrm{P} 2 \mathrm{EPH}$. Podemos somente inferir, por comparação com a literatura, que uma destas duas bandas do P2EPH é referente ao estiramento $\mathrm{C}-\mathrm{C}$ e a outra equivale a uma deformação angular $\mathrm{C}-\mathrm{C}-\mathrm{H}$ do anel piridínico.

A banda larga presente em $1312 \mathrm{~cm}^{-1}$, nos espectros do P2EPH e do P2EP, não foi observada nem para o P2VP nem para o P2VPH. Isto nos indica que ela pode ser atribuída ao esqueleto poliacetilênico. Comparando novamente com derivados do poliacetileno, vemos que nessa região espectral ocorre a deformação angular C-C-H da cadeia polimérica.

$\mathrm{Na}$ região entre 1450 e $1650 \mathrm{~cm}^{-1}$ devem aparecer as vibrações $\mathrm{C}=\mathrm{C}$ tanto dos anéis piridínicos quanto do esqueleto poliacetilênico. As bandas em 1501 e $1532 \mathrm{~cm}^{-1}$ do espectro do P2EPH não podem ser relacionadas com nenhum pico presente nos espectros do P2VP ou do P2VPH e, portanto, devem ser assinaladas como estiramentos $\mathrm{C}=\mathrm{C}$ da cadeia poliacetilênica. As bandas em 1553 e $1620 \mathrm{~cm}^{-1}$ estão presentes no espectro Raman do P2VPH e ausentes no espectro do P2VP mostrando serem referentes ao estiramento $\mathrm{C}=\mathrm{C}$ 
do piridinium. O contrário aconteceu com a banda em $1588 \mathrm{~cm}^{-1}$, que apareceu no espectro do P2VP mas não existe no espectro do P2VPH, ou seja, refere-se ao estiramento $\mathrm{C}=\mathrm{C}$ da piridina. $\mathrm{A}$ atribuição feita para as bandas em $1588 \mathrm{e}$ $1620 \mathrm{~cm}^{-1}$ corrige a atribuição dada por Blumstein e colaboradores ${ }^{78}$ a partir do espectro no infravermelho, mostrando claramente a importância da obtenção dos espectros Raman e no infravermelho para um estudo vibracional mais acurado.

A tabela 3.1 mostra, resumidamente, esta tentativa de atribuição das bandas do P2EPH com base em comparações com o P2EP, P2VP, P2VPH, piridina, sais de piridinium e poliacetilenos substituídos.

Pela atribuição descrita acima, as bandas mais intensas do espectro Raman do P2EPH excitado na região do visível, em aproximadamente 1160, 1300 e $1500 \mathrm{~cm}^{-1}$, foram atribuídas a vibrações principalmente da cadeia poliacetilênica enquanto que as bandas mais intensas do espectro excitado no UV (1627 e $\left.1592 \mathrm{~cm}^{-1}\right)$ foram atribuídas a modos normais onde vibrações dos grupos piridina e/ou piridinium são predominantes. Este fato dá suporte tanto à atribuição deduzida do espectro Raman quanto àquela do espectro eletrônico. 
Tabela 3.1- Freqüência e tentativa de atribuição vibracional do P2EPH.

\begin{tabular}{|c|c|c|c|c|c|}
\hline $\begin{array}{c}\text { UV-RR * } \\
\mathrm{cm}^{-1}\end{array}$ & $\begin{array}{c}\text { Eletrodo } \\
\left(\mathrm{cm}^{-1}\right)\end{array}$ & $\begin{array}{c}\text { Pastilha }{ }^{\#} \\
\left(\mathrm{~cm}^{-1}\right)\end{array}$ & $\begin{array}{c}\text { Colóide } \\
\left(\mathrm{cm}^{-1}\right)\end{array}$ & $\begin{array}{c}\mathrm{IR} \\
\left(\mathrm{cm}^{-1}\right)\end{array}$ & Atribuição \\
\hline $1000(w)$ & $997(w)$ & & $1009(w)$ & $994(w)$ & "respiração" do anel \\
\hline \multirow[t]{3}{*}{$1053(w)$} & $1056(\mathrm{w} / \mathrm{m})$ & $1054(\mathrm{~m})$ & $1056(\mathrm{w} / \mathrm{m})$ & $1050(w)$ & $\beta(\mathrm{CCH})$ da piridina \\
\hline & $1077(\mathrm{w} / \mathrm{m})$ & $1076(\mathrm{~m})$ & $1078(w / m)$ & $1078(\mathrm{vw})$ & $\beta(\mathrm{CCH})$ da piridina \\
\hline & $1138(\mathrm{~m})$ & $1137(w)$ & $1137(\mathrm{~m})$ & $1135(\mathrm{vw})$ & $\beta(\mathrm{CCH})$ da piridina \\
\hline \multirow[t]{4}{*}{$1169(w)$} & $1161(\mathrm{~s})$ & $1161(\mathrm{~s})$ & $1162(\mathrm{~m})$ & $1159(\mathrm{~m})$ & $v(C-C)$ da cadeia \\
\hline & $1183(\mathrm{vw})$ & & $1187(w)$ & & $\beta(\mathrm{CCH})$ do piridinium \\
\hline & $1308(\mathrm{~s})$ & $1304(\mathrm{~m} / \mathrm{s})$ & $1312(\mathrm{~s})$ & $1305(w)$ & $\beta(\mathrm{CCH})$ da cadeia \\
\hline & 1443 & 1440 & 1442 & 1436 & $?$ \\
\hline \multirow[t]{3}{*}{$1527(\mathrm{~m})$} & $1509(\mathrm{~m} / \mathrm{s})$ & $1507(\mathrm{~m})$ & $1501(\mathrm{~m})$ & & $v(\mathrm{C}=\mathrm{C})$ da cadeia \\
\hline & $1533(w)$ & $1530(\mathrm{vw})$ & $1532(w)$ & & $v(C=C)$ da cadeia \\
\hline & $1550(w)$ & $1546(\mathrm{vw})$ & $1553(w)$ & $1547(w)$ & $v(C=C)$ do piridinium \\
\hline $1592(s)$ & $1589(\mathrm{~m})$ & $1586(w)$ & $1588(w)$ & $1588(s)$ & $v(C=C)$ da piridina \\
\hline $1627(\mathrm{~s})$ & $1620(\mathrm{~m})$ & $1620(\mathrm{~m})$ & $1620(\mathrm{w} / \mathrm{m})$ & $1622(s)$ & $v(C=C)$ do piridinium \\
\hline
\end{tabular}


Para a obtenção e comparação dos espectros Raman em diferentes radiações excitantes preferimos a utilização de colóides de prata pela maior facilidade de obtenção dos dados nesse tipo de superfície em relação às outras. Antes de iniciada esta coleta de dados, entretanto, fez-se necessário encontrar as condições para as quais a relação sinal/ruído fosse máxima, ou, em outras palavras, qual a concentração de polímero na solução coloidal que maximizava o sinal obtido. Para tal, variamos a concentração do polímero na solução de colóide e obtivemos seus espectros com excitação em 514,5 nm (figura 3.11), $647,1 \mathrm{~nm}$ (figura 3.12) e 457,9 nm (figura 3.13). Notamos que, nessas três radiações excitantes, os espectros obtidos com a concentração de polímero em $10^{-2}$ e $10^{-3} \mathrm{~g} / \mathrm{L}$ foram os que apresentaram melhor qualidade. Concentrações superiores ou inferiores a estas, invariavelmente, provocaram queda na relação sinal/ruído. Então, as concentrações de polímero usadas serão sempre estas, inclusive extrapolando os resultados para as outras radiações a serem usadas.

A comparação dos espectros Raman do P2EPH excitados com diferentes radiações é feita na figura 3.14 e os valores de suas freqüências são mostrados na tabela 3.2 .

É possível notar que os espectros da figura 3.14 apresentam diferentes relações sinal/ruído. Como nos espectros Raman do P2EPH com excitação no visível há a presença do efeito Raman ressonante, a maior proximidade da radiação excitante com a banda de transição eletrônica do polímero aumenta a magnitude desse efeito, resultando em uma melhor relação sinal/ruído. Sendo assim, os espectros excitados em 514,5 e 568,2 nm são os que apresentam radiação excitante com maior proximidade da transição eletrônica $(540 \mathrm{~nm}$, conforme a figura 3.1) e que, portanto, devem apresentar, e efetivamente apresentam, melhor relação sinal/ruído. Com as outras radiações observamos 
apenas um efeito de pré-ressonância com a transição eletrônica, provocando menor intensificação do sinal Raman.

Outra característica observada nestes espectros é a variação na intensidade relativa de algumas bandas com a mudança da radiação excitante. Os espectros obtidos com radiações excitantes de menores energias têm as bandas da cadeia poliacetilênica (aproximadamente em 1150, 1300 e 1520 $\mathrm{cm}^{-1}$ ) como as mais intensas do espectro. Por outro lado, para excitações com energias superiores o espectro passa a ser dominado pelas bandas do anel piridínico, tornando-se semelhante ao espectro UV-Raman (figura 3.8). Isto é devido ao polímero apresentar duas transições eletrônicas distintas: uma em $540 \mathrm{~nm}$ e outra por volta de $250 \mathrm{~nm}$. Quando excitado com radiações menos energéticas, estas ressoam com a transição eletrônica em $540 \mathrm{~nm}$, que é uma transição da cadeia poliacetilênica, produzindo a intensificação dos modos normais desta cadeia. Quando aumentamos a energia da excitação, estas passam a ressoar (na realidade uma pré-ressonância) com a transições eletrônica no UV, que são atribuídas aos anéis piridínicos, tornando as bandas destes anéis as mais intensas do espectro. Essa pré-ressonância com as transições em $250 \mathrm{~nm}$ ocorre mesmo para excitação em 457,9 nm, cuja energia está mais próxima da transição eletrônica em $540 \mathrm{~nm}$, isto porque os valores de $\varepsilon$ das transições em $250 \mathrm{~nm}$ são consideravelmente maiores que o da transição em $540 \mathrm{~nm}$ (figura 3.1A). 


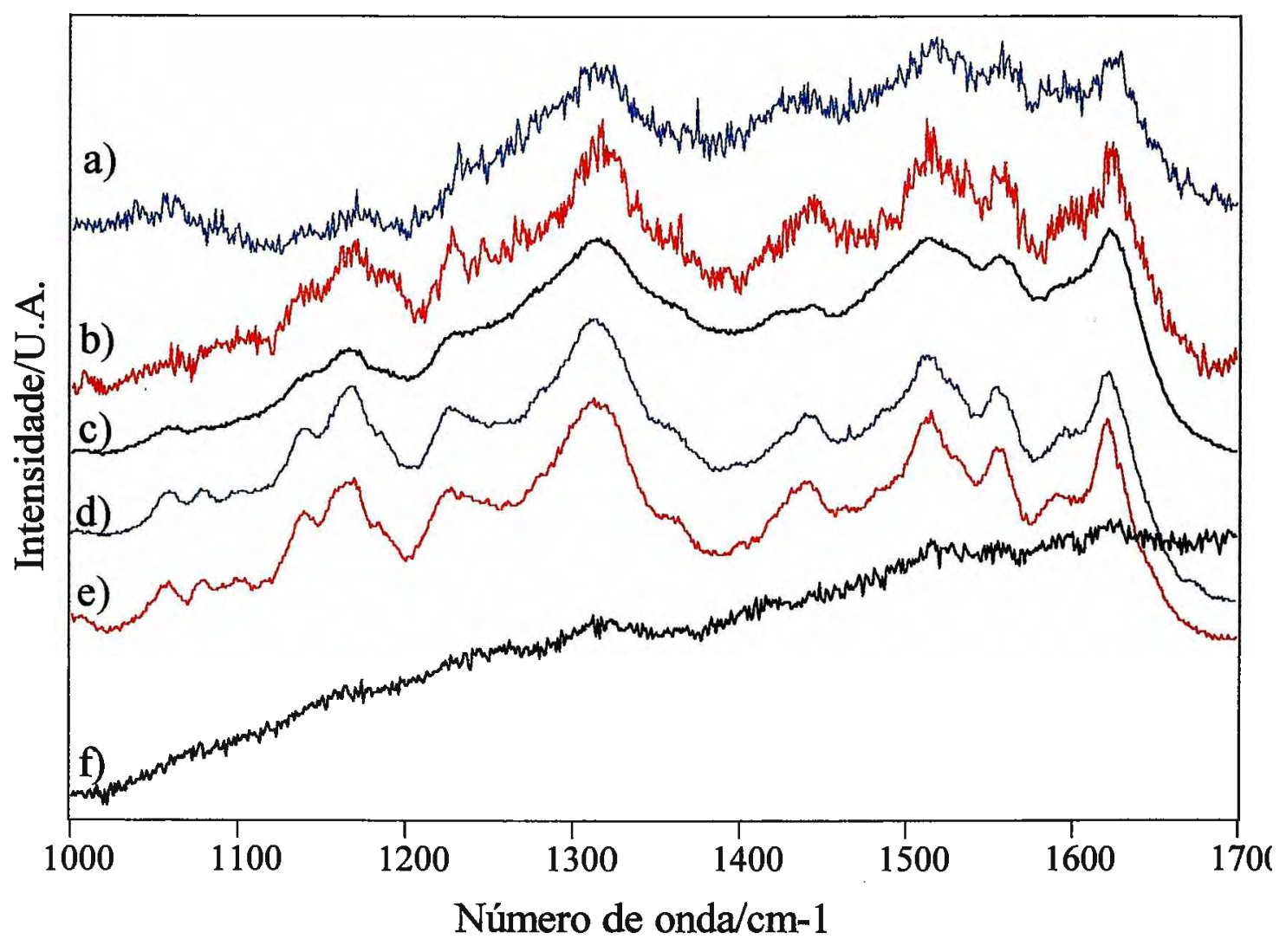

Figura 3.11- Espectros Raman do P2EPH em colóide de prata excitados em $514,5 \mathrm{~nm}$ com diferentes concentrações de polímero: a) $10^{-7} \mathrm{~g} / \mathrm{L}$; b) $10^{-5} \mathrm{~g} / \mathrm{L}$; c) $10^{-4} \mathrm{~g} / \mathrm{L}$; d) $10^{-3} \mathrm{~g} / \mathrm{L}$; e) $10^{-2} \mathrm{~g} / \mathrm{L}$; f) $10^{-1} \mathrm{~g} / \mathrm{L}$. 


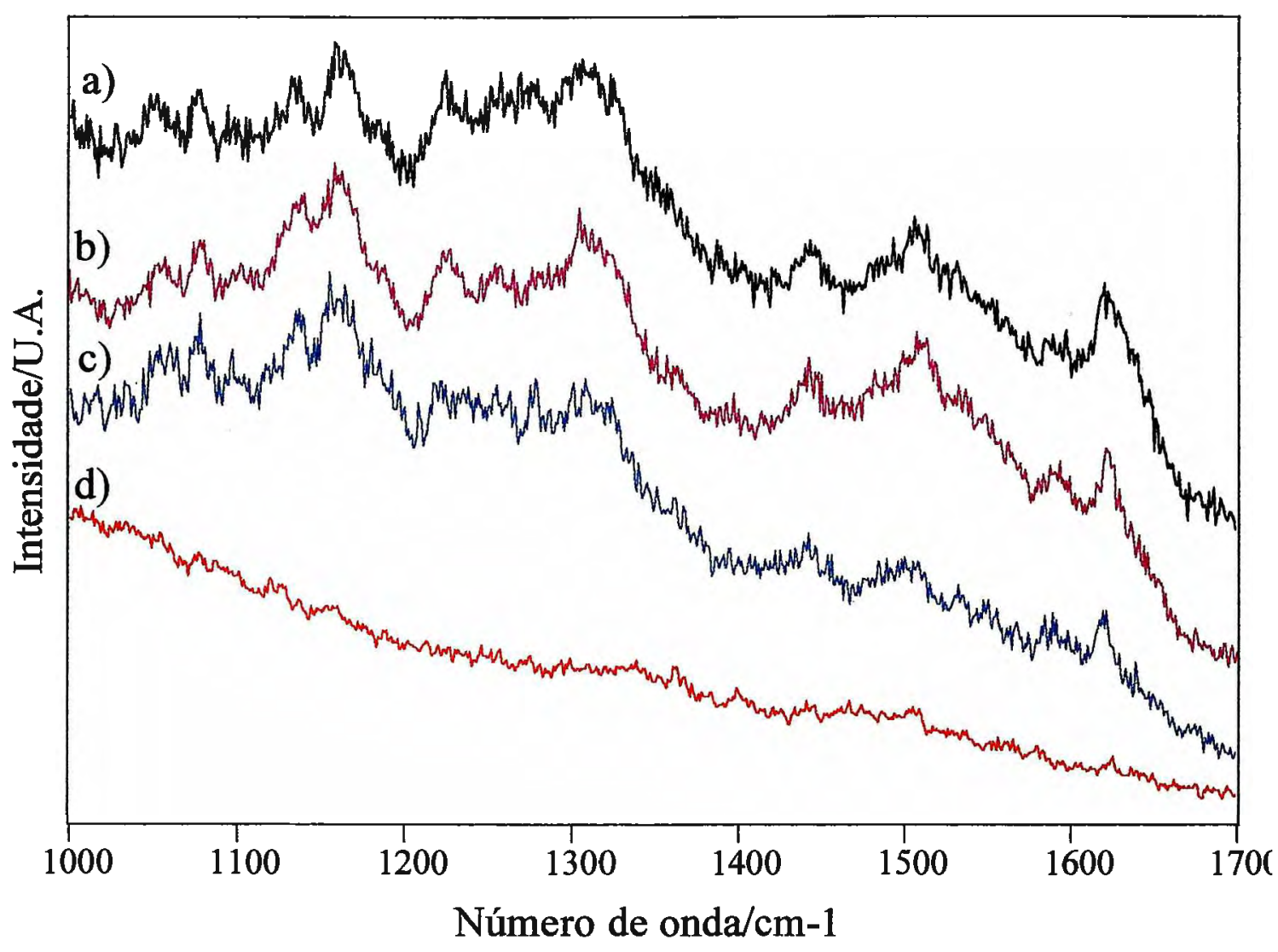

Figura 3.12- Espectros Raman do P2EPH em colóide de prata excitados em $647,1 \mathrm{~nm}$ com diferentes concentrações de polímero: a) $10^{-4} \mathrm{~g} / \mathrm{L}$; b) $10^{-3} \mathrm{~g} / \mathrm{L}$; c) $10^{-2} \mathrm{~g} / \mathrm{L}$; d) $10^{-1} \mathrm{~g} / \mathrm{L}$. 


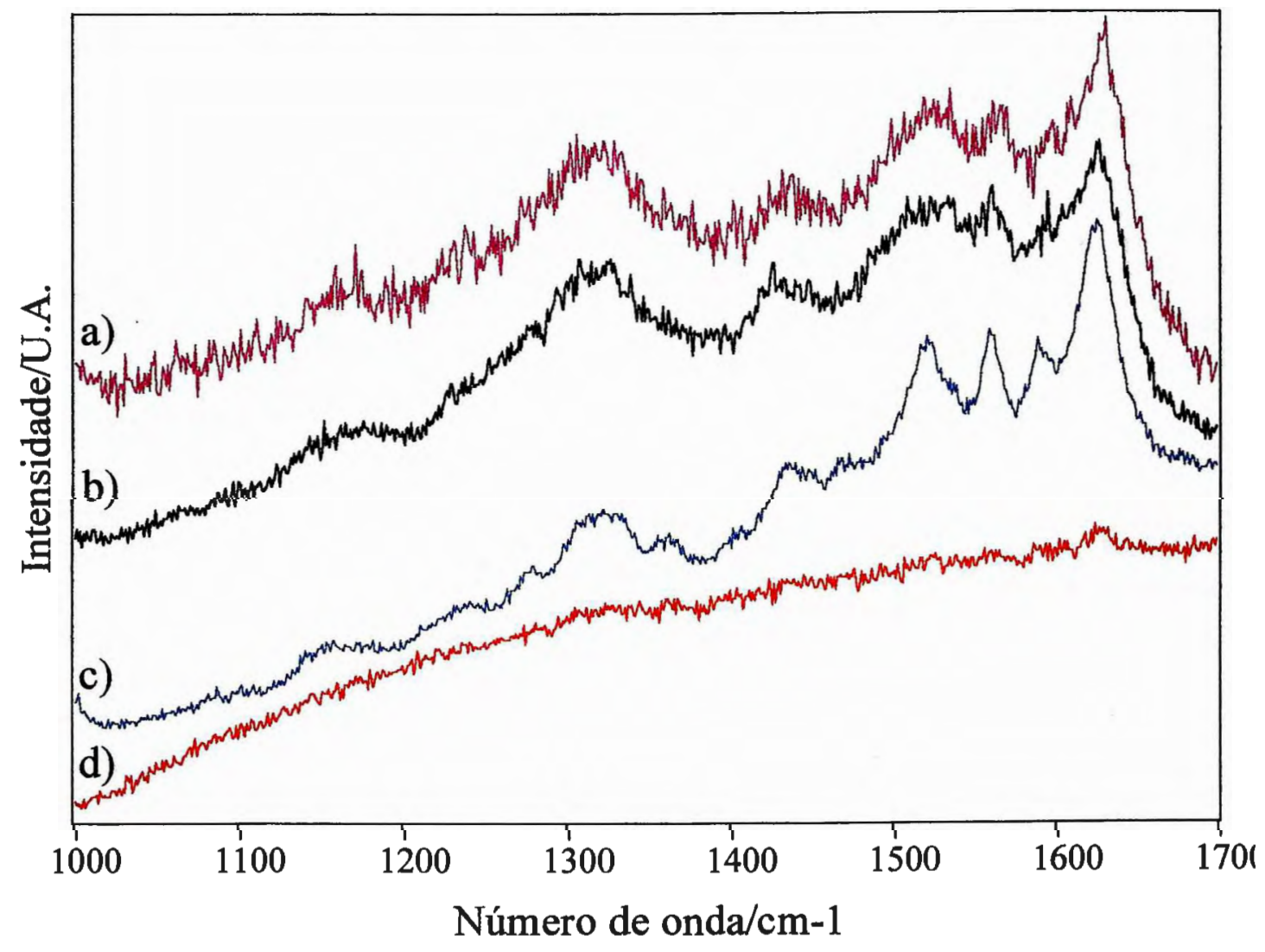

Figura 3.13- Espectros Raman do P2EPH em colóide de prata excitados em $457,9 \mathrm{~nm}$ com diferentes concentrações de polímero: a) $10^{-4} \mathrm{~g} / \mathrm{L}$; b) $10^{-3} \mathrm{~g} / \mathrm{L}$; c) $10^{-2} \mathrm{~g} / \mathrm{L}$; d) $10^{-1} \mathrm{~g} / \mathrm{L}$. 


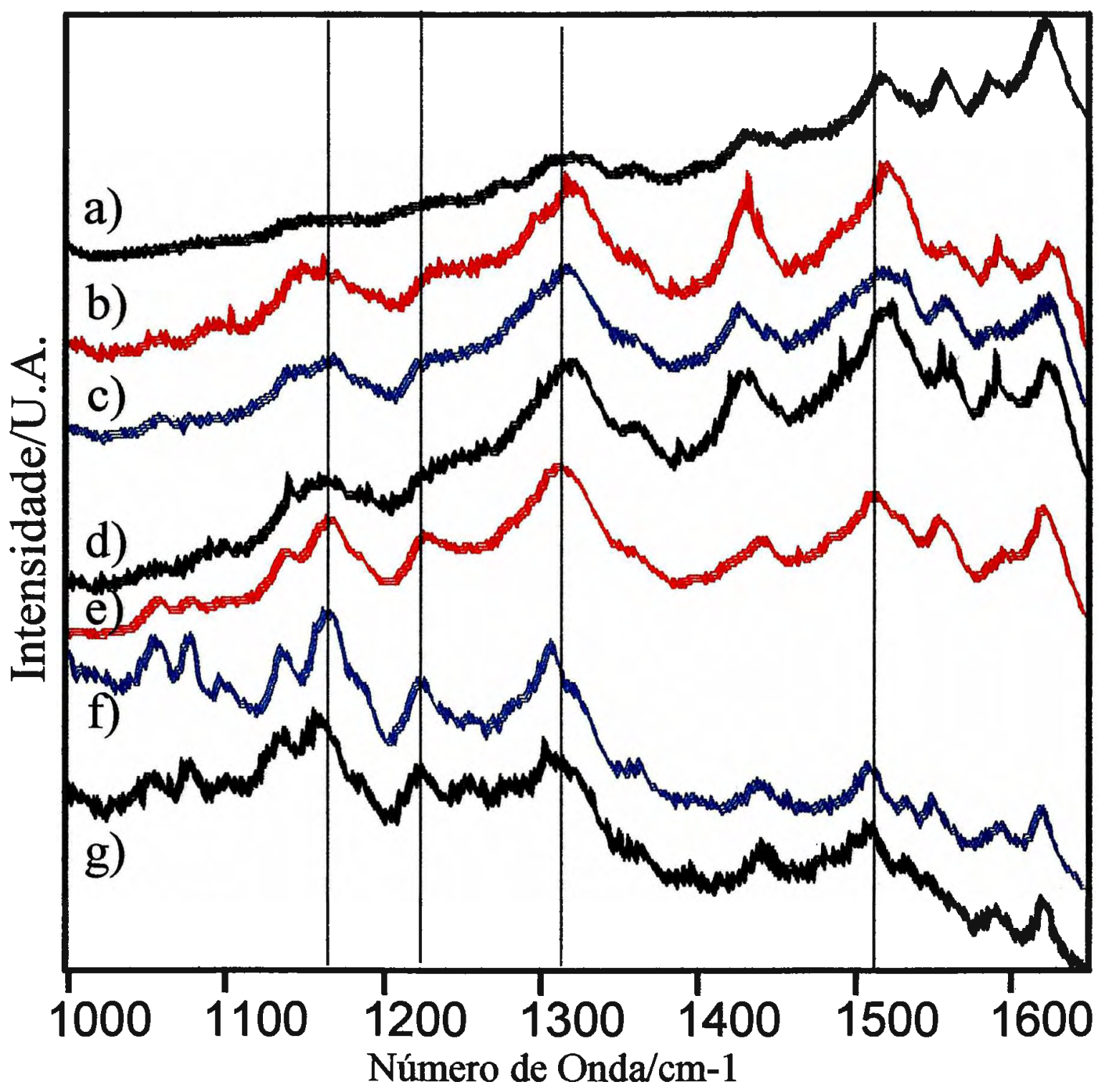

Figura 3.14- Espectros Raman do P2EPH em colóide: a) excitação $=457,9$ nm;

b) $488,0 \mathrm{~nm}$; c) $496,5 \mathrm{~nm}$;) $501,7 \mathrm{~nm}$; e) $514,5 \mathrm{~nm}$; f) $568,2 \mathrm{~nm}$;

g) $647,1 \mathrm{~nm}$. Para os espectros a), b) e d) a concentração do polímero foi de $10^{-2} \mathrm{~g} / \mathrm{L}$ e para os espectros $\left.\mathrm{c}\right)$, e), f) e $\mathrm{g}$ ) a concentração foi de $10^{-3} \mathrm{~g} / \mathrm{L}$. 
Tabela 3.2- Relação das freqüências $\left(\mathrm{cm}^{-1}\right)$ das bandas dos espectros Raman do $\mathrm{P} 2 \mathrm{EPH}$ *

\begin{tabular}{cccccccc}
\hline $\begin{array}{c}244,0 \\
\mathrm{~nm}\end{array}$ & $\begin{array}{c}457,9 \\
\mathrm{~nm}\end{array}$ & $\begin{array}{c}488,0 \\
\mathrm{~nm}\end{array}$ & $\begin{array}{c}496,5 \\
\mathrm{~nm}\end{array}$ & $\begin{array}{c}501,7 \\
\mathrm{~nm}\end{array}$ & $\begin{array}{c}514,5 \\
\mathrm{~nm}\end{array}$ & $\begin{array}{c}568,2 \\
\mathrm{~nm}\end{array}$ & $\begin{array}{c}647,1 \\
\mathrm{~nm}\end{array}$ \\
\hline 1053 & & & & & 1059 & 1059 & 1055 \\
& & & & & 1079 & 1078 & 1078 \\
& & & & & 1100 & 1102 & 1102 \\
$\mathbf{1 1 6 9}$ & & & & & 1139 & 1136 & 1137 \\
& & & $1141(?)$ & & 1169 & $\mathbf{1 1 6 4}$ & $\mathbf{1 1 6 0}$ \\
& & $\mathbf{1 2 3 5}$ & $\mathbf{1 2 3 3}$ & & $\mathbf{1 2 3 2}$ & $\mathbf{1 2 2 7}$ & $\mathbf{1 2 2 6}$ \\
& $\mathbf{1 3 2 0}$ & $\mathbf{1 3 2 0}$ & $\mathbf{1 3 2 0}$ & $\mathbf{1 3 1 9}$ & $\mathbf{1 3 1 1}$ & $\mathbf{1 3 0 7}$ & $\mathbf{1 3 0 5}$ \\
& 1358 & 1358 & 1358 & 1361 & 1361 & & \\
& 1433 & 1431 & 1427 & 1431 & 1443 & & 1442 \\
1527 & $\mathbf{1 5 1 8}$ & $\mathbf{1 5 1 8}$ & $\mathbf{1 5 1 9}$ & $\mathbf{1 5 1 9}$ & $\mathbf{1 5 1 5}$ & $\mathbf{1 5 1 1}$ & $\mathbf{1 5 1 0}$ \\
& 1557 & 1562 & 1559 & 1561 & 1557 & & \\
\hline 1592 & 1587 & 1592 & 1593 & 1591 & 1595 & 1591 & 1590 \\
1627 & 1623 & 1626 & 1623 & 1625 & 1624 & 1621 & 1622 \\
\hline *as & & & & & 1187 & 1187 & 1187 \\
\hline
\end{tabular}

* as bandas em negrito correspondem àquelas que apresentam fotosseletividade 
Com relação à freqüência, os espectros Raman excitados com diferentes radiações mostram pequenas variações. Em alguns casos essas variações parecem ser aleatórias, como na banda por volta de $1620 \mathrm{~cm}^{-1}$, por exemplo, onde o aumento da energia da radiação excitante ora provoca diminuição na freqüência vibracional, ora acarreta em aumento da mesma (ver tabela 3.2). Este caráter aleatório indica que essas variações devem ser entendidas como erros na marcação dos valores das bandas devido, principalmente, à largura das mesmas e, em alguns casos, ao alto nível de ruído apresentado pelo espectro.

Em contrapartida, algumas bandas mostraram variação da freqüência vibracional não aleatória. É o caso, por exemplo, da banda em $1310 \mathrm{~cm}^{-1}$ aproximadamente. Nela há sempre um deslocamento para maiores freqüências conforme a energia da radiação excitante é aumentada, caracterizando a presença de um efeito intrínseco ao polímero, a fotosseletividade.

Análises semelhantes às mostradas acima foram feitas para as outras bandas, levando à conclusão de que somente aquelas em aproximadamente $1165,1230,1310$ e $1515 \mathrm{~cm}^{-1}$ apresentam a fotosseletividade.

A variação da freqüência Raman com a radiação excitante apresentada pelo $\mathrm{P} 2 \mathrm{EPH}$ é bem inferior àquela mostrada pelo poliacetileno. Enquanto para o P2EPH a freqüência varia, em média, $0,05 \mathrm{~cm}^{-1}$ por $\mathrm{nm}$ de variação na excitação, para o poliacetileno este número é, na média, 6 vezes maior. Ozaki e colaboradores ${ }^{120}$ mostraram que polímeros condutores luminescentes apresentam fotosseletividade consideravelmente menos extensa que polímeros condutores não luminescentes. Esta diferença foi atribuída, pelos autores, como sendo principalmente devido à energia do primeiro estado excitado opticamente proibido. Em polímeros luminescentes (como é o caso do P2EPH) 
o estado excitado de menor energia é opticamente permitido e, portanto, o primeiro estado excitado opticamente proibido está acima do "gap". Em polímeros não luminescentes (como o poliacetileno), por outro lado, o estado excitado de menor energia é um estado opticamente proibido e que, portanto, está no meio do "gap". Como a energia deste estado opticamente proibido é inversamente proporcional a $d\left[\Pi_{n}\left(\omega_{n}{ }^{R} / \omega_{n}{ }^{0}\right)^{2}\right] / d \mathrm{E}_{\mathrm{g}}$, então quão maior a energia desse estado, menor será fotosseletividade.

A análise da fotosseletividade apresentada pelo P2EPH pode ser feita à luz dos modelos existentes para esse fenômeno. Pelo modelo de comprimento de conjugação (CLM) a freqüência vibracional deve ser proporcional ao inverso do comprimento de conjugação. Podemos determinar esse comprimento de conjugação através do valor da radiação excitante segundo a equação de Lewis-Calvin ${ }^{110}\left(\lambda^{2}=\mathrm{kN}\right.$, onde $\left.\mathrm{k}=17532 \mathrm{~nm}^{2}\right)$. Fazendo essa relação, chegamos ao gráfico apresentado na figura 3.15 onde é possível notar uma boa correlação dos valores obtidos com o inverso do comprimento de conjugação.

Ao impormos o modelo de modo de amplitude (AMM) aos dados obtidos teríamos que o valor de $\Pi_{n}\left(\omega_{n}{ }^{R} / \omega_{n}{ }^{0}\right)^{2}$ deveria apresentar uma dependência linear com a energia da radiação incidente ${ }^{118,120}$. Fazendo esta relação (figura 3.16) é possível notar que esta dependência também existe. Isto mostra que apesar do modelo considerar que o polímero é unidimensional e infinito, suposição válida para poliacetileno porém não rigorosa para a amostra do P2EPH que utilizamos (lembrar que o espectro eletrônico indicou que o P2EPH é um oligômero), ainda podemos utilizá-lo com boa concordância em sistemas onde essas condições iniciais não sejam totalmente atendidas.

$\mathrm{O}$ método de conjugada de coordenação efetiva (ECCM) tem sua 
utilização dificultada pela necessidade do cálculo da constante de força efetiva. $f_{\mathrm{Ja}}$, a qual é correlacionada com a freqüência. 
Resultados e Discussão

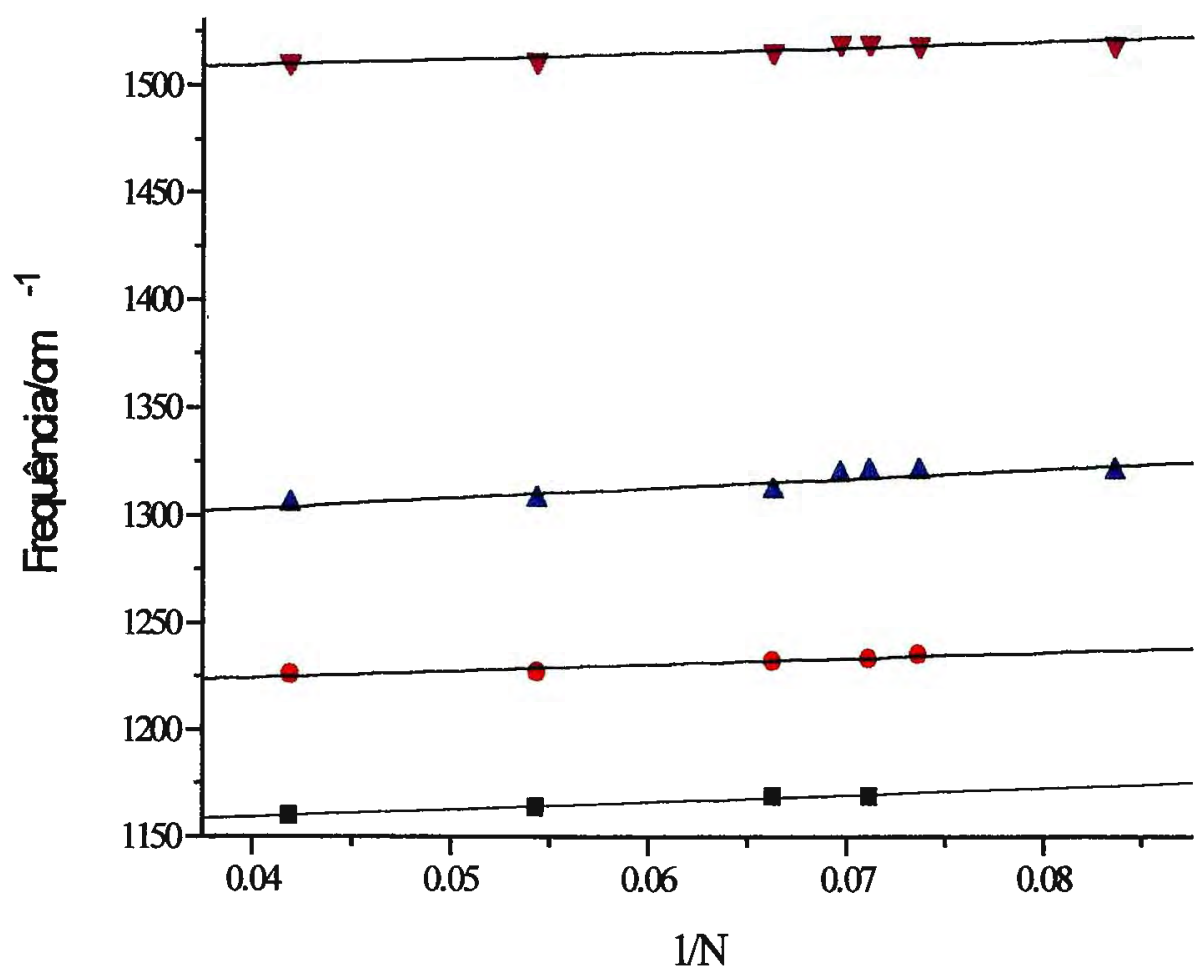

Figura 3.15- Gráfico da freqüência vibracional dos diversos modos que apresentam fotosseletividade no P2EPH versus o inverso do comprimento de conjugação 


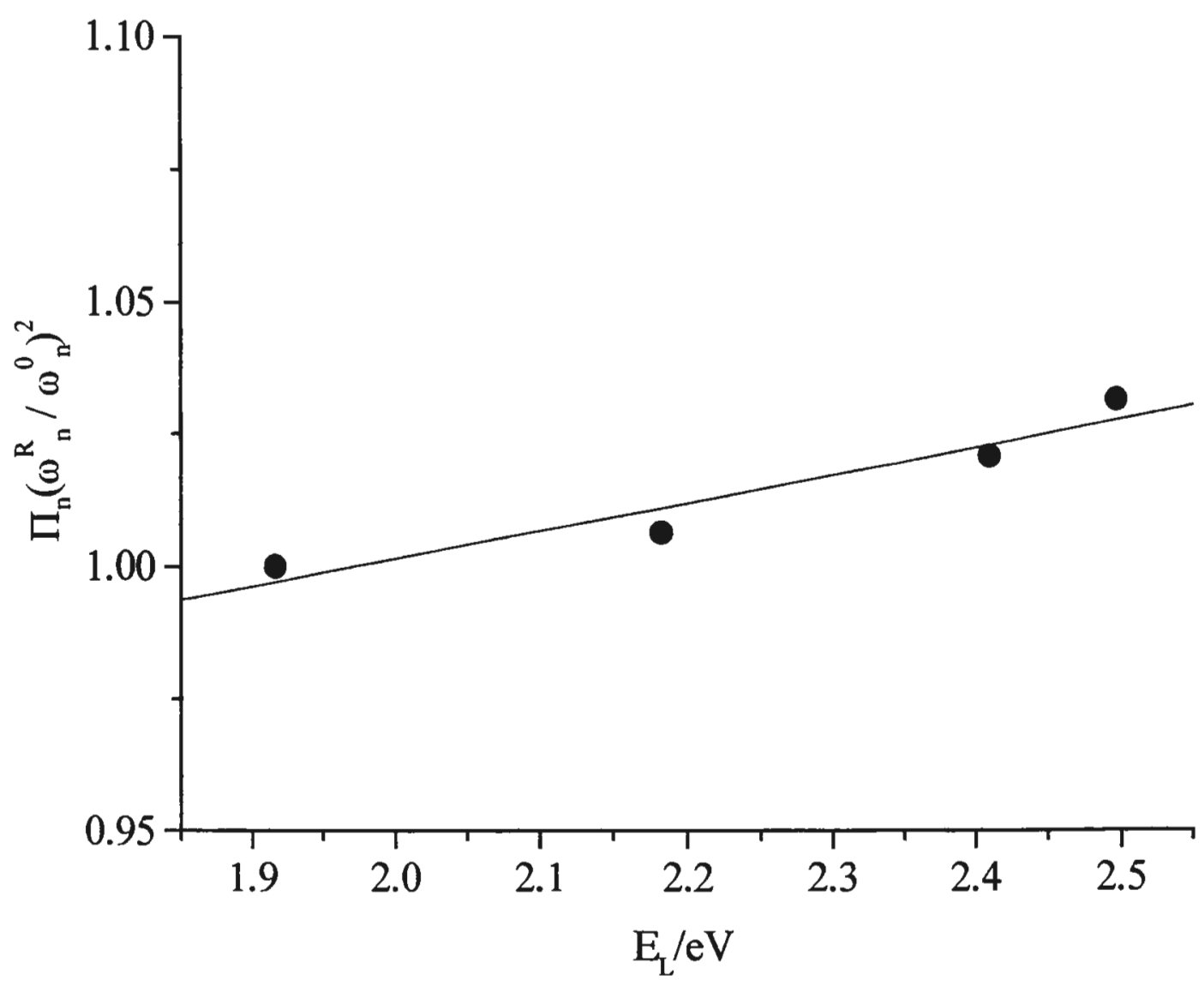

Figura 3.16- Gráfico da produtória $\Pi_{n}\left(\omega_{n}{ }^{R} / \omega_{n}{ }^{0}\right)^{2}$ versus a energia da radiação excitante 
Resultados e Discussão

\section{2- Comportamento da 2-Etinilpiridina em Eletrodo de Prata}

Um dos objetivos desse trabalho era a polimerização eletroquímica da 2etinilpiridina em eletrodo de prata, a qual poderia ser seguida pela técnica SERS. Essa idéia foi inspirada pela polimerização eletroquímica da 2 e 4vinilpiridina $^{121,122}$.

Devido a isso fez-se necessário conhecer o comportamento da 2etinilpiridina em eletrodo de prata em solução neutra e ácida para diferentes potenciais aplicados ao eletrodo.

$\mathrm{Na}$ figura 3.17 são apresentados os espectros SERS da 2-etinilpiridina adsorvida em eletrodo para dois tipos de ativação de superfície (ciclos de oxidação e redução): ex situ, onde a ativação é feita sem a presença do composto, e in situ, onde a ativação acontece na presença do composto. Como os espectros obtidos para essas duas maneiras de ativação do eletrodo são semelhantes, só diferindo na maior intensificação do sinal quando a ativação foi feita in situ, adotamos esse último procedimento para monitorar a adsorção da 2-etinilpiridina à superfície.

$\mathrm{Na}$ figura 3.18 são apresentados os espectros SERS da 2-etinilpiridina em eletrodo de prata em solução $0,1 \mathrm{~mol} / \mathrm{L}$ de $\mathrm{KCl}(\mathrm{pH}=6)$. Podemos notar que à medida que o potencial torna-se mais negativo ocorre variação na intensidade relativa das bandas, mas nenhum dos espectros obtidos concordaram com o do polímero (figura 3.6b). A presença da banda em 2000 $\mathrm{cm}^{-1}$, referente ao estiramento $\mathrm{C} \equiv \mathrm{C}$, e o não aparecimento de coloração avermelhada, típica das soluções do polímero mesmo em concentrações da ordem de $10^{-5} \mathrm{~g} / \mathrm{L}$, somente confirmam a não polimerização da 2-etinilpiridina. 


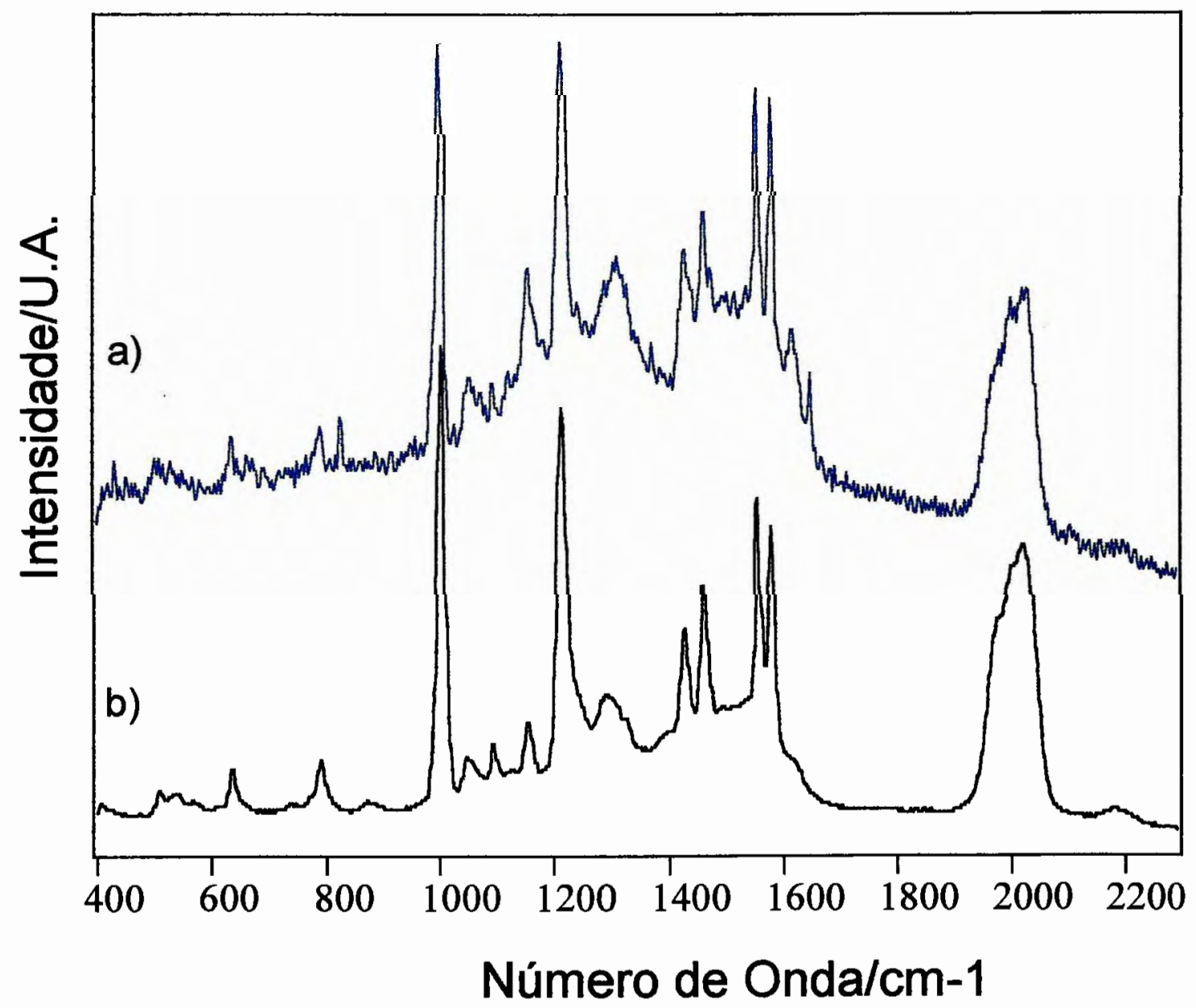

Figura 3.17- Espectros SERS $\left(\lambda_{o}=632,8 \mathrm{~nm}\right)$ da 2-etinilpiridina em eletrodo de prata no potencial de $-0,1 \mathrm{~V}$ (vs. $\mathrm{Ag} / \mathrm{AgCl}$ ) para diferentes tipos de ativação do eletrodo: a) ex situ (sem o composto); b) in situ (com o composto) 

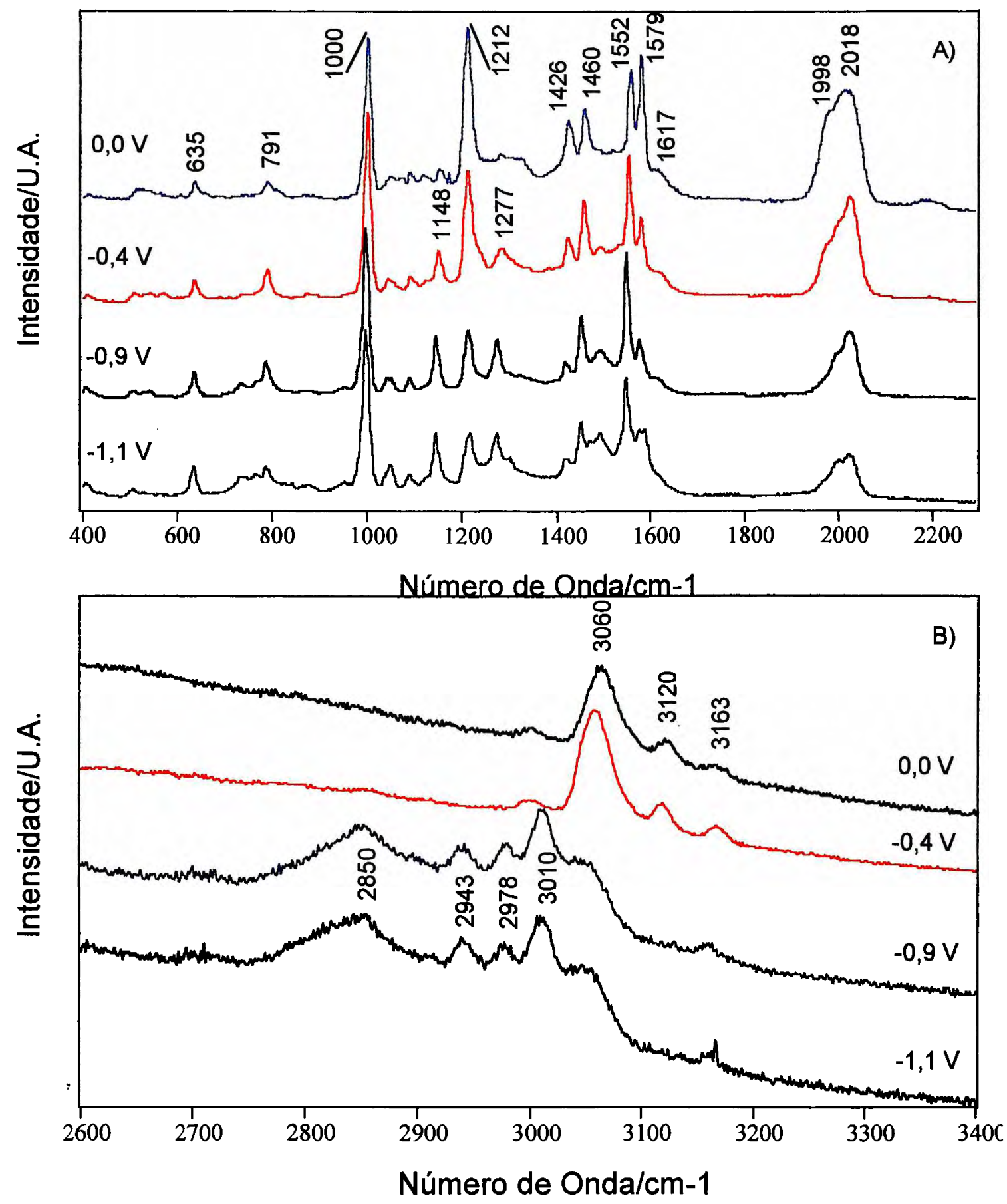

Figura 3.18- Espectro SERS $\left(\lambda_{o}=632,8 \mathrm{~nm}\right)$ da 2-etinilpiridina em eletrodo de prata sem a adição de ácido $(\mathrm{pH}=6): \mathrm{A})$ de 400 a $2300 \mathrm{~cm}^{-1}$; B) de 2600 a $3400 \mathrm{~cm}^{-1}$. 
Verificamos se a polimerização eletroquímica poderia ocorrer em meio ácido, uma vez que a síntese química do polímero é feita nessas condições. A figura 3.19 apresenta os espectros SERS da 2-etinilpiridina em $\mathrm{pH}=1$. O espectro no potencial mais negativo alcançado nestas condições de trabalho também não coincide com o do polímero.

Para interpretar as variações espectrais observadas nos espectros SERS da 2-etinilpiridina adsorvida em prata é necessário compararmos esses espectros com o espectro Raman normal e no infravermelho do mesmo composto.

A molécula da 2-etinilpiridina apresenta apenas dois elementos de simetria: identidade e plano de reflexão, que coincide com o plano da molécula. Isto faz com que a 2-etinilpiridina pertença ao grupo de ponto $\mathrm{C}_{\mathrm{s}}$ (ou $m$, segundo o sistema internacional). Moléculas pertencentes a esse grupo de ponto têm todas as suas bandas ativas tanto no espectro Raman quanto no infravermelho ${ }^{123}$.

Os espectros Raman e no infravermelho da 2-etinilpiridina são mostrados, respectivamente, nas figuras 3.20 e 3.21 . A atribuição das bandas desses espectros pode ser feita comparando-os com o etinilbenzeno ${ }^{124,125} \mathrm{e}$ com a piridina ${ }^{119}$. Na tabela 3.3 são apresentadas as freqüências e intensidades relativas das bandas observadas nos espectros Raman e no infravermelho. 


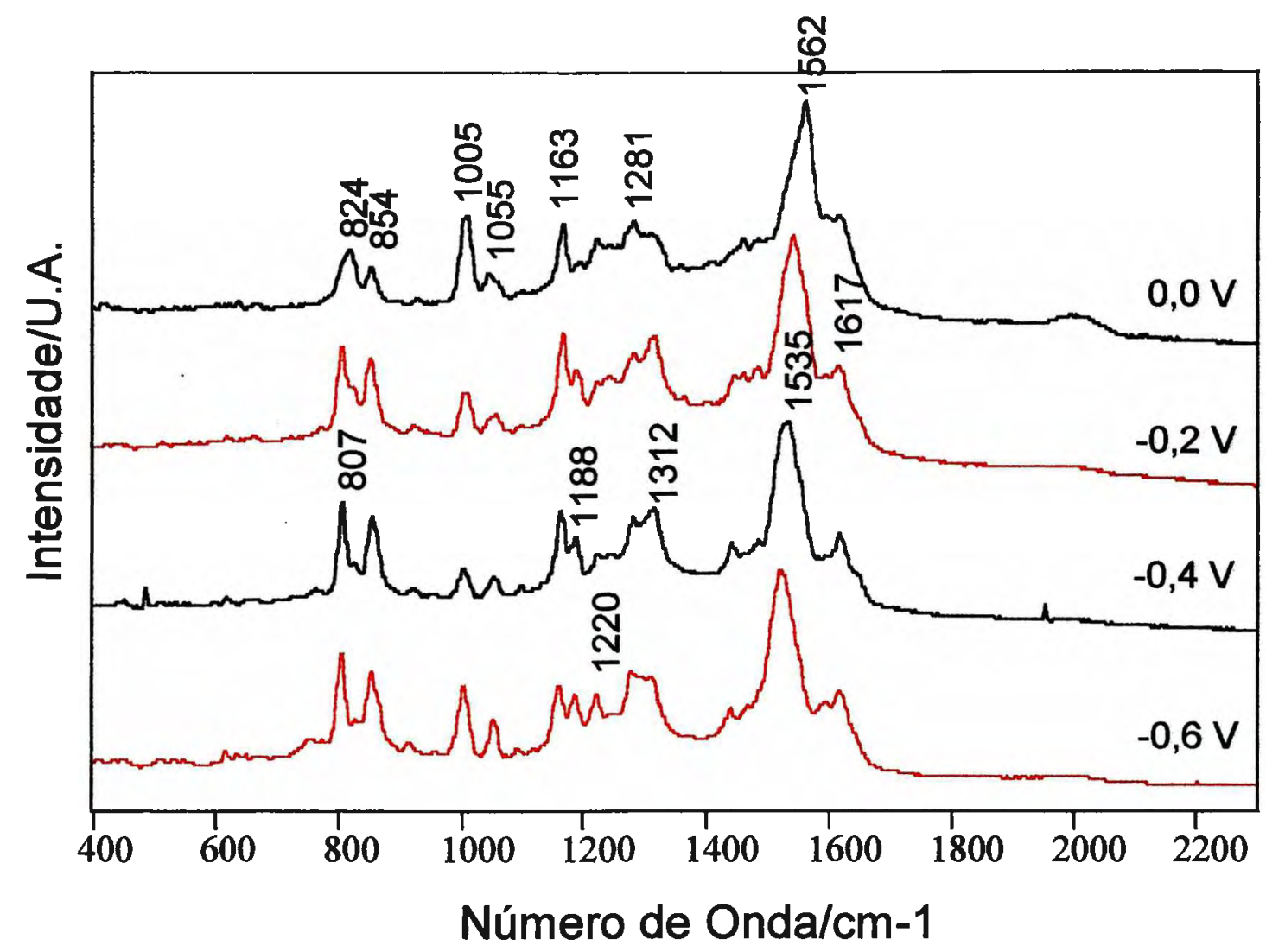

Figura 3.19- Espectros SERS $\left(\lambda_{\mathrm{o}}=632,8 \mathrm{~nm}\right)$ da 2-etinilpiridina em eletrodo de prata em $\mathrm{pH}=1$. 

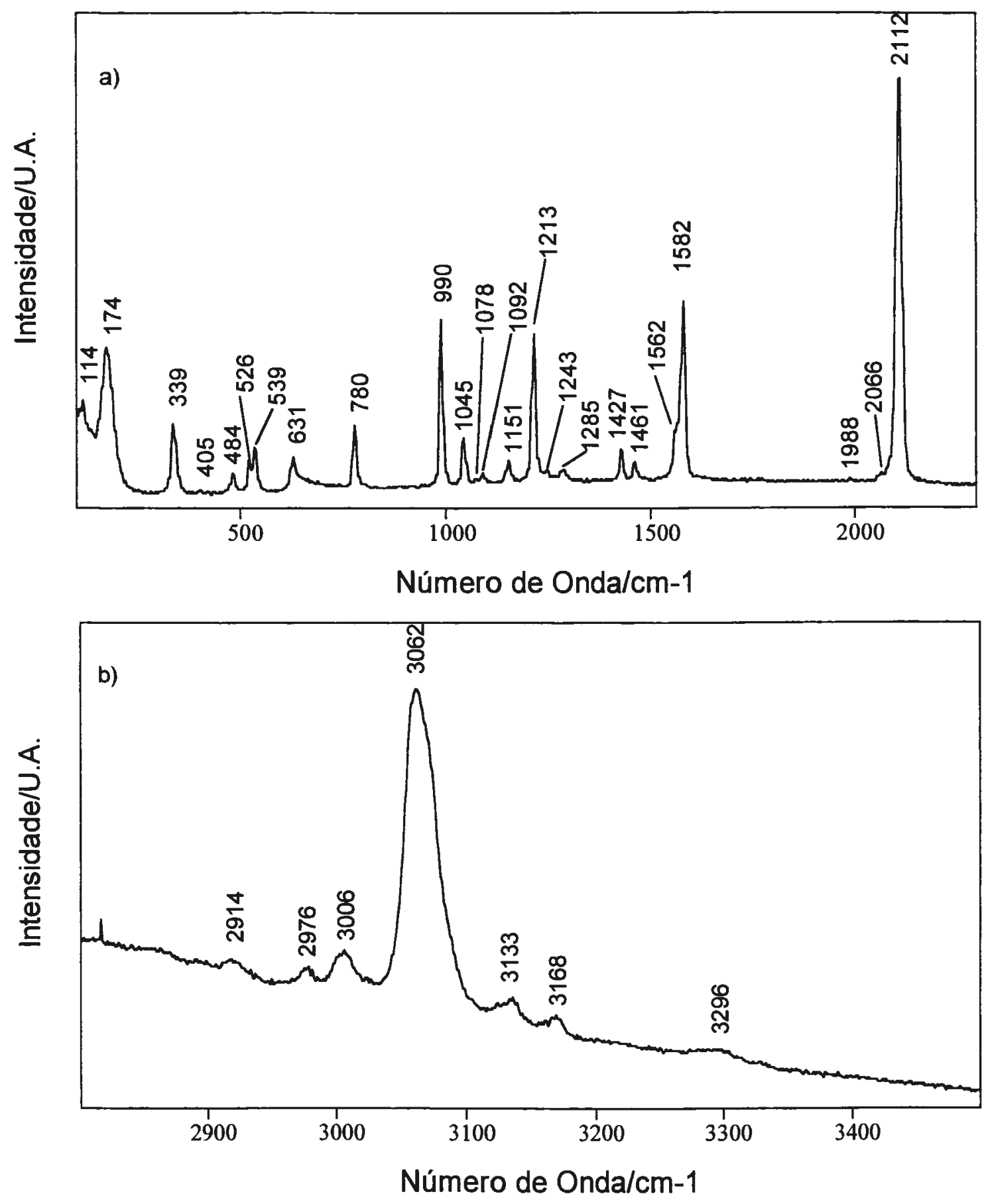

Figura 3.20- Espectro Raman da 2-etinilpiridina com excitação em 632,8 nm na região até $2300 \mathrm{~cm}^{-1}$ (a) e de 2800 a $3500 \mathrm{~cm}^{-1}$ (b). 


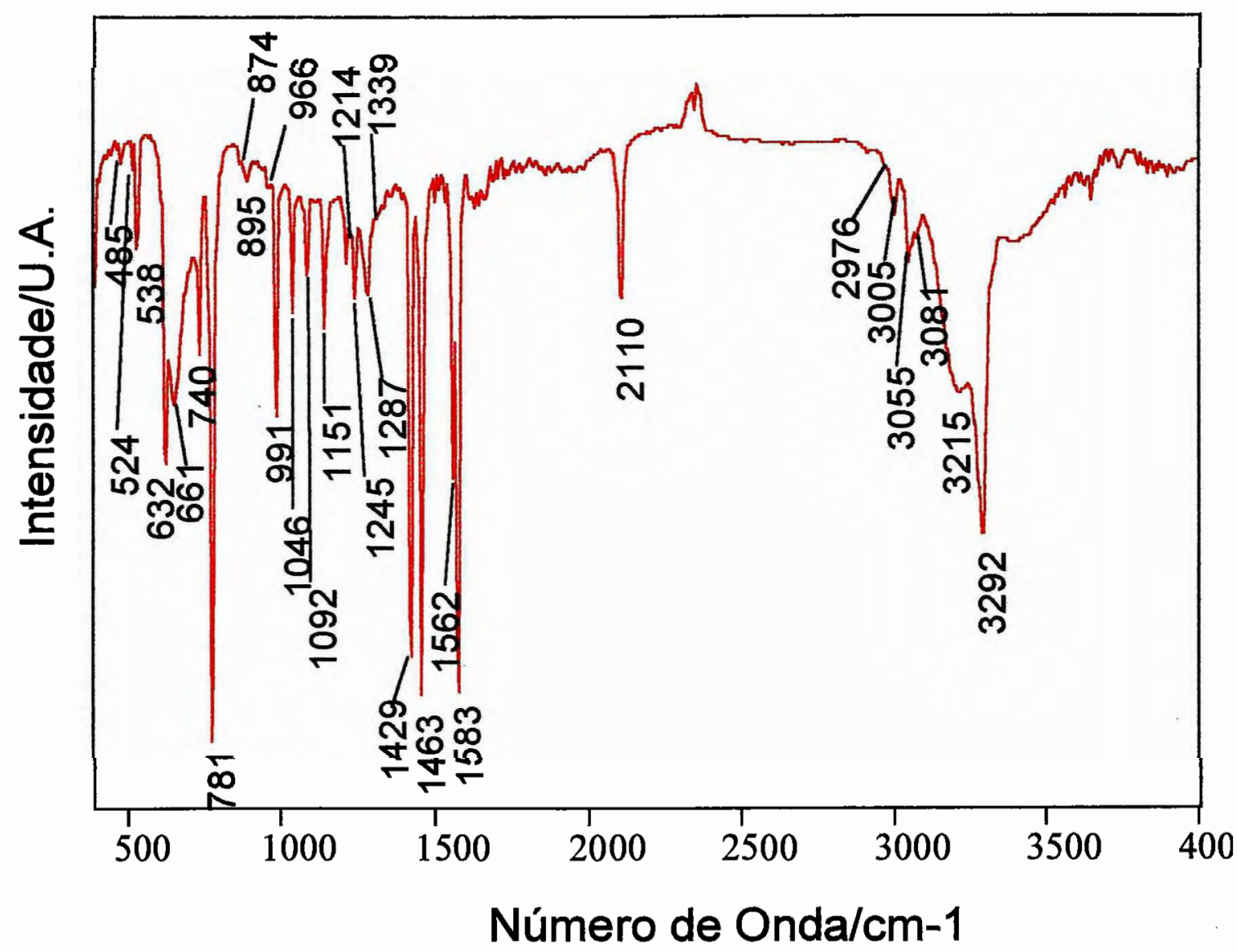

Figura 3.21- Espectro no infravermelho da 2-etinilpiridina. 
Tabela 3.3- Freqüências Raman e no infravermelho $\left(\mathrm{cm}^{-1}\right)$ da 2-etinilpiridina. Entre parênteses estão as intensidades relativas das bandas.

\begin{tabular}{|c|c|c|}
\hline Raman & IR & Atribuição \\
\hline $114(10)$ & & deformação angular $\mathrm{C}-\mathrm{C} \equiv \mathrm{C}$ fora do plano; $v_{33}$ \\
\hline $174(36)$ & & deformação angular $\mathrm{C}-\mathrm{C} \equiv \mathrm{C}$ no plano; $v_{23}$ \\
\hline $339(17)$ & & deformação angular C-C-C $\equiv$ fora do plano; $v_{32}$ \\
\hline $405(1)$ & & torção do anel; $v_{31}$ \\
\hline $484(5)$ & $485(w)$ & deformação angular do anel no plano; $v_{22}$ \\
\hline $526(4)$ & $524(w)$ & deformação angular $\mathrm{C}-\mathrm{C}-\mathrm{C} \equiv$ no plano; $v_{21}$ \\
\hline $539(11)$ & $538(\mathrm{~m})$ & torção do anel; $v_{30}$ \\
\hline \multirow[t]{3}{*}{$631(9)$} & $632(\mathrm{~m})$ & $\begin{array}{l}\text { deformação angular do anel no plano; } v_{20} \text { ou } \\
\text { deformação angular } \equiv \mathrm{C}-\mathrm{H} \text { fora do plano; } v_{29}\end{array}$ \\
\hline & $661(\mathrm{~m})$ & deformação angular $\equiv \mathrm{C}-\mathrm{H}$ no plano; $v_{19}$ \\
\hline & $740(\mathrm{~m})$ & deformação angular C-H fora do plano; $v_{28}$ \\
\hline \multirow[t]{5}{*}{$780(15)$} & $781(\mathrm{~s})$ & "respiração" trigonal do anel; $v_{18}$ \\
\hline & $874(w)$ & deformação angular C-H fora do plano; $v_{26}$ ou $v_{27}$ \\
\hline & $895(w)$ & deformação angular C-H fora do plano; $v_{25}$ \\
\hline & $950(\mathrm{vw})$ & $v_{18}+v_{23}$ \\
\hline & $966(w)$ & deformação angular C-H fora do plano; $v_{24}$ \\
\hline $990(42)$ & $991(\mathrm{~m})$ & "respiração" do anel; $v_{17}$ \\
\hline $1045(12)$ & $1046(\mathrm{~m})$ & deformação angular C-H no plano; $v_{16}$ \\
\hline $1078(0,9)$ & & $2 v_{30}$ \\
\hline \multirow[t]{2}{*}{$1092(2)$} & $1092(\mathrm{~m})$ & deformação angular C-H no plano; $v_{15}$ \\
\hline & $1119(\mathrm{vw})$ & $v_{18}+v_{32}$ \\
\hline $1151(6)$ & $1151(\mathrm{~m})$ & deformação angular C-H no plano; $v_{I 4}$ \\
\hline $1213(36)$ & $1214(\mathrm{~m})$ & estiramento $\equiv \mathrm{C}-\mathrm{C} ; v_{13}$ \\
\hline $1243(2)$ & $1245(w)$ & $?$ \\
\hline \multirow[t]{4}{*}{$1285(3)$} & $1287(w)$ & deformação angular $\mathrm{C}-\mathrm{H}$ no plano; $v_{12}$ \\
\hline & $1318(\mathrm{vw} / \mathrm{sh})$ & $2 v_{19}$ \\
\hline & $1339(\mathrm{vw})$ & estiramento do anel; $v_{11}$ \\
\hline & 1397 (vw) & $v_{17}+v_{31}$ \\
\hline $1427(8)$ & $1429(\mathrm{~s})$ & estiramento do anel; $v_{10}$ \\
\hline $1461(4)$ & $1463(\mathrm{~s})$ & estiramento do anel; $v_{9}$ \\
\hline $1562(10)$ & $1562(\mathrm{~m})$ & estiramento do anel; $v_{8}$ \\
\hline $1582(44)$ & $1583(\mathrm{~s})$ & estiramento do anel; $v_{7}$ \\
\hline $1988(0,9)$ & & $v_{9}+v_{21}$ \\
\hline
\end{tabular}


Resultados e Discussão

Tabela 3.3 (continuação)

\begin{tabular}{|c|c|l|}
\hline $2066(2)$ & & $v_{7}+v_{22}$ \\
\hline $2112(100)$ & $2110(\mathrm{~m})$ & estiramento C $\equiv \mathrm{C} ; v_{6}$ \\
\hline $2206(0,7)$ & $2207(\mathrm{vw})$ & $v_{7}+v_{20}$ (ou $\left.v_{29}\right)$ ou $v_{10}+v_{18}$ \\
\hline & $2241(\mathrm{vw})$ & $v_{7}+v_{19}$ ou $v_{9}+v_{18}$ \\
\hline & $2576(\mathrm{vw})$ & $v_{10}+v_{14}$ ou $v_{7}+v_{17}$ \\
\hline & $2613(\mathrm{vw})$ & $v_{9}+v_{14}$ \\
\hline & $2641(\mathrm{vw})$ & $v_{10}+v_{13}$ \\
\hline & $2669(\mathrm{vw})$ & $v_{9}+v_{13}$ \\
\hline & $2733(\mathrm{vw})$ & $v_{7}+v_{14}$ \\
\hline & $2743(\mathrm{vw})$ & $v_{13}+v_{20}\left(\right.$ ou $\left.v_{29}\right)$ \\
\hline & $2773(\mathrm{vw})$ & $v_{8}+v_{13}$ \\
\hline & $2792(\mathrm{vw})$ & $v_{7}+v_{13}$ \\
\hline & $2888(\mathrm{vw})$ & $v_{9}+v_{10}$ \\
\hline $2914(0,7)$ & $2914(\mathrm{w})$ & $2 v_{9}$ \\
\hline $2976(0,8)$ & $2976(\mathrm{w} / \mathrm{sh})$ & estiramento C-H; $v_{5}$ \\
\hline $3006(1)$ & $3005(\mathrm{~m})$ & estiramento C-H; $v_{4}$ \\
\hline $3062(10)$ & $3055(\mathrm{~m})$ & estiramento C-H; $v_{3}$ \\
\hline & $3081(\mathrm{w} / \mathrm{sh})$ & estiramento C-H; $v_{2}$ \\
\hline $3133(1)$ & & $v_{7}+v_{8}$ \\
\hline $3168(0,8)$ & & $2 v_{7}$ \\
\hline & $3215(\mathrm{~m} / \mathrm{sh})$ & $?$ \\
\hline $3296(0,2)$ & $3292(\mathrm{~s})$ & estiramento $\equiv \mathrm{C}-\mathrm{H} ; \mathrm{v}_{1}$ \\
\hline & $3324(\mathrm{vw} / \mathrm{sh})$ & $v_{6}+v_{13}$ \\
\hline
\end{tabular}

Abreviações: $v s=$ muito forte; $\mathrm{s}=$ forte; $\mathrm{m}=$ média; $\mathrm{w}=$ fraca; $\mathrm{vw}=$ muito fraca; $\mathrm{sh}=$ ombro. 
A comparação do espectro SERS da 2-etinilpiridina $(E=0,0 \mathrm{~V})$ com $o$ espectro Raman normal do mesmo composto (figura 3.22) mostra variações, das quais as mais significativas são o deslocamento e o alargamento da banda do estiramento $\mathrm{C} \equiv \mathrm{C}$ em $2112 \mathrm{~cm}^{-1}$ para aproximadamente $2020 \mathrm{~cm}^{-1}$, e o aumento da intensidade relativa das bandas em 1562 e $1461 \mathrm{~cm}^{-1}$. O aparecimento de uma pequena banda em $1618 \mathrm{~cm}^{-1}$ indica a protonação do anel piridínico $^{119}$.

$\mathrm{O}$ alargamento e o deslocamento da banda do estiramento $\mathrm{C} \equiv \mathrm{C}$ podem estar demonstrando que a molécula está sendo adsorvida por esse sítio ao eletrodo, não excluindo a adsorção pelo par de elétrons do nitrogênio piridínico ou pelos elétrons $\pi$ do anel. Outra possibilidade seria a adsorção com perda do hidrogênio acetilênico formando o íon 2-piridilacetileto na superfície do eletrodo.

Poderíamos comprovar a formação do 2-piridilacetileto na superficie do eletrodo observando se a banda do estiramento $\equiv \mathrm{C}$-H está presente ou não no espectro SERS. Esta banda (em $3296 \mathrm{~cm}^{-1}$ ) é, entretanto, muito fraca no espectro Raman normal da 2-etinilpiridina (ver figura 3.20b ou tabela 3.3) fazendo com que esse tipo de análise torne-se ineficaz. Na figura 3.23 são comparados os espectros SERS da 2-etinilpiridina com o Raman normal do 2piridilacetileto de prata. Esses espectros são muito parecidos, inclusive o espectro Raman do 2-piridilacetileto de prata também apresenta o deslocamento e alargamento da banda do estiramento $\mathrm{C} \equiv \mathrm{C}$, em aproximadamente $2000 \mathrm{~cm}^{-1}$. A semelhança dos espectros poderia indicar que o 2-piridilacetileto estaria sendo formado. 


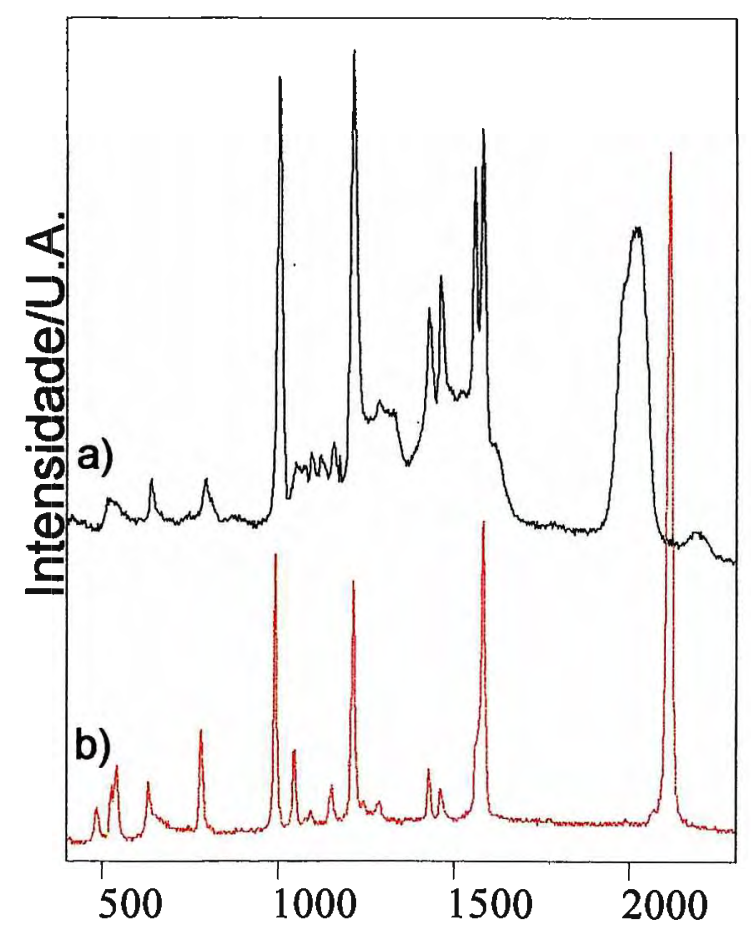

Número de Onda/cm-1

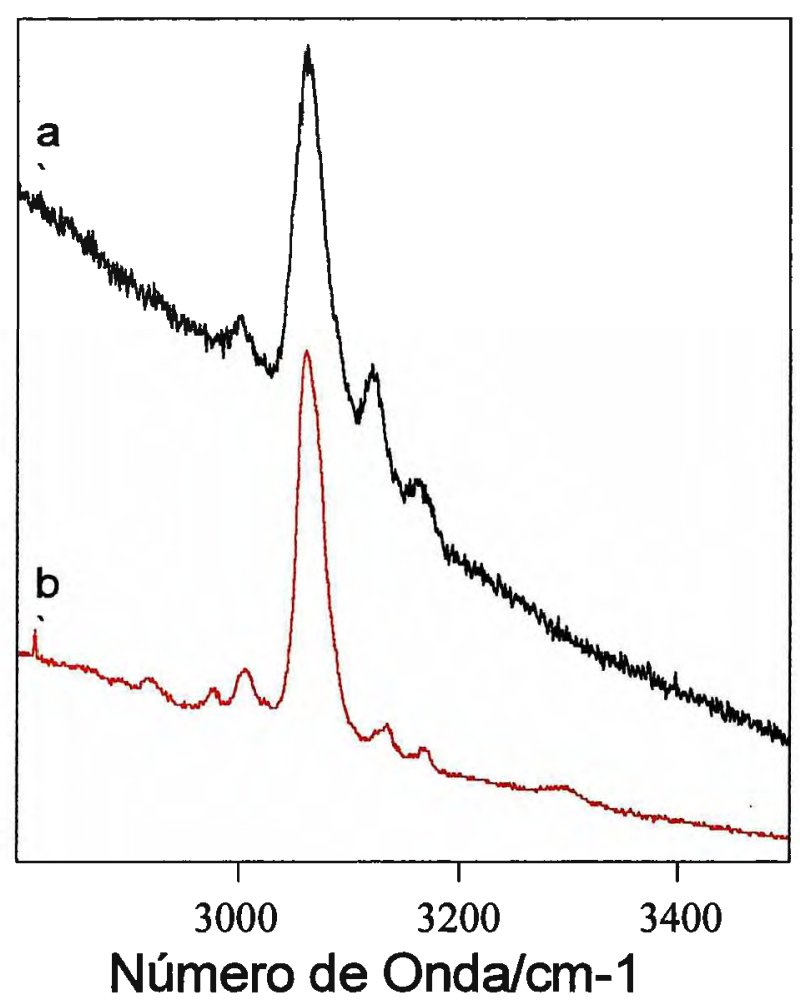

Figura 3.22- Espectros Raman da 2-etinilpiridina excitados em 632,8 nm: a) espectro SERS em eletrodo de prata $(\mathrm{E}=0,0 \mathrm{~V}$ vs. $\mathrm{Ag} / \mathrm{AgCl}$ e $\mathrm{pH}=6$ ); b) espectro Raman normal. 


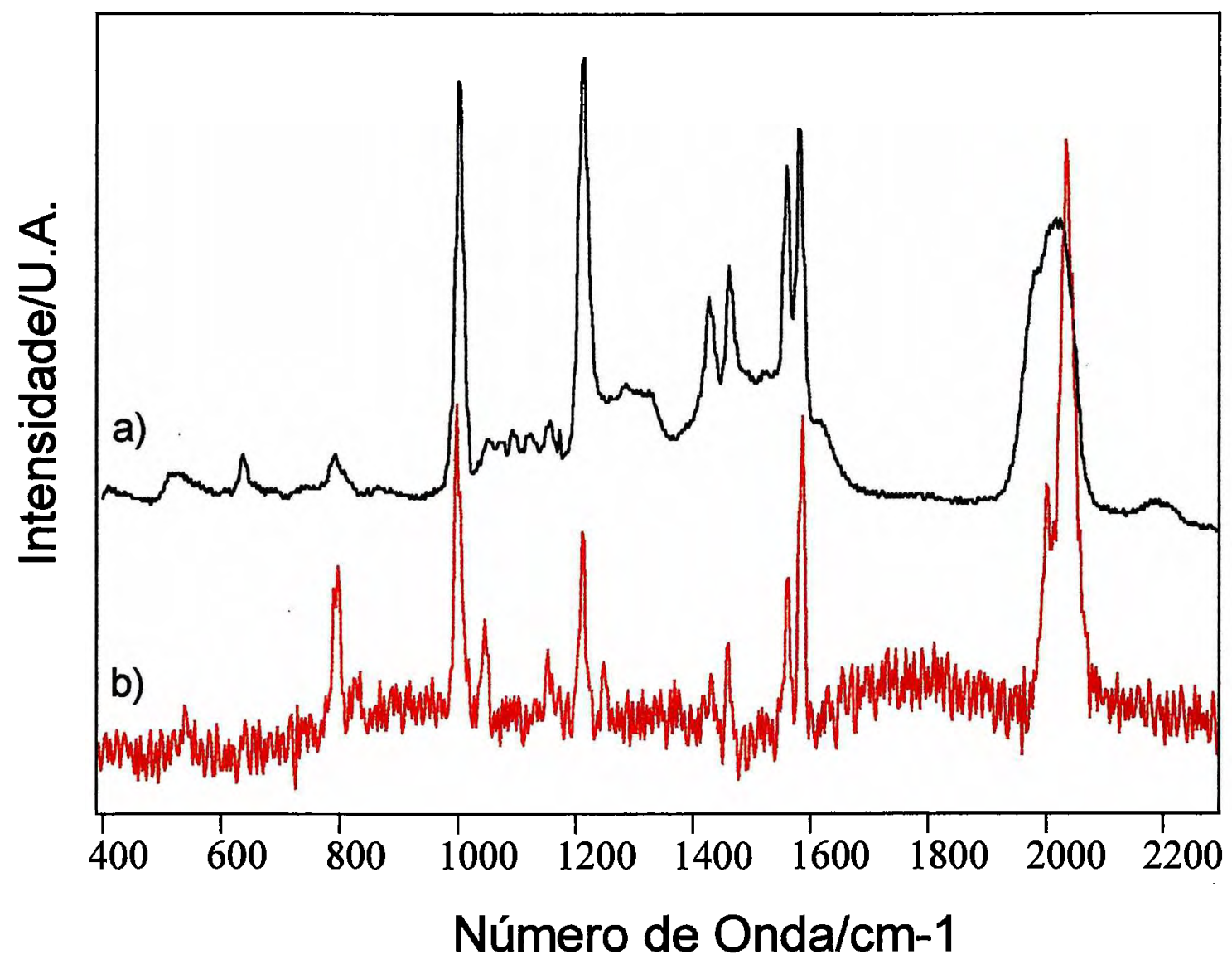

Figura 3.23- Espectros Raman excitados em $632,8 \mathrm{~nm}$ : a) espectro SERS da 2etinilpiridina em eletrodo de prata $(\mathrm{E}=0,0 \mathrm{~V}$ vs. $\mathrm{Ag} / \mathrm{AgCl}$ e $\mathrm{pH}=6$ ); b) espectro Raman normal do 2-piridilacetileto de prata (com acerto de linha base). 
Quando a comparação dos espectros vibracionais, porém, é feita na região dos estiramentos $\mathrm{C}-\mathrm{H}$ do anel piridínico (figura 3.24) podemos notar que, para o 2-piridilacetileto de prata, há um deslocamento das freqüências desses estiramentos quando comparados com a 2-etinilpiridina, sendo que esse deslocamento não é observado no espectro SERS da 2-etinilpiridina (em $\mathrm{pH}=6 \mathrm{e} \mathrm{E}=0,0 \mathrm{~V}$ vs. $\mathrm{Ag} / \mathrm{AgCl}$ ), levando-nos a concluir que as mudanças ocorridas no espectro do composto em superfície de prata não são devido à formação do 2-piridilacetileto.

A explicação para a observação da mesma freqüência vibracional para as bandas do estiramento $\mathrm{C} \equiv \mathrm{C}$ nos espectros SERS da 2-etinilpiridina e Raman normal do 2-piridilacetileto de prata pode vir da estrutura proposta na literatura para o fenilacetileto de cobre ${ }^{126}$ (figura 3.25). Assumindo uma estrutura similar para o 2-piridilacetileto de prata, quando a 2-etinilpiridina adsorve na superfície de prata um processo de transferência de carga ocorreria entre o composto e a superficie do eletrodo semelhante ao que ocorreria no 2piridilacetileto de prata.

Considerando então que a espécie presente na superfície é a 2etinilpiridina, podemos analisar as variações espectrais ocorridas com o potencial. 


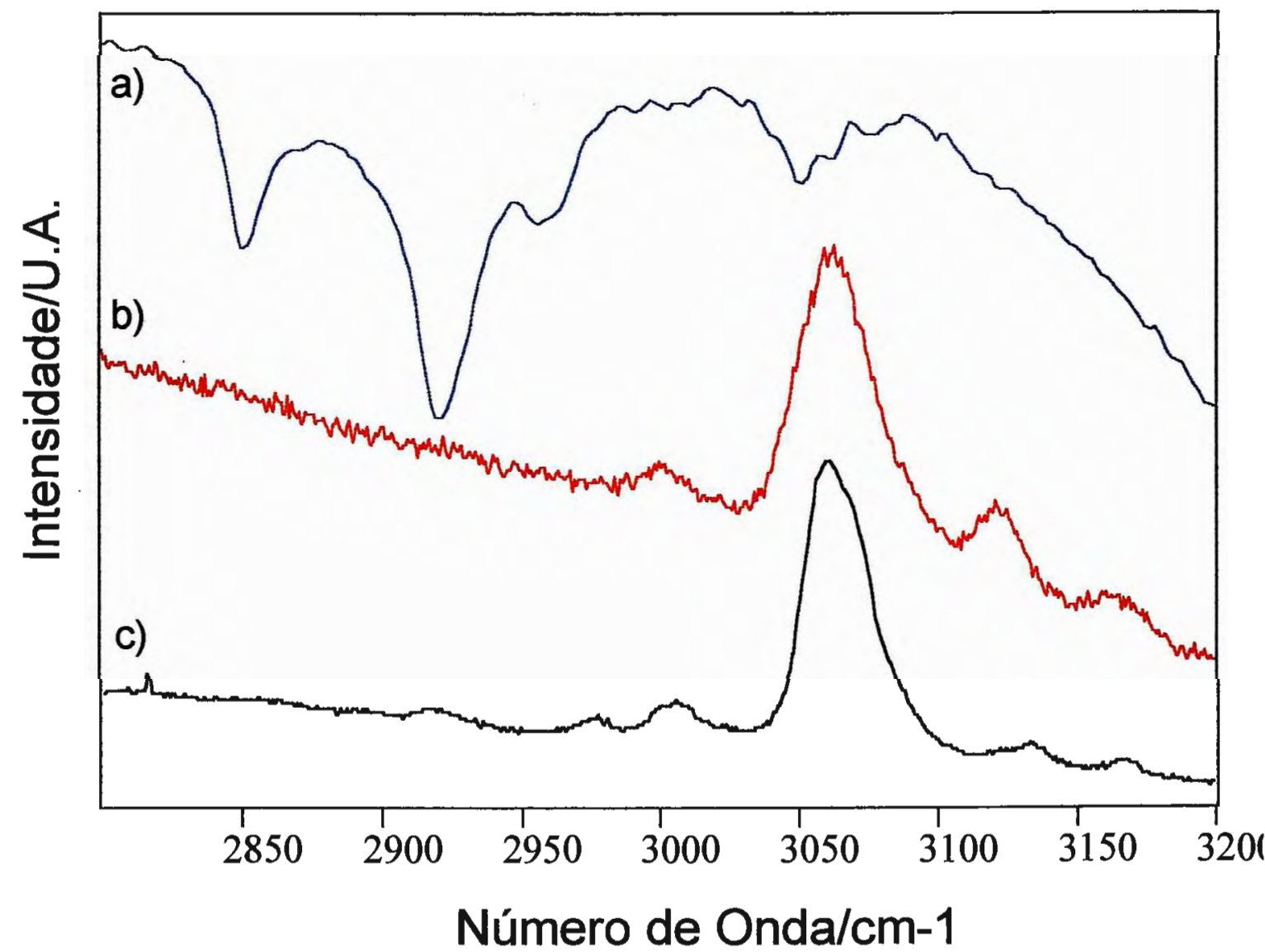

Figura 3.24- a) Espectros no infravermelho do 2-piridilacetileto de prata em $\mathrm{KBr}$; b) Espectro SERS da 2-etinilpiridina $\left(\lambda_{\mathrm{o}}=632,8 \mathrm{~nm}\right) \mathrm{em}$ eletrodo de prata $(\mathrm{E}=0,0 \mathrm{~V}$ vs. $\mathrm{Ag} / \mathrm{AgCl}$ e $\mathrm{pH}=6) ; \mathrm{c})$ Espectro Raman normal $\left(\lambda_{o}=632,8 \mathrm{~nm}\right)$ da 2-etinilpiridina. 


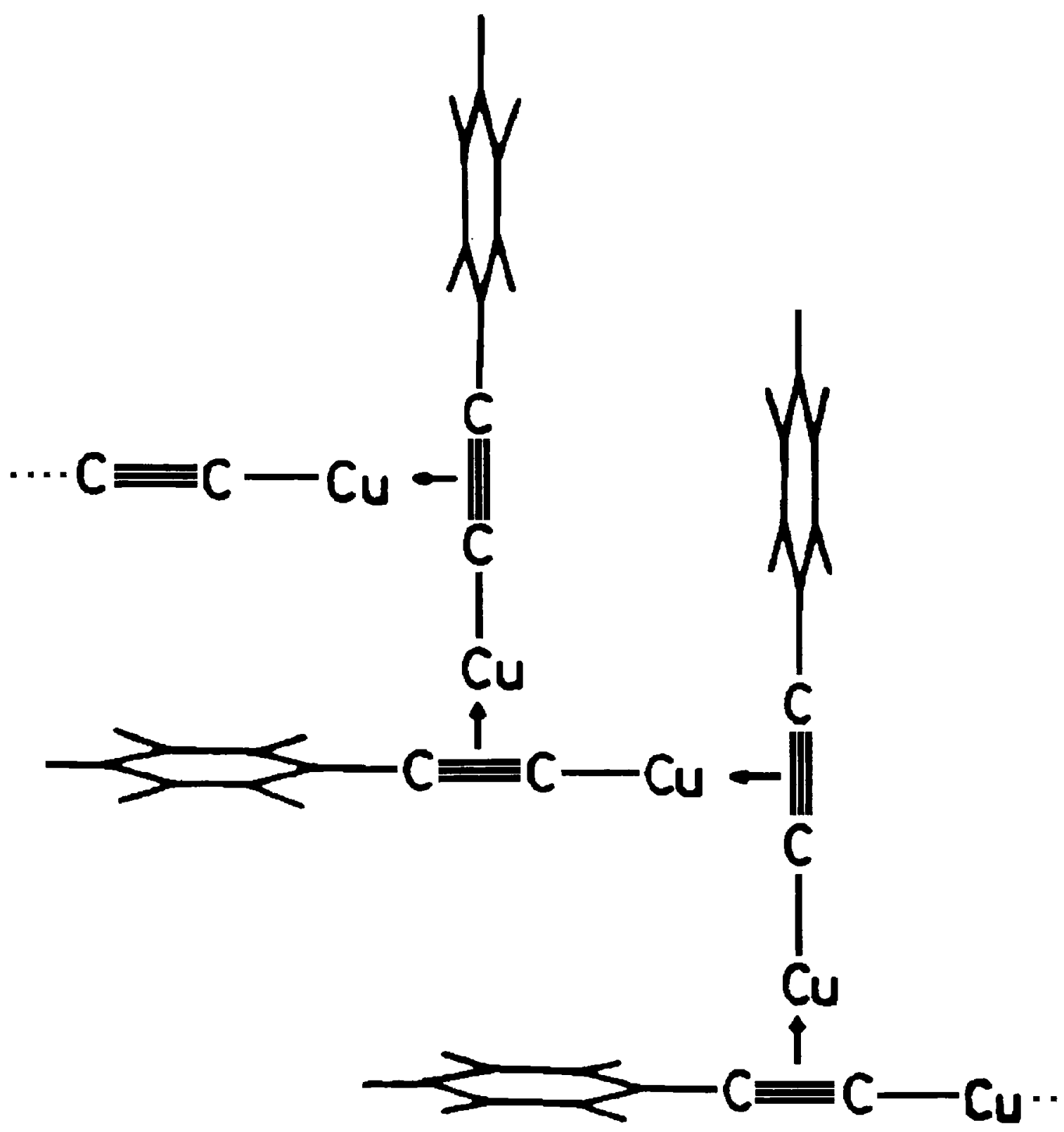

Figura 3.25- Estrutura proposta do fenilacetileto de cobre ${ }^{126}$. 
A atribuição vibracional das bandas da piridina, da pirimidina, da pirazina e de outros anéis aromáticos substituídos por heteroátomos é feita utilizando a atribuição de Wilson para o benzeno ${ }^{119}$. A quebra da simetria $D_{6 h}$ do benzeno para $\mathrm{C}_{2 \mathrm{v}}$ (piridina, por exemplo) ou para $\mathrm{C}_{\mathrm{s}}$ (como a piridina substituída nas posições 2 ou 3) aparece na atribuição das bandas quando um modo normal degenerado do benzeno origina dois modos normais no composto em análise. Um exemplo é o modo 8 do benzeno (estiramento do anel) que na piridina transforma-se em $8 \mathrm{a}$ e 8 b. Essa maneira de atribuição tem facilitado muitas explicações do comportamento SERS de derivados da piridina, como por exemplo no caso da 4-cianopiridina ${ }^{127}$ onde foi verificado que à medida que o potencial tornava-se mais negativo ocorria intensificação de uma das bandas provindas da quebra da degenerescência, indicando que ocorre uma mudança de orientação da 4-cianopiridina de perpendicular para paralela em relação à superfície.

Esse mesmo tipo de análise pode ser feita no espectro SERS da 2etinilpiridina, entretanto, a sua baixa simetria torna essa análise mais complexa. Mesmo assim podemos notar que nos espectros SERS mostrados na figura 3.18 são os pares de bandas em 1580/1550 $\mathrm{cm}^{-1}, 1460 / 1430 \mathrm{~cm}^{-1}$ e $1210 / 1150$ $\mathrm{cm}^{-1}$ que variam de intensidade relativa com a mudança no potencial aplicado, sugerindo uma mudança de orientação do composto na superfície de perpendicular para paralela quando o potencial torna-se mais negativo.

$\mathrm{A}$ análise da região do estiramento $\mathrm{C}-\mathrm{H}$ do anel piridínico (figura 3.18B) mostra que para potenciais mais positivos que $-0,7 \mathrm{~V}$ só são observadas bandas com freqüências semelhantes ao espectro Raman normal da 2etinilpiridina enquanto que a partir de $-0,7 \mathrm{~V}$ podemos observar novas bandas em 2850, 2943, 2978 e $3010 \mathrm{~cm}^{-1}$, as quais correspondem às bandas 
observadas no espectro Raman normal do 2-piridilacetileto de prata. Essa observação sugere que em potenciais negativos a formação de 2-piridilacetileto na superficie metálica.

Comparando os espectros SERS da 2-etinilpiridina em eletrodo de prata para diferentes concentrações de $\mathrm{H}^{+}$(figura 3.26) nota-se que algumas bandas com freqüências inferiores a $1000 \mathrm{~cm}^{-1}$ são intensificadas, especialmente aquelas em 825 e $855 \mathrm{~cm}^{-1}$, as quais correspondem àquelas presentes em $874 \mathrm{e}$ $895 \mathrm{~cm}^{-1}$ no espectro Raman normal da 2-etinilpiridina e são atribuídas a estiramentos $\mathrm{C}-\mathrm{H}$ fora do plano. Sendo as principais bandas do espectro SERS em $\mathrm{pH}=6$ referentes a vibrações no plano molecular (toda as deformações fora do plano têm freqüência inferior a $1000 \mathrm{~cm}^{-1}$ ), o aparecimento de vibrações fora do plano da molécula indica que o composto está tendendo a adsorver paralelamente à superfície. A protonação do nitrogênio piridínico, que é mais efetiva em pHs mais ácidos como mostra a intensidade da banda em $1620 \mathrm{~cm}^{-1}$, dificulta a adsorção perpendicular com a superfície.

Outra mudança notável nos espectros SERS em meio ácido foi o desaparecimento quase que completo da banda em $2000 \mathrm{~cm}^{-1}$ (estiramento $\mathrm{C} \equiv \mathrm{C}$ ). Essa observação corrobora as conclusões feitas acima pois esse estiramento deve sofrer maior intensificação quando a adsorção da molécula é feita perpendicularmente à superfície enquanto que a intensificação deve ser menor quando a molécula adsorver paralela ao metal.

Outra evidência experimental indicativa de que grande parte do composto adsorvido tenha orientação mais paralela à superfície em solução ácida do que em solução neutra é a maior intensificação das bandas em 1150, 1460 e $1552 \mathrm{~cm}^{-1}$ em meio ácido em relação ao espectro sem adição de ácido. 


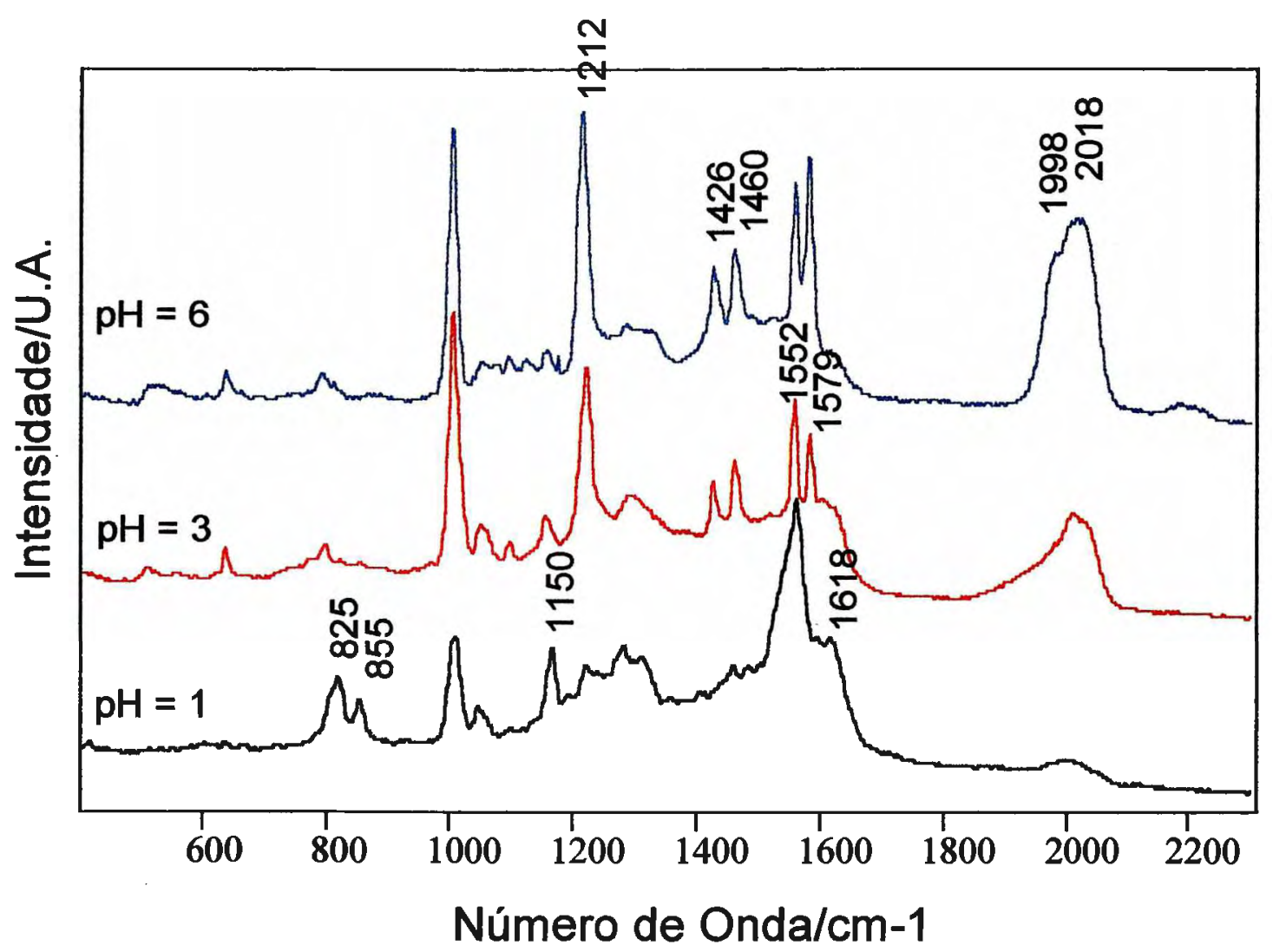

Figura 3.26- Espectros SERS da 2-etinilpiridina $\left(\lambda_{o}=632,8 \mathrm{~nm}\right)$ em diferentes $\mathrm{pHs}(\mathrm{E}=0,0 \mathrm{~V}$ vs. $\mathrm{Ag} / \mathrm{AgCl})$ 
Na região de $3000 \mathrm{~cm}^{-1}$, os espectros em diferentes pHs não apresentam os deslocamentos das freqüências dos estiramentos $\mathrm{C}-\mathrm{H}$ do anel piridínico (figura 3.27a), mostrando que a espécie presente é a 2-etinilpiridina. A origem da banda em aproximadamente $2850 \mathrm{~cm}^{-1}$ não foi determinada. Quando a comparação é feita para potenciais mais negativos que $-0,7 \mathrm{~V}$ diferenças passam a ser notadas entre os espectros SERS em meio neutro e em meio ácido (figura 3.27b). Para a solução não acidificada foi possível observar o aparecimento de novas bandas que indicam a formação do 2-piridilacetileto, enquanto que na solução ácida essas bandas não foram observadas mostrando que nessas condições esse íon não é formado. Isso acontece porque em soluções ácidas o equilíbrio da reação de desprotonação da 2-etinilpiridina para formar o 2-piridilacetileto é deslocado no sentido da formação da 2etinilpiridina devido à maior concentração de íons $\mathrm{H}^{+}$.

As mudanças nos espectros SERS da 2-etinilpiridina notadas com a variação do potencial aplicado para a solução neutra (figura 3.18) são similares àquelas observadas com a variação da concentração de íons $\mathrm{H}^{+}$(sem alteração no potencial, ver figura 3.26). Isto nos mostra que os efeitos provocados pela mudança na acidez da solução eletrolítica ou pela variação do potencial na adsorção da molécula são os mesmos, com a exceção de que no primeiro caso o efeito é mais intenso. 

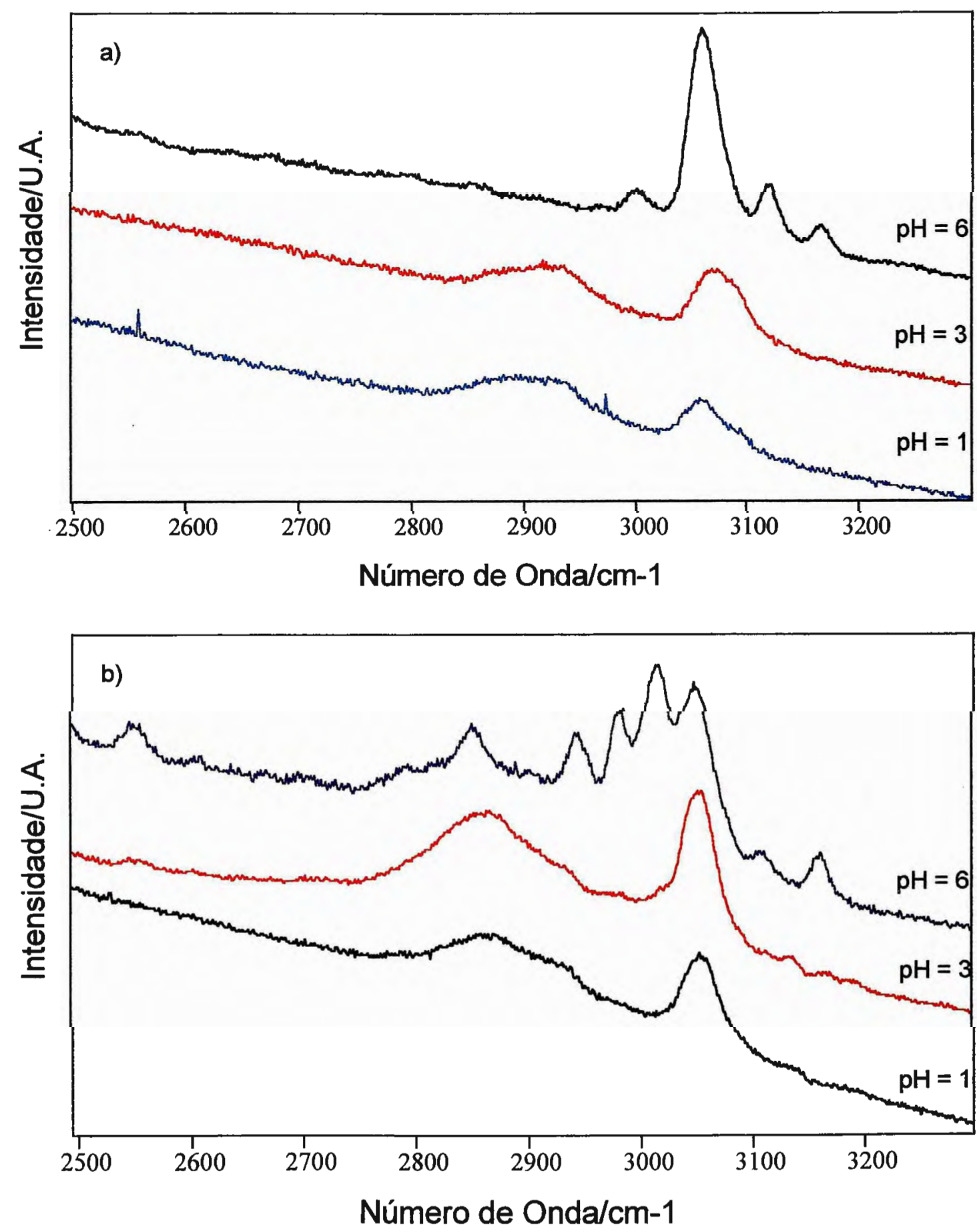

Figura 3.27- Espectros SERS da 2-etinilpiridina $\left(\lambda_{o}=632,8 \mathrm{~nm}\right)$ em diferentes pHs: a) $\mathrm{E}=0,0 \mathrm{~V}$; b) $\mathrm{E}=-0,8 \mathrm{~V}$. 


\section{CONCLUSÕES}




\section{4- Conclusões}

Neste trabalho pudemos observar que a polimerização da 2etinilpiridina em meio ácido não necessariamente forma um composto polimérico com a relação entre o número de anéis de piridina e piridinium igual a 1, como proposto na literatura. Este fato também implica na necessidade de uma revisão do mecanismo proposto para esta polimerização, pois, através deste mecanismo, a produção de polímeros com diferentes quantidades de piridinas protonadas e não protonadas seria impossível.

Também verificamos que a fluorescência apresentada pelo $\mathrm{P} 2 \mathrm{EPH}$ pode ser suplantada, através da utilização de superfícies de prata metálica, para a obtenção do espectro Raman com radiação excitante no visível ou obtendo os espectros com excitação na região do ultravioleta (abaixo de $250 \mathrm{~nm}$ ).

Os espectros em diferentes tipos de superfícies de prata metálica apresentaram-se similares indicando que estas superfícies não interagem fortemente com o polímero. Este fato, que também pode ser notado pela falta de grandes variações nas freqüências vibracionais Raman (em superfície de prata) em relação àquelas obtidas do espectro no infravermelho, nos permitiu utilizar estes espectros em superfícies metálicas para fazer uma atribuição das bandas do P2EPH além de observar e quantificar a presença da fotosseletividade nos espectros Raman deste polímero com diferentes radiações excitantes.

O estudo vibracional feito neste trabalho permitiu melhorar a atribuição das bandas vibracionais do P2EPH devido à utilização também da espectroscopia Raman em adição à espectroscopia no infravermelho. Uma das 
mais importantes bandas do espectro, o estiramento $\mathrm{C}=\mathrm{C}$ da cadeia poliacetilênica, era atribuída erroneamente como sendo a banda em $1620 \mathrm{~cm}^{-1}$ enquanto que este trabalho mostrou que esta vibração ocorre em $1530 \mathrm{~cm}^{-1}$.

A comparação dos espectros Raman do P2EPH em colóide de prata utilizando diferentes radiações excitantes mostrou que somente as bandas da cadeia poliacetilênica desse polímero apresentam fotosseletividade. A dimensão da fotosseletividade no P2EPH é muito inferior àquela apresentada pelo poliacetileno, porém condiz com a observação de que esse fenômeno é menor em polímeros condutores luminescentes (caso do $\mathrm{P} 2 \mathrm{EPH}$ ) do que naqueles que não apresentam luminescência.

A análise dos resultados da fotosseletividade através dos modelos CLM e AMM mostraram que ambos apresentam correlação razoável dos dados apesar do primeiro ser um modelo considerado simplista e o segundo ser baseado em condições de contorno que não eram válidas para a amostra que utilizamos, como polímeros unidimensionais e infinitos.

$\mathrm{O}$ estudo do comportamento da 2-etinilpiridina em eletrodo através da espectroscopia SERS mostrou que esse composto não polimerizou eletroquimicamente nem com o decréscimo do $\mathrm{pH}$, nem com a aplicação de potencial. Também foi observado que, em meio neutro e com aplicação de potencial de $0,0 \mathrm{~V}$, a espécie que adsorve ao eletrodo é a 2-etinilpiridina e não o 2-piridilacetileto. Esse último somente aparece em meio neutro para potenciais mais negativos que $-0,7 \mathrm{~V}$. Em soluções ácidas esse íon não foi detectado, independente do potencial. aplicado, pois o excesso de íons $\mathrm{H}^{+}$ presente quando a solução é acidulada desloca o equilíbrio da reação de formação do 2-piridilacetileto no sentido dos reagentes. 
Outras variações além daquelas atribuídas à formação do 2piridilacetileto foram observadas com a variação do $\mathrm{pH}$ e do potencial e indicaram que a molécula, que inicialmente está adsorvida perpendicularmente à superfície, tende a adsorver mais paralelamente ao eletrodo quando potenciais mais negativos são aplicados ou quando o meio é acidificado. 


\section{REFERÊNCIAS BIBLIOGRÁFICAS}




\section{5- Referências Bibliográficas}

1. R.A. Zoppi e M. A. De Paoli; Química Nova 16, 560 (1993).

2. H. Shirakawa, E.J. Louis, A.G. MacDiarmid, C.K. Chiang e J.A. Heeger; J. Chem. Soc.; Chem. Commun., 578, (1977).

3. A.F. Diaz e K.K. Kanazawa; Extended Linear Chain Compounds, editado por J.S. Miller, vol. 3, cap. 8, Plenum, Nova Iorque (1983).

4. G. Tourillon e F. Garnier; J. Electrochem. Soc. 130, 2042 (1983).

5. S. Gleni, M. Benz, E. LeGoff, J.L. Schindler, C.R. Kannewurf e M.G. Kanatzidis; J. Am. Chem. Soc. 115, 12519 (1993).

6. D.M. Ivory, G.G. Miller, J.M. Sowa, L.W. Sacklette, R.R. Chance e R.H. Baughman; J. Chem. Phys. 71, 1506 (1979).

7. A.G. MacDiarmid e A.J. Epstein; Faraday Discuss. Chem. Soc. 88, 317 (1989).

8. J.L. Brédas e G.B. Street; Acc. Chem. Res. 18, 309 (1985).

9. S. Ikehata, J. Kaufer, T. Woerner, A. Pron, M.A. Druy, A. Sivak, A.J. Heeger e A.G. McDiarmid; Phys. Rev. Lett. 45, 423 (1980).

10. M. Peo, S. Roth, K. Dransfeld, B. Tieke, J. Hocker, H. Gross, A. Grupp e H. Sixl; Solid State Commun. 35, 119 (1980).

11. J.C. Scott, M. Krounbi, P. Pfluger e G.B. Street; Phys. Rev. B: Condens. Matter 28, 2140 (1983).

12. J.C. Scott, J.L. Brédas, J.H. Kaufman, P. Pfluger, G.B. Street e K. Yakushi; Mol. Cryst. Liq. Cryst. 118, 163 (1985).

13. W.P. Su, J.R. Schrieffer e A.J. Heeger; Phys. Rev. Lett. 42, 1698 (1979).

14. G. Natta, G. Mazzanti e P. Corradini; Atti Accademia Naz. Lincei, 
Bibliografia

Rend. Sci. Fis. Mat. Nat. 25, 2 (1958).

15. M. Gussoni, C. Castiglioni e G. Zerbi; Spectroscopy of Advanced Materials, editado por R.J.H. Clark e R.E. Hester, vol. 19, cap. 5, John Wiley, Nova Iorque (1991).

16. T. Ito, H. Shirakawa e S. Ikeda; J. Polym. Sci. Polym. Chem. Ed. 12, 11 (1974).

17. J.H. Edwards e W.J. Feast, Polym. Commun. 21, 595 (1980).

18. F.S. Bates e G.I. Baker, Macromolecules 16, 704 (1983).

19. S. Destri, M. Catellani e A. Bolognesi, Makromol. Chem. Rapid Commun. 5, 353 (1984).

20. G. Lugli, U. Pedretti e G. Perego; Molec. Cryst. Liq. Cryst. 117, 43 (1985).

21. P. Piaggio, G. Dellepiane, R. Tubino, L. Piseri e G. Lugli; Solid State Commun. 49, 895 (1984).

22. G. Leising, R. Uitz, B. Ankele, W. Ottinger e F. Stelzer; Molec. Cryst. Liq. Cryst. 117, 327 (1985).

23. H. Naarman; Synth. Met. 17, 223 (1987).

24. H. Naarman e N. Theophilou; Synth. Met. 22, 1 (1987).

25. T. Schimmel, G. Denninger, V. Riess, J. Voit, M. Schowerer, V. Schoepe e H. Naarman; Synth. Met. 28, D1 1 (1989).

26. N. Theophilou, D.B. Swanson, A.G. MacDiarmid, A. Chakraborti, H.H. Jarady, R.P. MacCall, S.P. Treat, F. Zuo e A.J. Epstein; Synth. Met. 28, D35 (1989).

27. K. Kamiya, T. Miyamae, M. Oku, K. Seki, H. Inokuchi, C. Tanaka e J. Tanaka; J. Phys. Chem. 100, 16213 (1996).

28. G. Ahlgren e B. Krische; J. Polym. Sci. Pol. Lett. 22 (1984), 173. 
29. H. Shirakawa, T. Masuda e K. Takeda; The Chemistry of Triple Bonded Functional Groups, editado por S. Patei, cap. 17, John Willey, Nova Iorque, 1994.

30. C.K. Chiang, Y.W. Park, A.J. Heeger, H. Shirakawa, E.J. Louis e A.G. MacDiarmid; J. Chem. Phys. 69, 5098 (1978).

31. Y.W. Park, A.J. Heeger, M.A. Druy e A.G. MacDiarmid; J. Chem. Phys. 73, 946 (1980).

32. I. Harada, Y. Furukawa, M. Tasumi, H. Shirakawa e S. Ikeda; J. Chem. Phys. 73, 4746 (1980).

33. I. Harada, M. Tasumi, H. Shirakawa e S. Ikeda; Chem. Lett., 1411 (1978).

34. S. Lefrant, L.S. Lichtmann, H. Temkin, D.B. Fitchen, D.C. Miller, G.E. Whitewell II e J.M. Burlitch; Solid State Commun. 29, 191 (1979).

35. S.L. Hsu, A.J. Signorelli, G.P. Pez e R.H. Baughman; J. Chem. Phys. 69, 106 (1978).

36. N.S. Murthy, G.G. Miller e R.H. Baughman; J. Chem. Phys. 89, 2523 (1988).

37. R.H. Baughman, S.L. Hsu, G.P. Pez e A.J. Signorelli; J. Chem. Phys. 68, 5405 (1978).

38. T. Matsuyama, H. Sakai, H. Yamaoka, Y. Maeda e H. Shirakawa; Solid State Commun. 40, 563 (1981).

39. G. Kaindl, G. Wortmann, S. Roth e K. Menke; Solid State Commun. 41, 75 (1982).

40. G.D. Stucky, S.R. Marder e J.E. Sohn; Materials for Nonlinear Optics - Chemical Perspectives, editado por S.R. Marder, J.E. Sohn e 
G.D. Stucky, cap. 1, American Chemical Society, Washington, 1991.

41. M. Sinclair, D. Moses, A.J. Heeger, K. Vilhelmsson, B. Vakl e M. Salour; Solid State Commun. 61, 221 (1987).

42. O. Sala; Fundamentos da Espectroscopia Raman e no Infravermelho, cap. 2, Editora UNESP, São Paulo (1996).

43. R.J.H. Clark e T.J. Dines; Angew. Chem., Int. Ed. Engl. 25, 131 (1986).

44. H. Shirakawa e S. Ikeda; Polym. J. 2, 231 (1972).

45. D.B. Fitchen; Molec. Cryst. Liq. Cryst. 83, 95 (1982).

46. H. Shirakawa, T. Ito e S. Ikeda; Polym. J. 4, 460 (1973).

47. H. Kuzmany; Phys. Stat. Sol. B 97, 521 (1980).

48. H. Takeuchi, T. Arakawa, Y. Furukawa e I. Harada; J. Molec. Struct. 158, 179 (1987).

49. F. Coter, Z. Vardeny, E. Ehrefreund e O. Brafman; Synth. Met. 17, 331 (1987).

50. Y. Furukawa, T. Arakawa, H. Takeuchi, I. Harada e H. Shiradawa; J. Chem. Phys. 81, 2907 (1984).

51. M.A. Schen, J.C.W. Chien, E. Perrin, S. Lefrant e E. Mulazzi; J. Chem. Phys. 89, 7615 (1988).

52. R.H. Friend, D.D.C. Bradley, P.D. Townsend e D.C. Bott; Synth. Met. 17, 267 (1987).

53. G. Masetti, E. Campani, G. Gorini, L. Piseri, R. Tubino, P. Piaggio e G. Dellepiane; Solid State Commun. 55, 737 (1985).

54. S. Lefrant e E. Mulazzi; Electronic Properties of Conjugated Polymers II, editado por H. Kuzmany, M. Mehring e S. Roth, pag. 141, Springer, Berlim (1987). 
55. R.S. Cataliotti, G. Paliani, G. Dellepiane, S. Fuso, S. Destri, L. Piseri e R. Tubino; J. Chem. Phys. 82, 2223 (1985).

56. H. Kuzmany, E.A. Imhoff, D.B. Fitchen e A. Sarhangi; Phys. Rev. B 26, 7109 (1982).

57. P. Brivio e E. Mulazzi; Chem. Phys. Lett. 95, 555 (1983).

58. E. Mulazzi, G.P. Brivio, E. Falques e S. Lefrant; Solid State Commun. 46, 851 (1983).

59. G.P. Brivio e E. Mulazzi; Phys. Rev. B 30, 876 (1984).

60. H. Kuzmany; Pure Appl. Chem. 57, 235 (1985).

61. B. Horovitz; Solid State Commun. 41, 729 (1982).

62. B. Horovitz, Z. Vardeny, E. Ehrenfreund e O. Brafman; J. Phys. C 19, 7291 (1986).

63. E. Ehrenfreund, Z. Vardeny, O. Brafman e B. Horovitz; Phys. Rev B 36, 1535 (1987).

64. C. Castiglioni, J.T. López Navarrete, G. Zerbi e M. Gussoni; Solid State Commun. 65, 625 (1983).

65. G. Zerbi, C. Castiglioni, J.T. López Navarrete, T. Bogang e M. Gussoni; Synth. Met. 28, D359 (1989).

66. J.T. López Navarrete, B. Tian e G. Zerbi; Solid State Commun. 74, 199 (1990).

67. A.C. Albrecht; J. Chem. Phys. 34, 1476 (1961).

68. J. Tang e A.C. Albrecht; Raman Spectroscopy, editado por A. Szymanski, pag. 33, Plenum, Nova Iorque (1970).

69. P.A. Lee, T.M. Rice e P.W. Anderson; Solid State Commun. 14, 703 (1974).

70. J. Kürti e H. Kuzmany; Phys. Rev. B 44, 597 (1991). 
71. H.W. Gibson; Handbook of Conducting Polymers, editado por T.A. Skotheim, vol. 1, cap. 11, Marcel Dekker, Nova Iorque (1986).

72. S. Subramanyam, M.S. Chetan e A. Blumstein; Macromolecules 26, 3212 (1993).

73. Y.S. Gal e S.K. Choi; J. Appl. Polym. Sci. 50, 601 (1993)

74. Y. Okamoto e D. Alia; Chem. Ind. (London), 1311 (1964).

75. Y.S. Gal, H.N. Cho, S.K. Kwon e S.K. Choi; Polymer (Korea) 12, 30 (1988).

76. S. Subramanyam e A. Blumstein; Macromolecules 24, 2668 (1991).

77. S. Subramanyam e A. Blumstein; Macromolecules 25, 2065 (1992).

78. S. Subramanyam e A. Blumstein; Macromolecules 25, 4058 (1992).

79. L. Balogh e A. Blumstein; Macromolecules 28, 5691 (1995).

80. P. Zhou e A. Blumstein; Polymer 37, 1477 (1996).

81. L. Balogh, L. Samuelson, K.S. Alva e A. Blumstein; Macromolecules 29, 4180 (1996).

82. P. Zhou e A. Blumstein; Polymer 38, 595 (1997).

83. P. Zhou, L. Samuelson, K.S. Alva, C.-C. Chen, R.B. Blumstein e A. Blumstein; Macromolecules 30, 1577 (1997).

84. A. Blumstein e L. Samuelson; Adv. Mater. 10, 173 (1998).

85. L. Balogh, A. de Leuze-Jallouli, P. Dvornic, Y. Kunugi, A. Blumstein e D.A. Tomalia; Macromolecules 32, 1036 (1999).

86. M. Fleischmann, P.J. Hendra e A.J. McQuillan; Chem. Phys. Lett. 26, 123 (1974).

87. D.L. Jeanmarie e R.P. Van Duyne; J. Electroanal. Chem. 84, 1 (1977).

88. M.G. Albrecht e J.A. Creighton; J. Am. Chem. Soc. 99, 5215 (1977). 
89. J.C. Rubim, I.G.R. Gutz, O. Sala e W.J. Orville-Thomas; J. Mol. Struct. 100, 571 (1983).

90. M. Fleischmann, I.R. Hill, G. Mengoli, M.M. Musiani e J. Akhavan; $J$. Electrochim. Acta 30, 879 (1985).

91. J.R. Bertolino, M.L.A. Temperini e O. Sala; J. Mol. Struct. 178, 113 (1988).

92. R.L. Sobocinski e J.E. Pemberton; Langmuir 4, 836 (1988).

93. C. Shi, W. Zhang, R.L. Birke, D.K. Grosser e J.R. Lombardi; J. Phys. Chem. 95, 6276 (1991).

94. T.M. Cotton, D. Kaddi e D. Iorga; J. Am. Chem. Soc. 105, 7462 (1983).

95. L.S. Pinheiro, M.L.A. Temperini; J. Electroanal. Chem. 295, 169 (1990).

96. M.L.A. Temperini, M.R. dos Santos e V.R.P. Monteiro; Spectrochim. Acta 51A, 1517 (1995).

97. T.M. Cotton, J.H. Kim e G.D. Chumanov; J. Raman Spectrosc. 22, 729 (1991).

98. T. Lopez-Rios, C. Pettenkoffer, I. Pockrand e A. Otto; Surf. Sci. 121, 541 (1982).

99. R. Aroca, C. Jenning, G.J. Kovacs, R. Loufty e P.S. Vincett; J. Phys. Chem. 89, 4051 (1985)

100. S.A. Bilmes, J.C. Rubim, A. Otto e A.J. Arvia; Chem. Phys. Lett. 159, 89 (1989)

101. D.L.A. de Faria, M.L.A. Temperini e O. Sala; Química Nova 22, 541 (1999).

102. A. Otto, I. Mrozek, H. Grabhorn e W. Akermann; J. Phys.: Cond. 
Bibliografia

Matter. 4, 1143 (1992).

103. H.S. Pearce e H. Shepphard; Surf. Sci. 59, 205 (1976).

104. H. Nichols e R.M. Hexter; J. Chem. Phys. 73, 965 (1980).

105. N.V. Richardson e J.K. Sass; Chem. Phys. Lett. 62, 267 (1979).

106. V.M. Hallmark e A. Campion; J. Chem. Phys. 84, 2933 (1986).

107. J.A. Creighton, C.G. Blatchford e M.G. Albrecht; J. Chem. Soc., Faraday Trans. II 75, 790 (1979).

108. M. Kasha; Discuss. Faraday Soc. 9, 14 (1950).

109. U. Olsher; Spectrochim. Acta 34A, 211 (1978).

110. G.N. Lewis e M. Calvin; Chem. Rev. 25, 273 (1939).

111. L. Dai, J.W. White; Polymer 32, 2120 (1991).

112. J.A. Nimmo, A.J. Bovill, A.A. McConnell e W.E. Smith; J. Raman Spectrosc. 16, 245 (1985).

113. S. Nie e N.-T. Yu; J. Raman Spectrosc. 22, 489 (1991).

114. S.A. Asher e C.R. Johnson; Science 255, 313 (1984).

115. J.H.S. Green, W. Kynaston e H.M. Paisley; Spectrochim. Acta 19, 549 (1963).

116. R. Foglizzo e A. Novak; J. Chim. Phys. 66, 1539 (1969).

117. W.F. Lewis e D.N. Batchelder; Chem. Phys. Lett. 60, 232 (1979).

118. M. Ozaki, M. Liess, R.E. Benner, Z.V. Vardeny, K. Yoshino e R. Sugimoto; Synth. Met. 84, 511 (1997).

119. F.R. Dollish, W.G. Fateley e F.F. Bentley; Characteristic Raman Frequencies of Organic Compounds, cap. 18, John Wiley, Nova Iorque (1974).

120. M. Ozaki, R.E. Benner, Z.V. Vardeny e E. Ehrenfreund; Synth. Metals 84, 489 (1997). 
121. J.L. Lippert e E.S. Brandt; Langmuir 4, 127 (1988).

122. K. Tashiro, K. Matsushima e M. Kobayashi; J. Phys. Chem. 94, 3197 (1990).

123. K. Nakamoto; Infrared Spectra of Inorganic and Coordination Compounds, apêndice I, John Wiley, Nova Iorque (1963).

124. J.C. Evans e R.A. Nyquist; Spectrochim. Acta 16, 918 (1960).

125. G.W. King e S.P. So; J. Molec. Spectrosc. 36, 468 (1970).

126. L.M. Abrantes, M. Fleischmann, I.R. Hill, L.M. Peter, M. Mengoli e G. Zotti; J. Eletroanal. Chem. 164, 177 (1984).

127. J.C. Rubim; J. Eletroanal. Chem. 220, 339 (1987). 